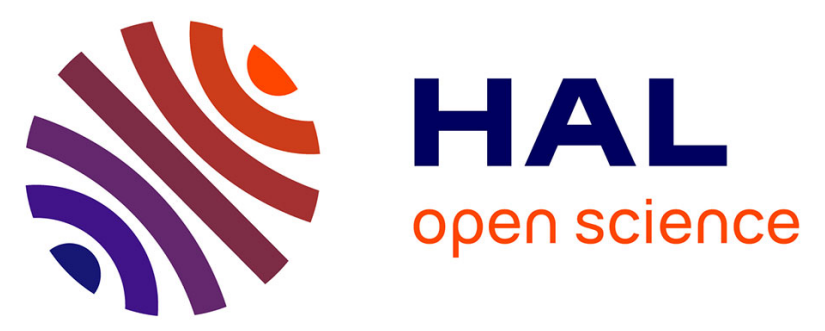

\title{
Spectral properties of simulated impact glasses produced from Martian soil analogue JSC Mars-1
}

\author{
L.V. Moroz, A.T. Basilevsky, T. Hiroi, S.S. Rout, D. Baither, C.H. van Der
}

Bogert, O.I. Yakovlev, A.V. Fisenko, L.F. Semjonova, V.S. Rusakov, et al.

\section{- To cite this version:}

L.V. Moroz, A.T. Basilevsky, T. Hiroi, S.S. Rout, D. Baither, et al.. Spectral properties of simulated impact glasses produced from Martian soil analogue JSC Mars-1. Icarus, 2009, 202 (1), pp.336. 10.1016/j.icarus.2009.02.007 . hal-00545287

\section{HAL Id: hal-00545287 \\ https://hal.science/hal-00545287}

Submitted on 10 Dec 2010

HAL is a multi-disciplinary open access archive for the deposit and dissemination of scientific research documents, whether they are published or not. The documents may come from teaching and research institutions in France or abroad, or from public or private research centers.
L'archive ouverte pluridisciplinaire HAL, est destinée au dépôt et à la diffusion de documents scientifiques de niveau recherche, publiés ou non, émanant des établissements d'enseignement et de recherche français ou étrangers, des laboratoires publics ou privés. 


\section{Accepted Manuscript}

Spectral properties of simulated impact glasses produced from Martian soil analogue JSC Mars-1

L.V. Moroz, A.T. Basilevsky, T. Hiroi, S.S. Rout, D. Baither, C.H. van der Bogert, O.I. Yakovlev, A.V. Fisenko, L.F. Semjonova, V.S. Rusakov, D.A. Khramov, N.G. Zinovieva, G. Arnold, C.M. Pieters

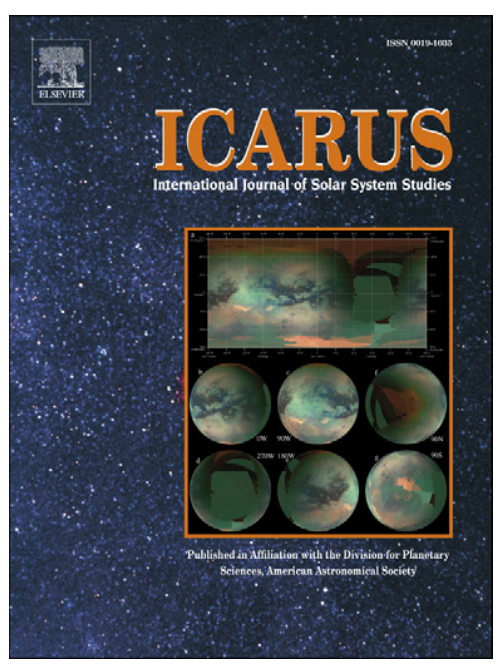

PII: S0019-1035(09)00066-9

DOI: $\quad$ 10.1016/j.icarus.2009.02.007

Reference: $\quad$ YICAR 8919

To appear in: Icarus

Received date: 28 December 2008

Accepted date: 13 February 2009

Please cite this article as: L.V. Moroz, A.T. Basilevsky, T. Hiroi, S.S. Rout, D. Baither, C.H. van der Bogert, O.I. Yakovlev, A.V. Fisenko, L.F. Semjonova, V.S. Rusakov, D.A. Khramov, N.G. Zinovieva, G. Arnold, C.M. Pieters, Spectral properties of simulated impact glasses produced from Martian soil analogue JSC Mars-1, Icarus (2009), doi: 10.1016/j.icarus.2009.02.007

This is a PDF file of an unedited manuscript that has been accepted for publication. As a service to our customers we are providing this early version of the manuscript. The manuscript will undergo copyediting, typesetting, and review of the resulting proof before it is published in its final form. Please note that during the production process errors may be discovered which could affect the content, and all legal disclaimers that apply to the journal pertain. 


\section{Spectral Properties of Simulated Impact Glasses Produced from}

\section{Martian Soil Analogue JSC Mars-1}

L. V. Moroz ${ }^{1,2}$, A. T. Basilevsky ${ }^{3}$, T. Hiroi ${ }^{4}$, S. S. Rout ${ }^{1}$, D. Baither ${ }^{5}$, C. H. van der Bogert ${ }^{1}$, O. I. Yakovlev $^{3}$, A. V. Fisenko ${ }^{3}$, L. F. Semjonova ${ }^{3}$, V. S. Rusakov ${ }^{6}$, D. A. Khramov ${ }^{3}$, N. G. Zinovieva $^{7}$, G. Arnold ${ }^{2,1}$, C. M. Pieters ${ }^{4}$

${ }^{1}$ Institute of Planetology, University of Münster, Wilhelm-Klemm Str. 10, D-48149, Münster, Germany;

${ }^{2}$ German Aerospace Center (DLR), Institute of Planetary Research, Rutherfordstr.2, D-12489 Berlin, Germany;

${ }^{3}$ Vernadsky Institute of Geochemistry and Analytical Chemistry, Russian Academy of Sciences, Kosygin St. 19, 117975 Moscow, Russia;

${ }^{4}$ Department of Geological Sciences, Brown University, Lincoln Field Building, 324 Brook Street, USA;

${ }^{5}$ Institute of Materials Physics, University of Münster, Wilhelm-Klemm Str. 10, D-48149, Münster, Germany;

${ }^{6}$ Department of Physics, Moscow State University, Vorob'evy Gory, 117234 Moscow, Russia;

${ }^{7}$ Department of Geology, Moscow State University, Vorob'evy Gory, 117234 Moscow, Russia.

E-mail: Ljuba.Moroz@dlr.de

Pages: 69

Tables: 1

Figures : 
Proposed running head : REFLECTANCE SPECTRA OF SIMULATED MARTIAN IMPACT GLASSES

Editorial correspondence and proofs to:

Lyuba Moroz

Institute of Planetary Research

German Aerospace Center (DLR)

Rutherford Str. 2

D-12489 Berlin, Germany

e-mail: Ljuba.Moroz@dlr.de 


\section{ABSTRACT}

To simulate the formation of impact glasses on Mars, an analogue of Martian bright soil (altered volcanic soil JSC Mars-1) was melted at relevant oxygen fugacities using a pulsed laser and a resistance furnace. Reduction of $\mathrm{Fe}^{3+}$ to $\mathrm{Fe}^{2+}$ and in some cases formation of nanophase $\mathrm{Fe}^{0}$ in the glasses were documented by Mössbauer spectroscopy and TEM studies. Reflectance spectra for several size fractions of the JSC Mars-1 sample and the glasses were acquired between 0.3 and $25 \mu \mathrm{m}$. The glasses produced from the JSC Mars-1 soil show significant spectral variability depending on the method of production and the cooling rate. In general, they are dark and less red in the visible compared to the original JSC Mars-1 soil. Their spectra do not have absorption bands due to bound water and structural $\mathrm{OH}$, have positive spectral slopes in the near-infrared range, and show two broad bands centered near 1.05 and $1.9 \mu \mathrm{m}$, typical of glasses rich in ferrous iron. The latter bands and low albedo partly mimic the spectral properties of Martian dark regions, and may easily be confused with mafic materials containing olivine and low-Ca pyroxene. Due to their disordered structures and vesicular textures, the glasses show relatively weak absorption features from the visible to the thermal infrared. These weak absorption bands may be masked by the stronger bands of mafic minerals. Positive near-infrared spectral slopes typical of fresh iron-bearing impact or volcanic glasses may be masked either by oxide/dust coatings or by aerosols in the Mars' atmosphere. As a result, impact glasses may be present on the surface of Mars in significant quantities that have been either misidentified as other phases or masked by phases with stronger infrared features. Spectrometers with sufficient spatial resolution and wavelength coverage may detect impact glasses at certain locations, e.g., in the vicinity of fresh impact craters. Such dark materials are usually interpreted as accumulations of mafic volcanic sand, but the possibility of an impact melt origin of such materials also should be considered. In addition, our data suggest that high contents of feldspars or zeolites are not necessary to produce the transparency feature at $12.1 \mu \mathrm{m}$ typical of Martian dust spectra.

Key words: Mars, surface, spectroscopy, impact processes, regoliths 


\section{Introduction}

Impact processes probably produced significant volumes of melt throughout Martian history (e.g., Clifford, 1993). Most impact glasses exposed at the surface have likely been altered, especially during warmer and wetter epochs. A number of studies suggests that a large fraction of soils on Mars are erosional products of hydrothermally altered (oxidized) impact melt sheets (e.g., Newsom et al., 1980; Allen, 1982; Clifford, 1993; Morris et al., 1995, 2000a, 2001; Hagerty and Newsom, 2003). However, relatively young impact glasses produced under the prevailing climatic conditions over the last billion years or so could have survived unaltered (Bouška and Bell, 1993; Lorenz, 2000; Schultz and Mustard, 2004). Impact glasses are much more likely to be found on Martian surface than on Earth due to the different exogenic conditions and slower weathering rates on Mars (Bouška and Bell, 1993; Schultz and Mustard, 2004). Indeed, high-resolution images recently returned by the Optical Microscope (OM) onboard Phoenix lander (Smith et al., 2008) show abundant translucent and dark particles $(50-80 \mu \mathrm{m})$ of glassy appearance, which could be ejected from the nearby Heimdal crater (Goetz et al., 2008). Impact melts may be present on the surface of Mars both in dispersed and concentrated forms (Bouška and Bell, 1993; Lorenz, 2000; Basilevsky et al., 2000a; Schultz and Mustard, 2004). Several types of impact debris are expected on Mars: distal clastic debris (breccias, fall-out-dust), distal glasses (tektites and microtektites), and proximal melts including glassy impactites (Schultz and Mustard, 2004).

The question arises whether impact-generated glasses contribute to the optical properties of Martian dust at a global scale and whether accumulations of impact glasses at certain locations might be identified spectroscopically and distinguished from volcanic glasses. The first step towards solving this issue is the investigation of the spectral properties of natural impact glasses and synthetic glasses produced from suitable analogue materials at relevant conditions. One should keep in mind that optical properties of glasses may vary significantly as a function of composition of the target, cooling rate, temperature, and oxygen fugacity (Bell et al., 1977).

Thomson and Schultz (2002), Schultz and Mustard (2004), and Thomson (2006) studied 
spectral properties of natural glasses generated by impacts into thick loess deposits in Argentina. Impact melt products from Argentina loess include not only dispersed tektites but also vesicular blocks as large as $2 \mathrm{~m}$ across (Schultz and Mustard, 2004). The fresh impact glasses have low reflectance (5-10\%) and neutral spectra with few features. Absorption bands, when present, are broad and weak. The more oxidized samples are brighter and show absorption bands associated with hematite (Schultz and Mustard, 2004). Similar spectral changes resulting from oxidation were reported by Morris et al. (1995) for impact melt rocks from Manicouagan (Canada). However, due to the slow cooling of the thick melt sheet and the resulting crystallization of individual mineral phases, the samples studied by Morris et al. (1995) showed well-defined mafic absorption bands. Schultz and Mustard (2004) note that the impact glasses from Argentina exhibit flat to slightly negative continuum slopes in the near-infrared (NIR) range and that the spectra between 0.4 and $1.1 \mu \mathrm{m}$ resemble those of rocks from the Mars Pathfinder landing site. Thomson and Schultz (2002) and Thomson (2006) also studied the spectral properties of the Argentina impact glasses in the thermal infrared (TIR) range and found that they are spectrally similar to the Type 2 Martian surface composition, interpreted by the MGS TES (Thermal Emission Spectrometer onboard Mars Global Surveyor) team as andesitic (Bandfield et al., 2000).

Morris et al. (2000a) compared spectral properties of impact melt beads produced during the formation of Meteor Crater (Arizona) to multispectral data (IMP) on soils and rocks, obtained during Mars Pathfinder mission. The IMP spectra of several rocks from the Mars Pathfinder landing site are characterized by a negative NIR spectral slope from $\sim 0.8$ to $1 \mu \mathrm{m}$ (McSween et al. 1999; Morris et al. 2000a). This is consistent with the spectral properties of the impactites from Meteor Crater, although alternative spectral analogues (SNC-meteorites, some palagonitic tephras, or thin coatings of bright dust on dark rocks) have also been suggested as the cause of the negative slope (Morris et al., 2000a).

Morris et al. (2000b) synthesized several glass samples using a mixture of oxides whose chemical composition was consistent with the major-element composition of Martian soil based 
on Viking and Pathfinder analyses. The glasses were characterized by X-ray diffraction (XRD), magnetic techniques, iron Mössbauer spectroscopy (FeMS), visible and near-infrared (VNIR) reflectance spectroscopy and the thermal emission spectroscopy (TES). In the visible and nearinfrared spectral ranges the samples showed significant spectral variations as a function of oxygen fugacity. In particular, reflectivity of the glasses in the visible range decreased with increasing oxygen fugacity. However, thermal emission spectra were essentially independent from the oxidation state of the samples and exhibited two broad emissivity minima centered near 10 and $23 \mu \mathrm{m}$. These bands are located at longer wavelengths and have lower contrasts than corresponding features in the spectra of more $\mathrm{SiO}_{2}$-rich glasses. It should be noted that various glasses studied by Morris et al. (2000b) were kept at $1300{ }^{\circ} \mathrm{C}$ for 16 hours at different oxygen fugacities in order to reach chemical equilibrium. Such conditions are very different from impact melting on Mars surface, where it takes milliseconds to melt the soil and seconds to solidify the melt. Because of the speed of this process, chemical equilibrium between the melt and the Martian atmosphere cannot be achieved.

Basilevsky et al. (2000a) used a different approach for their simulation of impact glass formation from Martian bright soil. The glasses were produced by quickly melting the Martian bright soil simulant JSC Mars-1 (Allen et al., 1998) using two primary techniques: (a) irradiation with a pulsed laser and (b) melting in a resistant furnace. Basilevsky et al. (2000a) reported details of the melting experiments, sample preparation, compositional variations of the produced melts. Furthermore, Basilevsky et al. (2000a) discussed the visual colors of the experimentally produced melts and their possible implications for the origin of dark materials from polar layered deposits on Mars.

In this study we present a detailed study and discussion of the reflectance spectra for the samples produced and characterized by Basilevsky et al. (2000a). In addition, iron Mössbauer spectroscopy and high-resolution transmission electron microscopy (HRTEM) of the samples were performed to provide further information about the nature of the optical variations discussed below. 


\section{Experimental procedures and sample characterization}

\subsection{Glass production and mineralogy}

The glass production procedures are described in detail by Basilevsky et al. (2000a). For convenience of the reader, we provide a brief description of the experiments and mineralogy of the samples, which include three different experimentally produced glasses..

The starting material from which the glasses were produced is an altered volcanic soil from Hawaii known as JSC Mars-1 (Allen et al., 1998). It is a mixture of glassy volcanic ash particles with alteration rinds and particles consisting entirely of weathered ash (Fig. 1). The chemical

\section{[Figure 1]}

composition of the JSC Mars-1 was reported by Allen et al. (1998) and Basilevsky et al. (2000a).

The first two glasses labeled as "S" and "F", were produced by quickly melting the non-sieved JSC Mars-1 sample in a resistance furnace under a vacuum of $10^{-1} \mathrm{~mm} \mathrm{Hg}$. In these conditions, the partial pressure of oxygen approximately corresponds to that near the surface of Mars. The samples were heated to $\sim 1650^{\circ} \mathrm{C}$ for $\sim 60-90$ seconds. Two different cooling paths were then followed for each of the S- and F-glasses. For the S-glass, the solidification temperature was reached after $\sim 40-60$ seconds of cooling due to the slow decrease in the electric current and resulting slow cooling path. Thus, the samples produced in this regime are labeled as "S" ("slow cooling"). For the F-glass, the electric current was turned off abruptly after the sample had reached the temperature of $\sim 1650^{\circ} \mathrm{C}$. The solidification temperature of $800-900^{\circ} \mathrm{C}$ was reached within few seconds; the glasses produced this way were labeled as "F" (fast cooling). The experimental products in both cases were sharp-edged fragments of dark glass (Fig. 2b, c). The scanning electron microscope (SEM)

\section{[Figure 2]}

study shows that the S-glass is very homogeneous in composition and appears massive in BSE images, though the arcuate edges of the fragments indicate that vesicles of hundreds microns in diameter were originally present in the glass (Fig. 2c; 3d). In rare cases, unmelted 
[Figure 3]

clasts of olivine and plagioclase along with submicron grains of Fe-Ti oxides are present. The rare Fe-Ti oxides probably crystallized from the melt.

The F-glasses are darker than the S-glasses and are more variable in composition and texture (Fig. 3a, b), probably since the material spent less time above its melting point than the S-melt (Basilevsky et al., 2000a). Sometimes clusters of submicron Fe-Ti oxide grains are seen in the BSE images. In rare cases, skeletal crystals of plagioclase, olivine, and ilmenite are embedded in the glass (Fig. 3a). The F-glasses are generally massive but often contain vesicles of 15-30 $\mu \mathrm{m}$ in diameter, as well as the larger vesicles of $100-200 \mu \mathrm{m}$ in diameter (Fig. 2b; 3b).

The glasses labeled as "L" ("laser irradiated") were produced by irradiation with a ND-YAG pulsed laser with a pulse frequency of $30-40 \mathrm{kHz}$ and pulse duration of $0.5-1 \mu \mathrm{s}$. The technique was similar to that described by Moroz et al. (1996). Before irradiation the JSC Mars-1 sample was powdered and sieved to particle size of $<75 \mu \mathrm{m}$. In the first case, "L2", the starting pressure in the chamber was $\sim 10^{-2} \mathrm{~mm} \mathrm{Hg}$. During the irradiation, loss of volatiles from the sample caused an increase in the pressure to $3 \times 10^{-2} \mathrm{~mm} \mathrm{Hg}$. In the second case, "L4", the starting pressure was about $10^{-4} \mathrm{~mm} \mathrm{Hg}$ and reached $\sim 3 \times 10^{-3} \mathrm{~mm} \mathrm{Hg}$ during irradiation. The latter regime was used to verify whether a pressure two orders of magnitude lower would affect the optical properties and composition of the produced glasses. The melting products are spheroid droplets (Fig. 2a) and irregular fragments (Fig. 3c) containing ubiquitous gas vesicles ranging from $\sim 80 \mathrm{~nm}$ to $\sim 100$ $200 \mu \mathrm{m}$ in size, according to our TEM and SEM studies. The gas was released from the samples during the melting and trapped in the melt due to very quick cooling. Basilevsky et al. (2000a) estimated the total porosity of the laser irradiated glasses at $50-55 \%$. The glass is compositionally heterogeneous. No noticeable differences in composition and texture between the L2 and L4 glasses were observed.

All the glasses do not significantly differ in chemical composition from each other and from the JSC Mars-1 soil, except for their obvious depletion in $\mathrm{H}_{2} \mathrm{O}$ (Basilevsky et al., 2000a). In addition, the L2 and L4 glasses are moderately depleted in $\mathrm{K}$ and $\mathrm{Na}$, probably due to high- 
temperature vaporization.

\subsection{Oxidation state of iron in the samples}

Mössbauer (MB) spectroscopy is an excellent tool to determine $\mathrm{Fe}^{3+} / \mathrm{Fe}^{2+}$ ratios in minerals, rocks, and amorphous phases (e.g., Bancroft et al., 1977; Heller-Kallai and Rozenson, 1981; Mysen et al., 1985; Dyar, 1985, 1987, 2006; Kuzmann et al., 2003). Its usefulness for characterization of the $\mathrm{Fe}^{3+} / \mathrm{Fe}^{2+}$ ratios and $\mathrm{Fe}$ site occupancies in silicate glasses has been demonstrated by many researchers (see reviews by Kurkjian, 1970; Coey, 1974; Dyar, 1985). Iron partitioning in a glass depends on many factors: oxygen fugacity; duration, temperature and pressure of the precursor melt's equilibration; cooling rate and sample size; temperature and pressure of the glass during the MB measurement; and composition of the sample (Mysen et al., 1980; Sack et al., 1980; Dyar and Birnie, 1984; Virgo and Mysen, 1985; Dyar, 1985; Dyar et al., 1987; Helgason et al., 1989, 1992).

${ }^{57} \mathrm{Fe}$ Mössbauer spectroscopic studies (FeMS) of the samples were performed at M.V. Lomonosov Moscow State University (Moscow, Russia) in order to identify the abundances of iron-bearing species and the oxidation state of iron in the samples. The spectra were analyzed by performing mathematical fits to separate $\mathrm{Fe}^{2+}, \mathrm{Fe}^{3+}, \mathrm{Fe}_{3} \mathrm{O}_{4}$, and $\alpha-\mathrm{Fe}$ from one another. The fitting procedures were performed using the SPECTR and DISTRI programs (Rusakov, 2000; Rusakov and Kadyrzhanov, 2005). The MB spectra of selected samples are shown in Fig. 4. The contents of different iron species are listed in TABLE I.

\section{[Figure 4]}

We found that $\sim 10 \%$ of Fe atoms in the JSC Mars- 1 sample are attributable to magnetite.

\section{[Table I]}

The rest of iron atoms in this altered volcanic soil are paramagnetic, and about $80 \%$ of them are ferric $\left(\mathrm{Fe}^{3+}\right)$. Our MB data on the JSC Mars-1 are consistent with those of Carpenter et al. (2003) who reported the $\mathrm{Fe}^{3+} / \mathrm{Fe}^{2+}$ ratio of $\sim 3.2$ in their sample of the Mars soil analogue. A much higher 
$\mathrm{Fe}^{3+} / \mathrm{Fe}^{2+}$ ratio of 16 was reported by McAdam et al. (2004) for the fine $(<20 \mu \mathrm{m})$ fraction of the JSC Mars-1. This indicates that the largest portion of ferric iron is concentrated in the finest fraction of the soil.

All the glasses are enriched in $\mathrm{Fe}^{2+}$ compared to the JSC Mars-1. This is likely results from the thermal reduction of iron during glass formation. In the samples produced in the resistance furnace, $3-17 \%$ of the iron atoms belong to magnetite, while only $25-30 \%$ of the remaining iron is ferric. The S-glass is more reduced than the F-glass (TABLE I). It is likely that iron reduction was more effective in this case, because the S-sample spent a longer time at a high temperature than the F-melt. However, the glasses produced by pulsed laser irradiation are the most reduced of all the glasses. About $5 \%$ of Fe atoms in these samples are reduced to Fe metal $\left(\alpha-\mathrm{Fe}^{0}\right)$, as confirmed by high-resolution TEM studies (see below), and only $2-7 \%$ of remaining Fe atoms are ferric (TABLE I). This may be due to the higher temperatures of the melts produced by the pulsed laser and/or due to lower oxygen pressure in the vacuum chamber during the formation of L-glasses compared to the S- and F-glasses. An $\alpha-\mathrm{Fe}^{0}$ sextet has also been observed in MB spectra of lunar soils (e.g., Hafner et al., 1970; Gibb et al., 1977; Morris et al., 1998). However, a singlet corresponding to nanophase superparamagnetic metallic iron (np- $\mathrm{Fe}^{0}$ ) strongly overlaps with the low velocity peaks of $\mathrm{Fe}^{2+}$ doublets (e.g., Housley et al., 1971; Morris et al., 1998) and has not been resolved in this study. Therefore, if any single-domain np-Fe ${ }^{0}$ is present in any of our glasses, Mössbauer spectroscopy is not a suitable technique for its detection.

It should be noted that the peak centers and widths in MB spectra of $\mathrm{Fe}^{2+}$-bearing glasses are very similar to those of pyroxenes (particularly the M2 doublet). Pyroxenes have not been detected in our samples by SEM (Basilevsky et al., 2000). However, pyroxenes have been detected by MER Mössbauer spectrometers in the rocks and soils at Gusev crater (Morris et al., 2006a; 2008) and Meridiani Planum (Morris et al., 2006b). Due to the ambiguity mentioned above, one cannot exclude that at least some fraction of these pyroxenes may in fact be Febearing glasses. However, Morris et al. (2008) recently suggested that careful comparison of MB 
parameters of Mars spectra with those of laboratory samples may allow for identification of nonaltered Fe-bearing glasses.

\subsection{Transmission electron microscopy}

The micro and nano-scale studies of all the glasses were performed using three different TEMs. A Hitachi H800-NA with a $\mathrm{LaB}_{6}$ cathode operated at $200 \mathrm{kV}$, a JEOL 3010 using a LaB 6 cathode at $297 \mathrm{kV}$, and a Zeiss LIBRA 200FE with a field emission gun at $200 \mathrm{kV}$. The preparation of the samples using standard thin-sectioning and Ar-ion milling was unsuccessful.

Comment [CudB1]: The part about the energy filter is not needed since EELS results are not being presented. One sample prepared in this way was successfully thinned to electron transparency; however, it was heavily contaminated with sputtered copper from the grid. Ultramicrotomy was also not suitable for preparing the samples, since it is nearly impossible to produce smooth thin sections of brittle glassy particles of this size using the diamond knife. Therefore, we used a Zeiss 1540 XB Focused Ion Beam-Scanning Electron Microscope (FIB-SEM) to cut 15-20 $\mu \mathrm{m}$ long lamellae from the glasses (e.g., Fig. 2a). Various $\mathrm{Ga}^{+}$ion beam currents, ranging from $2 \mathrm{nA}$ to $500 \mathrm{pA}$, were used to ablate material on both sides of the desired lamellae to a thickness of $<100 \mathrm{~nm}$. No protective layer of $\mathrm{Pt}$ was deposited over the surface of the lamellae, as we were not concerned about protecting the surfaces of the samples from the effects of the ion beam, since this was not the focus of the study. After cutting the lamellae, they were lifted out using a manipulator and attached to a half-circular copper grid. Within each lamella, an area of about $7 \times 10 \mu \mathrm{m}^{2}$ was thinned to electron transparency for analysis.

TEM investigation of the FIB lamellae of all the glass samples showed that the bulk of the samples are indeed amorphous glass. However, small areas containing crystalline phases were also observed in all the samples. For example, the ion-milled S-glass sample contained silicate crystals concentrated in discrete areas (Fig. 5), and the F-glass lamella contained a single small crystal $(\sim 180 \mathrm{~nm})$. Although plagioclase laths and Fe-Ti oxides were observed in SEM images of the F-glasses (Fig. 3a), they were not encountered in the lamellae prepared for TEM 
analysis. The differences between the TEM samples are due to their small size compared to the larger scale heterogeneity in the bulk glass. In contrast with the S- and F-glasses, the L-glass lamella exhibited large vesicles and numerous nano-phase inclusions ranging from $25-80 \mathrm{~nm}$ in diameter that were dispersed randomly throughout an amorphous matrix (Fig. 6a). The nanophase inclusions were too small and few to be analyzed using conventional selected area and convergent beam electron diffraction techniques, so high resolution imaging of the inclusion lattice was required for their identification. The inclusions show clear lattice fringes (Fig. 6). The orientations of the lattice planes show that the inclusions are not single crystals, but that different crystal domains are present within individual inclusions (e.g., Fig. 6b, c). The fast Fourier transform (FFT) of this HRTEM image (equivalent to a diffraction pattern) is consistent with $\alpha \mathrm{Fe}$ (bcc), and the inter-planar spacings of $0.20 \mathrm{~nm}$ are consistent with the $\{110\}$ planes of $\alpha \mathrm{Fe}$ (Fig. $6 \mathrm{c})$.

\subsection{Reflectance measurements}

Five fractions ranging from silt to medium sand grain sizes $(<40,40-80,80-125,125-200$, and 200-380 $\mu \mathrm{m}$ ) from each sample were prepared for spectroscopic studies. The samples included the non-altered Mars soil analogue JSC Mars-1 (marked as „P“) and the four glasses: F, S, L2, and L4. The JSC Mars-1 sample was sieved without comminution, whereas the glasses were ground before sieving.

Bidirectional reflectance spectra in the range of 0.3-2.5 $\mu \mathrm{m}$ were recorded at incidence angle $(i)$ of $30^{\circ}$ and emergence angle $(e)$ of $0^{\circ}$ with the RELAB bidirectional spectrometer (Brown University) relative to a Halon standard (Pieters 1983). Biconical reflectance spectra were acquired in a $\mathrm{CO}_{2}$ - and $\mathrm{H}_{2} \mathrm{O}$ - purged environment using two different FTIR-spectrometers. Bruker IFS 88 (DLR) equipped with a "Seagull ${ }^{\mathrm{TM} "}$ " variable angle reflectance accessory (Harrick Scientific Co.) was employed for biconical reflectance measurements between 0.5 and $17 \mu \mathrm{m}$ at $i=e=20^{\circ}$. An Si-diode detector was used from 0.55 to $1.1 \mu \mathrm{m}$, an InSb detector between 0.9 and 5 
$\mu \mathrm{m}$, and an MCT-detector from 5 to $16 \mu \mathrm{m}$. The measurements with the Si-detector were performed relative to a pressed Halon standard, while the infrared spectra were recorded relative to gold-plated sandpaper standard. Nicolet 740 FTIR-spectrometer (RELAB, Brown University) was used for biconical reflectance measurements between 2.5 and $25 \mu \mathrm{m}$ at $i=e=30^{\circ}$. The spectra were acquired using a DTGS-detector relative to a rough gold standard. All the spectra were measured at ambient temperature. The use of different instruments in two laboratories in overlapping spectral ranges allowed us to distinguish spectral variations due to composition/texture from the instrumental effects. In general, good agreement in terms of absolute reflectivity and spectral shape was observed between the different instruments used in this study.

\section{Reflectance spectra}

\subsection{Visible and near-infrared spectra}

3.1.1. VNIR spectra of JSC Mars-1 soil

The Hawaiian altered volcanic soil JSC Mars-1 is a good though not perfect spectral analogue for Martian bright regions in the visible and near-infrared (Allen et al., 1998). It is probably impossible to find a perfect analogue material, since soils from various areas on Mars demonstrate some spectral, mineralogical, and chemical variations (e.g., Murchie et al., 2000 and references therein; Bell et al., 2000; Morris et al., 2000a; Yen et al., 2005; 2008; Ming et al., 2008). The JSC Mars-1 spectra (Fig. 7) show relatively featureless $\mathrm{Fe}^{3+}$ absorption edge between 0.4 and $0.7 \mu \mathrm{m}$, suggesting an absence of well-crystallized Fe-oxides (Allen et al., 1998). A weak (1-5\%) broad absorption band near $0.9-1 \mu \mathrm{m}$ in the spectrum of JSC Mars-1 is probably due nanophase ferric oxides with a possible contribution from iron in clay minerals. Although the reflectance spectra of some bright areas on Mars show evidence for a more significant contribution from well-crystallized ferric oxides (e.g., "red" hematite) as suggested by characteristic absorption bands in the extended visible range (Morris et al., 1985; Bell et al., 1990), some other soils, for example from the Mars Pathfinder landing site (Morris et al., 2000a) 
are more similar to JSC Mars-1 in this spectral range.

The absorption feature at $1.42 \mu \mathrm{m}$ in the spectra of the JSC Mars- 1 separates may be both due to structural $\mathrm{OH}$ and $\mathrm{H}_{2} \mathrm{O}$ bound octahedrally to a cation, while the bands at $1.92 \mu \mathrm{m}, \sim 3 \mu \mathrm{m}$, and $6 \mu \mathrm{m}$ are due to chemically bound and physically adsorbed water (Eisenberg and Kauzmann 1969; Farmer 1974; Aines and Rossman 1984; Bishop et al. 1994). An additional weak Al-OH feature typical of Al-bearing clay minerals is present near $2.2 \mu \mathrm{m}$. This feature is especially pronounced in the spectrum of the $<2 \mu \mathrm{m}$ separate of the JSC Mars- 1 sample studied by Schiffman et al. (2002), indicating that clay minerals are concentrated in the finest fraction of this volcanic soil. Analysis of exact wavelength positions and shapes of absorption features in highresolution reflectance spectra often allows one to identify minerals containing structural $\mathrm{OH}$ and/or bound $\mathrm{H}_{2} \mathrm{O}$ (Clark et al., 1990). NIR reflectance spectra of the JSC Mars-1 indicate that it probably contains Al-bearing smectite clays. The clays in the JSC Mars-1 either have very low abundance, are very poorly crystalline, or the sizes of the clay crystallites are very small, because the related absorption features are weak and no clay minerals have been detected in XRD spectra of JSC Mars-1 samples (Allen et al., 1998, Schiffman et al., 2002).

\section{[Figure 7]}

The water-related features are more intense in the RELAB spectra of the JSC Mars-1 (Fig. 7a) compared to those acquired at DLR, since the samples measured at DLR were heated to $100^{\circ} \mathrm{C}$ in the oven prior to the measurements. However, such heating does not make the water features as weak as those in typical NIR remote spectra of Martian soils. The weak band near $2.2 \mu \mathrm{m}$ due to $\mathrm{Al}-\mathrm{OH}$ in aluminous clays is known to be more persistent and its intensity is not reduced by heating. Some areas on Mars, that are enriched in aluminous smectites and kaolinite, have recently been identified by the MEX OMEGA (Poulet et al., 2005, 2007; Loizeau et al. 2007) and MRO CRISM spectrometers (Mustard et al. 2008). Recently the CRISM team detected small areas with Al-rich micas (illite or muscovite) (Mustard et al. 2008). However, most of the phyllosilicates recently identified in OMEGA and CRISM spectra appear to be poor in Al (Poulet et al., 2005; Mangold et al. 2007; Loizeau et al. 2007; Bishop et al. 2008; Mustard et al. 2008; 
Wiseman et al. 2008).

Allen et al. (1998) compared a JSC Mars-1 spectrum to a spectrum of the Olympus-Amazonis bright region on Mars (Mustard and Bell, 1994) and noted that Martian soils were extremely dry compared to the simulant, based on the depths of the 1.4- and 1.9- $\mu \mathrm{m}$ bands. However, Milliken and Mustard (2005) recently showed that the latter bands do not provide reliable information on water (chemically bound and physically adsorbed) content in hydrated minerals and soils. These authors also demonstrated that only the $3-\mu \mathrm{m}$ absorption band may be used for this purpose, unless it is saturated. Surface water content on Mars shows significant variations across the planet (Bibring et al., 2005; Jouglet et al., 2007; Milliken et al., 2007). Milliken et al. (2007) demonstrate that equatorial regions are the driest ones with $\sim 2-5 \mathrm{wt} . \% \mathrm{H}_{2} \mathrm{O}$, while hydration increases with latitude and may be as high as 15 wt.\%. Our JSC Mars-1 sample analyzed by Basilevsky et al. (2000a) has LOI values of $\sim 15$ wt.\%, suggesting water content comparable to that of the wettest areas on Mars. Interestingly, phyllosilicate deposits near Mawrth Vallis (Poulet et al., 2005) probably contain only 7-9 wt.\% $\mathrm{H}_{2} \mathrm{O}$ (Milliken et al., 2007) despite the wellpronounced 1.4 and $1.9 \mu \mathrm{m}$ bands in the OMEGA and CRISM spectra.

The NIR slopes in the spectra of the JSC Mars-1 separates are relatively neutral and vary as a function of particle size and packing density. The slope is slightly negative (blue) for the coarsest separates and somewhat positive (red) for the finest ones (Fig. 7a).

The brightness of the sample is the highest for the finest fraction and significantly decreases with increasing particle size. This is both due to the particle size effect (decrease in multiple scattering) and the change in composition. The coarse fractions are dominated by basaltic glass, while the finest ones are dominated by the brighter weathering products.

Allen et al. (1998) and Basilevsky et al. (2000a) reported chemical analyses of JSC Mars-1 and compared them to available analyses of Martian soils from Viking (Toulmin et al., 1977; Clark et al., 1982) and Mars Pathfinder (Rieder et al., 1997) landing sites. Recently soils from Gusev crater and Meridiani Planum have been analyzed by the APXS instrument onboard Mars Exploration Rovers (Gellert et al., 2004; 2006; Rieder et al., 2004; Yen et al., 2005; 2008; Wang 
et al., 2008; Ming et al., 2008). In general, the simulant closely matches typical Martian soils for $\mathrm{SiO}_{2}, \mathrm{Fe}_{2} \mathrm{O}_{3}$ (except for Fe-rich dark hemate-rich soils from Meridiani Planum) and $\mathrm{CaO}$ but is significantly different for other oxides, notably $\mathrm{Al}_{2} \mathrm{O}_{3}, \mathrm{TiO}_{2}$ and $\mathrm{MgO}$. A close match in iron content is essential for our experiments, since iron content and its oxidation state play crucial role in controlling the VNIR spectral properties of glasses produced from Fe-bearing samples.

\subsubsection{VNIR spectra of glasses}

The glasses (S, F, L2, and L4) produced from the JSC Mars-1 soil show significant spectral variability depending on the method of production, but are characterized by several common features. All the glasses are darker and less red in the visible than the starting material (Fig. 8a).

\section{[Figure 8]}

As expected, their brightness and spectral slopes in the visible range (e.g., red/blue color ratios) decrease with increasing grain size (Fig 9 a, 10 a, 11 a). Along with the visible absorption edge, all the glasses show two moderate (band depth of 0.15-0.30) broad absorption bands near

\section{[Figure 9] [Figure 10] [Figure 11]}

1.05 and $1.9 \mu \mathrm{m}$. These bands demonstrate the short-range crystal order in the glass. The 1.05$\mu \mathrm{m}$ band corresponds to spin-allowed crystal-field transitions in octahedrally coordinated $\mathrm{Fe}^{2+}$ ions, while the weaker $1.9-\mu \mathrm{m}$ feature is caused by spin-allowed $\mathrm{Fe}^{2+}$ transitions in either tetrahedral (e.g., Burns 1970; Bell et al., 1976; Calas and Petiau, 1983) or, most likely in distorted octahedral coordination (Keppler, 1992). The positions of these broad bands are consistent with those seen in the spectra of synthetic low-Ti glasses prepared under reducing conditions (Bell et al., 1977; Keppler, 1992; Morris et al., 2000b). These two bands are superimposed by a much broader $\mathrm{Fe}^{3+}$ absorption which extends throughout the entire visible and near-infrared ranges. The latter absorption is responsible for the low albedos and positive (red) continuum slopes of the S- and F-glasses in the near-infrared. In addition, the spectra of the pure glasses lack features due to water and structural $\mathrm{OH}$ bound to metal cations, indicating complete decomposition of hydrated phases (Fig. 8, 9, 10, 11). 
The F-glass is darker than the S-glass (Fig. 8) in the visible and near-infrared. This is due to higher $\mathrm{Fe}^{3+}$ content in the F-melt (TABLE I) and possibly due to Ti-magnetite dispersed in the melt. Our TEM studies did not reveal abundant fine opaque inclusions neither in the F- nor in the S-glasses (see above), therefore, we think that ferric iron dissolved in the glass is the major darkening agent for these materials. The glasses produced by a pulsed laser (L2 and L4) are the brightest ones. They exhibit the weakest $\mathrm{Fe}^{2+}$-absorptions near 1.05 and $1.9 \mu \mathrm{m}$, even though iron in L-glass is almost entirely ferrous (TABLE I). The relatively high albedo and low band depth appear to be a textural effect, since this glass contains abundant tiny vesicles (see Fig. 2a, 3c) which act as internal scatterers significantly increasing multiple scattering. In addition, less oxidized glasses are known to be brighter than glasses with high contents of ferric iron (e.g., Bell et al., 1976; Wells and Hapke, 1977; Morris et al., 2000b; Hapke, 2001). Nevertheless, the Lglasses are darker than the JSC Mars-1 sample at most wavelengths and have slightly reddish NIR-slope, probably due to formation of metal iron nanoparticles finely dispersed in the melt (TABLE I; Fig. 6). The $\mathrm{Fe}^{0}$ nanoparticles in our L-samples have sizes $(25-80 \mathrm{~nm})$, which may produce both darkening and reddening from UV to NIR spectral ranges (Noble et al., 2007; Lucey and Noble, 2008). Note that the presence of shock-induced nanophase $\mathrm{Fe}^{0}$ in some Martian meteorites was recently reported (van de Moortèle et al., 2007; Pieters et al. 2008). Ferric iron may also contribute to the relatively dark color and slightly reddish NIR slope of the L-glasses, but its content in these glasses is very low ( $<5$ at.\%). The L-glasses are slightly brighter than the JSC Mars-1 only at wavelengths shorter than $0.5 \mu \mathrm{m}$, most likely due to the reduction of $\mathrm{Fe}^{3+}$ to $\mathrm{Fe}^{2+}$ in the glasses. The JCS Mars-1 samples are very dark in this spectral region due to very strong overlapping absorption bands caused by $\mathrm{O}^{2-} \rightarrow \mathrm{Fe}^{3+}$ charge transfer transitions and $\mathrm{Fe}^{3+}$ crystal field transitions (e.g., Morris et al., 1985; Sherman, 1982, 1985). These strong absorption features are not pronounced in the spectra of our most reduced L-glasses containing only $<5$ at. $\% \mathrm{Fe}^{3+}$ (Table I). The $\mathrm{O}^{2-} \rightarrow \mathrm{Fe}^{2+}$ absorption feature present in the near-UV and visible regions in the spectra of our L-glasses is weaker than $\mathrm{Fe}^{3+}$-related features mentioned above, therefore the L-glasses are brighter than the JSC Mars-1 in these spectral ranges. 
The finest fractions of the L-glass $(<40$ and $40-80 \mu \mathrm{m})$ are contaminated by non-melted volcanic soil. This is evident from pronounced absorption features of $\mathrm{H}_{2} \mathrm{O}$ and structural $\mathrm{OH}$ (Fig $11 b)$.

Near-infrared continua of the L-glass spectra are less red than those of the S- and F-glasses (Fig 8a). This is consistent with very low $\mathrm{Fe}^{3+}$ contents in the L-glasses.

By extrapolating the experimental production of glasses from the Mars analog soil to the formation of impact glasses on Mars, it appears that impacts into Martian soils should produce dark glassy materials, with red-sloped NIR reflectance spectra and two broad shallow absorption bands centered near 1.05 and $1.9 \mu \mathrm{m}$. Note that such VNIR spectral properties would be typical of any fresh (non-weathered) glass containing $\mathrm{Fe}^{2+}$ and $\mathrm{Fe}^{3+}$ ions, and is not characteristic of the impact origin of the glass. For example, fresh volcanic (e.g., Minitti et al., 2002; Bishop et al., 2003a) and impact (Ehlmann et al., 2008) glasses of basaltic composition have similar VNIR spectral properties. This indicates that VNIR reflectance spectra may be helpful for detecting fresh glasses on Mars, but can hardly be useful for distinction between glasses of volcanic and impact origins. The only expected difference between Martian volcanic and impact glasses of similar chemical compositions could be that fresh impact glasses might be brighter and have weaker NIR absorption bands compared to volcanic glasses, since Martian impact glasses are expected to be mechanically weak and enriched in vesicles (due to fast cooling) compared to volcanic glasses (Thomson, 2006). However, differences in brightness and the NIR band depths of the glasses on Mars may also be related to their degree of weathering and composition (total Fe content, $\mathrm{Fe}^{2+} / \mathrm{Fe}^{3+}$ ratio) of their precursors. For example, impacts into a plagioclase-rich (Fepoor) target would form brighter glasses with weaker NIR absorptions (Johnson and Hörz, 2003) compared to basaltic (Fe-bearing) glasses.

\subsection{Thermal-infrared spectra}


Thermal infrared spectra of silicates, silicate-rich rocks and glasses show characteristic features called Reststrahlen bands. Reststrahlen bands are very strong absorption bands with imaginary part of refractive index $k>0.1$ at the band center. Very little energy can pass through the grain boundaries, so that scattering and absorption properties are controlled by surface scattering. This results in a maximum in reflectance and a minimum in emissivity (e.g., Vincent and Hunt, 1968). Reststrahlen bands are of certain diagnostic potential (see below), although their shapes and intensities are strongly affected by grain size, crystal orientation, and degree of crystallinity (Lyon, 1964; Vincent and Hunt, 1968; Salisbury et al., 1991).

Reflectance minima called Christiansen features (Conel, 1969) occur just prior to each fundamental vibration band, where the refractive index approaches that of the medium (air), resulting in a minimum of backscattering. Christiansen features in reflectance spectra and corresponding emissivity maxima in thermal emission spectra are very useful for characterization of mineral composition, since wavelength positions of these features do not vary as a function of grain size, crystal orientation and crystallinity (Conel et al., 1969; Salisbury et al., 1991; Cooper et al., 2002).

Transparency features are reflectance maxima (emission minima) present in TIR spectra of fine grains (Conel, 1969) and are caused by change from surface to volume scattering. Their wavelength positions are controlled by both composition and particle size (Mustard and Hays, 1997), and can be helpful for detection of certain minerals in spectra of a fine dust, where Reststrahlen bands are very weak.

\subsubsection{TIR spectra of JSC Mars-1 soil}

The Christiansen minima in the spectra of JSC Mars-1 samples are located near $8 \mu \mathrm{m}$ and the corresponding Reststrahlen bands (see below) around $10 \mu \mathrm{m}$ are weak. Their spectral contrasts do not depend significantly on particle size, since even the coarsest particles consist mostly of aggregates of finer grains. This is consistent with previous TIR reflectance (Cooper and Mustard, 
2002; Schiffman et al., 2002) and emission (Ruff and Christensen, 2002) measurements of the JSC Mars-1 powders. However, only the spectra of the finest $(<40 \mu \mathrm{m})$ size fraction measured in this study show a weak but detectable transparency feature centered at 12.05-12.1 $\mu \mathrm{m}(825-830$ $\mathrm{cm}^{-1}$ ). This feature was also observed in other reflectance (Cooper and Mustard, 2002; Schiffman et al., 2002) and emission (Maturilli et al., 2008) spectra of fine JSC Mars-1 separates. Some published spectra of fine separates of other altered (e.g., palagonitic) volcanic materials also exhibit a similar transparency feature (e.g., Esposito et al., 2000; Bishop et al., 2002a; 2003a; 2007). The transparency feature at $12.1 \mu \mathrm{m}$ dominates TES and Mini-TES spectra of Martian bright soils and is likely due to a fine-grained feldspar component (Ruff and Christensen 2002; Bandfield and Smith 2003; Ruff et al., 2006) or zeolites (Ruff, 2004). Unlike all other available spectra of fine JSC Mars-1 fractions, the spectrum from the ASU library (Ruff and Christensen, 2002; Bandfield and Smith, 2003; Ruff, 2004) lacks the $12.1 \mu \mathrm{m}$ feature, leading these authors to conclude that the JSC Mars-1 is a poor match to the TIR spectra of dust and bright regions on Mars. Bandfield and Smith (2003) emphasize the similarity of the TES spectra from Mars' bright region to those of unaltered fine-grained plagioclase-rich rocks such as basaltic andesites and anorthosites, while Ruff (2004) suggests that zeolites are responsible for the transparency feature near $12.1 \mu \mathrm{m}$. We should note, however, that the $12.1-\mu \mathrm{m}$ transparency feature dominates the TIR spectra of many fine-grained altered (e.g., JSC Mars-1; palagonitic tuffs) and unaltered (e.g., some basalts - Bishop et al., 2002b) volcanic materials, and therefore is not conclusive evidence for very high feldspar or zeolite contents in Martian bright soils and dust. Very prominent transparency features are typical of feldspar fine powders (e.g., Maturilli et al., 2006). It seems that relatively minor feldspar or zeolite contents may dominate the TIR spectra of fine-grained materials, due to a very prominent transparency feature in the spectra of feldspars/zeolites, which may contribute to the TIR spectra of fine dust out of proportion. This effect may be explained by the fact that spectral behavior of fine grains in transparency spectral region is controlled by volume scattering, resulting in the non-linear mixing of endmember components. 
3.2.2. TIR spectra of glasses

In the TIR range the glasses produced from the JSC-Mars-1 exhibit a Christiansen feature near 8-8.2 $\mu \mathrm{m}$ and a very broad featureless Reststrahlen band centered near $10 \mu \mathrm{m}$ due to assymetric Si-O stretching vibrations (Fig. 8b, 9b, 10b, 11b). An additional weaker band due to Si-O bending is observed near 22-23 $\mu \mathrm{m}$. The Reststrahlen bands are broad and smooth (without internal spectral structure), which is typical of glasses (Simon and McMahon, 1953; Parke et al., 1974) and other non-crystalline phases.

The frequencies of Si-O vibrations, and hence wavelength positions of Christiansen features and Restrstahlen bands in spectra of silicate minerals and rocks and glasses, depend on Si-O bond strength which decreases with increasing depolymerization of the silicate framework.

The degree of polymerization is primarily a function of the $\mathrm{Si} / \mathrm{O}$ ratio and the number of nonbridging oxygen atoms. Christiansen features and Reststrahlen bands progressively move from longer wavelengths (low wavenumbers) in ultramafic rocks to shorter wavelengths in felsic rocks, as the silica content and depolymerization increase (Launer, 1952; Lyon, 1963; Lyon and Burns, 1965; Conel, 1969; Vincent et al., 1975; Walter and Salisbury, 1989). In addition, substitution of $\mathrm{Si}^{4+}$ for $\mathrm{Al}^{3+}$ in tetrahedral sites displaces the Christiansen features and Reststrahlen bands to longer wavelengths (e.g., Stubičan and Roy, 1961). Similar trends hold for silicate glasses (Wyatt et al., 2001; Michalski et al., 2005; Byrnes et al., 2005, Thomson, 2006; Minitti et al., 2006, 2007a), although additional factors such as cooling/quench rates and fictive temperatures may affect frequencies of Si-O vibrations in reflectance and thermal emission spectra of glasses (Fujita et al. 2003; Thomson 2006).

Positions of the Christiansen features and Reststrahlen bands are similar for all our glasses regardless oxidation state of iron, and correspond to the positions of similar features in emissivity spectra of synthetic "Martian" glasses prepared by Morris et al. (2000b). Differences in $\mathrm{Al}_{2} \mathrm{O}_{3}$ content between Martian soils and the JSC Mars-1 may affect positions of the 10- $\mu \mathrm{m}$ band in the TIR spectra of glasses produced from these materials. An increase in the $\mathrm{Al} / \mathrm{Si}$ ratio tends to shift 
this band to longer wavelengths, so that a similar feature in the spectra of glasses formed by impacts into Martian soils might be located at shorter wavelength. However, the glasses of Morris et al. (2000b) closely match Martian soils in both $\mathrm{Al}_{2} \mathrm{O}_{3}$ and $\mathrm{SiO}_{2}$, and nevertheless their TIR spectra exhibit the $10-\mu \mathrm{m}$ band at the same wavelength as the spectra of our glasses. This indicates that some enrichment of the JSC Mars-1 in $\mathrm{Al}_{2} \mathrm{O}_{3}$ has no critical effect on spectral properties of the glasses derived from this material.

The observed wavelength positions $(\sim 10 \mu \mathrm{m})$ and broad spectral shapes are typical of basaltic glasses (e.g., Pollack et al., 1973; Crisp et al., 1990; Wyatt et al., 2001; Minitti et al., 2002, 2006, 2007a; Bishop et al., 2003a, Michalski et al., 2005; Thomson, 2006) and differ from those of more $\mathrm{SiO}_{2}$-rich glasses. Reststrahlen bands in the spectra of $\mathrm{SiO}_{2}$-rich glasses are usually sharper (V-shaped) and centered at shorter wavelengths (Bandfield et al., 2000; Wyatt et al., 2001; Michalski et al., 2005; Thomson, 2006). It should be noted that the TIR features in the spectra of basaltic glasses (including our experimentally produced samples) are very similar to those of plagioclase impact glasses (Noble and Pieters, 2001; Johnson et al., 2002, 2003, 2006) and other glasses (synthetic or volcanic) formed from intermediate to calcic plagioclases (e.g., Nash and Salisbury, 1991; Byrnes et al., 2005).

Only slight differences in band positions, possibly related to variations in composition and cooling rate, are observed between the TIR spectra of our glasses. The $10-\mu \mathrm{m}$ Reststrahlen bands in the spectra of F-glass separates are centered at somewhat shorter wavelengths $(10.03 \mu \mathrm{m})$ than in the spectra of the S-glass separates $(10.17 \mu \mathrm{m})$, being consistent with higher cooling rate (and fictive temperature) of F-glass compared to the S-glass (Fujita et al., 2003; Thomson, 2006). The somewhat longer wavelength positions $(\sim 10.3 \mu \mathrm{m})$ of the Reststrahlen bands and Christiansen features in the spectra of the L-glasses may be explained by the higher $\mathrm{Al} / \mathrm{Si}$ ratios (Bouška, 1993; Zotov, 2003) of the L-glasses compared to the F- and S-glasses.

In addition, the bands at $10 \mu \mathrm{m}$ and $22-23 \mu \mathrm{m}$ in the spectra of our glasses and other glasses of basaltic composition are much less intense than the corresponding bands in obsidian glass spectra. This shows that the detectability of glasses derived from typical Martian soils or mafic 
rocks should be low compared to the more $\mathrm{SiO}_{2}$-rich glasses (Morris et al., 2000b). Band contrasts in the TIR spectra of our glasses (Fig. 9b, 10b, 11b) are higher for the coarser size separates, as expected. Spectral contrasts of Reststrahlen bands are known to be low for fine particle sizes (e.g., Lyon, 1964; Vincent and Hunt, 1968) due to increasing contribution of photon trapping (Lyon, 1964; Aronson et al., 1966; Salisbury and Eastes, 1985) and volume scattering (Salisbury and Wald, 1992). Vesicular textures of our L-glasses (Fig. 2a, 3c) also increase the volume scattering in the spectral region of fundamental Reststrahlen bands. Therefore, the Reststrahlen bands in the spectra of L-glasses (Fig. 11b) are weaker than those in the spectra of S- and F-glasses (Fig. 9b, 10b). The L-glasses with their vesicular texture (Fig. 2a, 3c) caused by fast cooling of the melt, are likely better analogues for Martian impact glasses formed by small-scale impacts into Martian soil, than the F- or S-glasses (Basilevsky et al., 2000a). Thomson (2006) also emphasized that Martian impact melts should have vesicular textures. If this is the case, then the bands due to $\mathrm{SiO}_{2}$-poor impact glasses near 10 and $22-23 \mu \mathrm{m}$ are likely to be difficult to detect in thermal emission spectra of Martian surface.

Transparency features are very weak or absent in the TIR reflectance spectra of the finest glass separates $(<40 \mu \mathrm{m})$, except for the fine separates of the L2 and L4 glasses, which are contaminated with non-melted JSC Mars-1 soil. The lack of transparency features is typical of fine separates of glasses (e.g., Nash and Salisbury, 1991; Minitti et al., 2002) and impact melts (Johnson et al. 2002, 2003; Thomson, 2006). Johnson et al. (2002) suggest that the possible absence of the 12.1- $\mu \mathrm{m}$ transparency feature in thermal emission spectra of some bright regions on Mars may indicate the presence of fine-grained impact melt. We should add, however, that in order to be detected this way, impact melt surfaces must be dust-free. Our TIR spectra of fine $(<40 \mu \mathrm{m})$ L2 and L4 glass fractions contaminated with JSC Mars-1 dust fully reproduce the shape of the spectrum of pure non-melted JSC Mars-1 finest $(<40 \mu \mathrm{m})$ fraction, including the transparency feature at $12.1 \mu \mathrm{m}$. This suggests very low detectability of impact glasses in TIR spectra of Mars bright regions. 


\subsection{3. $\mathrm{CO}_{2}$ feature in spectra of $L$-glasses}

A weak absorption band near $4.27 \mu \mathrm{m}$ is absent in the spectra of F- and S-glasses, as well as in the JSC Mars-1 but is well-pronounced in the spectra of all L-glass samples (Fig. 12). This band is probably due to $\mathrm{CO}_{2}$ trapped in the small vesicles (Fig. 3c) mentioned above. Since the depth of the $4.27-\mu \mathrm{m} \mathrm{CO}_{2}$ feature in the spectra of L-glasses does not depend on the pressure in the vacuum chamber, we suggest that the source of $\mathrm{CO}_{2}$ is the volcanic soil itself. Basilevsky et al. (2000b) analyzed a sample of the JSC Mars-1 with a CHNS-analyzer and detected $\sim$ wt.\% C. Another JSC Mars-1 sample was recently analyzed by gasometric method for total C (1.37 wt.\%), organic $\mathrm{C}\left(1.03\right.$ wt.\%), and $\mathrm{CO}_{2}\left(1.33\right.$ wt.\%). The analysis shows that $\mathrm{CO}_{2}$ is inorganic and corresponds to $<1$ wt. $\%$ carbonates in the analyzed sample. Bishop et al. (2001) demonstrated that carbonate content as low as $0.1 \mathrm{wt} . \% \mathrm{CO}_{2}$ may produce detectable features at 4 and $7 \mu \mathrm{m}$, but we should note that band detectability in reflectance spectra of intimate mixtures depends on many factors including optical properties and grain sizes of all components of the mixture. In particular, JSC Mars-1 powders are much darker in the 4- $\mu$ m spectral region than the samples from Bishop et al. (2001). This can explain that as much as $\sim 1 \mathrm{wt} . \%$ carbonates is not detectable in reflectance spectra of JSC Mars-1 samples. An XRD analysis of our sample showed 82.4 wt.\% X-ray-amorphous phases, 11.7 wt. \% andesine, $3.1 \mathrm{wt} \%$ augite and 2.8 wt. \% olivine. No crystalline carbonates were detected by the XRD method. We suggest that the main source of $\mathrm{CO}_{2}$ in our L-glasses is oxidation of organic and inorganic $\mathrm{C}$ in the silicate melt.

\section{[Figure 12]}

Interestingly, the $\mathrm{CO}_{2}$ feature is more intense in the spectra of the finest fractions of $\mathrm{L} 2$ and L4 glasses and has an appearance of the spectral signature typical of condensed $\mathrm{CO}_{2}$. In spectra of condensed $\mathrm{CO}_{2}$, the narrow band shape requires that $\mathrm{CO}_{2}$ must be in a form which does not allow molecular rotations (e.g., McCord et al., 1998). Similar narrow features consistent with trapped $\mathrm{CO}_{2}$ molecules are observed in spectra of some minerals, where the $\mathrm{CO}_{2}$ molecules may 
be under pressure (in inclusions) and/or electrically interact with neighbor molecules (McCord et al., 1998 and references therein). In our case, the band might be due to $\mathrm{CO}_{2}$ molecules trapped (under pressure?) in the tiniest vesicles in the glass. It is unlikely that the $4.27-\mu \mathrm{m}$ band is due to $\mathrm{CO}_{2}$ homogeneously dissolved in the glass at molecular scale (Mysen, 1976; Fine and Stolper, 1985), since $\mathrm{CO}_{2}$ dissolved in basalt melts produces absorptions near 6.2-7.3 $\mu \mathrm{m}$, caused by vibrations of anionic $\mathrm{CO}_{3}{ }^{2-}$ groups without IR signatures of molecular $\mathrm{CO}_{2}$ (Fine and Stolper, 1986; Mattey, 1991). The spectra of the coarser L-fractions containing large vesicles along with the tiny ones, and thus show more complex broad features typical of "normal" gaseous $\mathrm{CO}_{2}$ (Goody and Yung, 1989) which is probably trapped in relatively large vesicles (Fig. 2a, 3c).

A similar $4.27-\mu \mathrm{m}$ absorption feature is present in reflectance spectra of Martian meteorite ALH 84001 and has been attributed to either OH-bearing phosphates or trapped $\mathrm{CO}_{2}$ molecules (Bishop et al., 1998). However, spectra of synthetic (Rehman and Bonfield, 1997) and many natural $\mathrm{OH}$-bearing phosphates lack this band, so it is likely that the $4.27-\mu \mathrm{m}$ band in spectra of ALH 84001 and other minerals, including phosphates, is due to trapped $\mathrm{CO}_{2}$ molecules. Carbonates are abundant in that meteorite, but show absorption bands at shorter wavelengths. The $\mathrm{S}$ and $\mathrm{F}$ basaltic glasses lack the vesicles and the $\mathrm{CO}_{2}$-band because of slow cooling of the melts compared to the L-melts.

In spectra of the Martian surface this feature, if present, would be masked by strong atmospheric $\mathrm{CO}_{2}$ absorption. However, our finding may have other interesting implications. A narrow $\mathrm{CO}_{2}$ feature at $4.25 \mu \mathrm{m}$ was found in NIMS spectra of Callisto and Ganymede (McCord et al., 1998). Basilevsky et al. (2000b) suggested that this feature in the spectra of Galilean satellites may be caused by vibrations of $\mathrm{CO}_{2}$ molecules trapped in small bubbles in silicate glass formed by high-velocity micrometeorite impacts. Furthermore, Basilevsky et al. (2000b) suggested that similar features might be found in IR spectra of low-albedo asteroids as well, since their surfaces undergo micrometeorite bombardment and contain carbonaceous phases which may be a source of carbon for $\mathrm{CO}_{2}$ formation. However, the $4.27 \mu \mathrm{m}$ feature has not been found in the spectra of an artificial carbonaceous chondrite (Hiroi et al., 2003) and CM2 
chondrite Mighei (Moroz et al., 2004) irradiated with the same pulsed laser as was used in this study. We suggest that this is due to ultramafic compositions of the latter materials. Ultramafic melts can release trapped/dissolved gases more easily than viscous basaltic melts.

\section{Implications for Mars and conclusions}

The mineralogical composition of the Martian crust is very complex and missions to Mars significantly enriched our knowledge of Mars' surface mineralogy (Bibring and Erard, 2001; Bibring et al., 2006; Chevrier and Mathé, 2007). A wide variety of minerals has recently been detected on Mars' surface (e.g., Chevrier and Mathé, 2007 and references therein; Mustard et al. 2008). Globally, however, most optical spectra of the Martian surface are roughly consistent with the mixing of bright red ferric oxide-bearing dust with dark gray sand containing mafic minerals (Singer and McCord, 1979; Murchie et al., 2000; Poulet et al. 2007).

The bright regions on Mars are relatively homogeneous in the VNIR spectral range due to the high mobility of fine bright dust particles during dust storms, but show some spatial spectral variations (Murchie et al., 1993, 2000). Although impact glass fragments should contribute to these mobile fines (Schultz and Mustard 2004), their spectral signatures do not seem to be easily detectable in spectra of the soils. Nevertheless, some influence cannot be ruled out. For example, non-altered impact melt fragments may mask the weak metal-OH feature near $2.2 \mu \mathrm{m}$ observed in many spectra of bright areas (e.g., Murchie et al., 1993, Beinroth and Arnold, 1996) and may contribute to the decrease in depth of the bound water band at $3 \mu \mathrm{m}$, which also shows significant spatial variations (Bibring et al., 1989, 2005; Murchie et al., 1993; Calvin, 1997; Jouglet et al., 2007; Milliken et al., 2007). Recent analysis showed that a broad weak absorption band centered near $1.8 \mu \mathrm{m}$ is present in most OMEGA spectra of bright regions (Le Mouélic et al., 2006; Combe et al. 2008). This feature may be due to minor low-Ca pyroxene component (Le Mouélic et al., 2006; Combe et al. 2008). Alternatively, this feature can be caused by $\mathrm{Fe}^{2+}$ absorption in impact or volcanic glasses. 
Dark regions on Mars show considerable spectral variability compared to the bright areas (e.g., Pinet and Chevrel 1990; Bibring et al., 2005; Mustard et al., 2005; Poulet et al. 2007). Many NIR spectra of the dark areas show two broad $\mathrm{Fe}^{2+}$ absorptions near 0.9-0.95 and 2.1-2.2 $\mu \mathrm{m}$ which are consistent with low-Ca and high-Ca pyroxenes present in various proportions (e.g., Mustard and Sunshine, 1995; Bibring et al., 2005; Mustard et al., 2005). Although broad $\mathrm{Fe}^{2+}$ absorptions are present in NIR spectra of Fe-bearing glasses as well, their wavelength positions are somewhat different (1.05-1.1 $\mu \mathrm{m}$ and $\sim 1.9 \mu \mathrm{m})$. In addition, spectra of the dark areas on Mars are characterized by distinctive negative near-infrared continuum, while the spectra of fresh glasses tend to be red-sloped in this spectral range.

At first glance it seems that impact glasses do not show significant contribution to VNIR spectral properties of the Martian surface. However, this does not mean that they are not present, even in significant quantities. $\mathrm{Fe}^{2+}$ absorptions in glass spectra are much weaker than those in spectra of mafic minerals and thus can easily be masked in the spectra of mixtures of impact glass with mafic minerals. Although the positions of the $\mathrm{Fe}^{2+}$ absorptions in NIR spectra of glasses are different from those of individual mafic minerals, Fe-rich glasses can spectrally be confused with Fe-rich or coarse-grained olivines mixed with minor low-Ca pyroxenes. This has recently been confirmed by Nicholis et al. (2006) who studied glasses produced from olivine-rich basalt at relevant oxygen fugacity and compared their VNIR spectra to OMEGA spectra of certain dark areas on Mars interpreted as enriched in fayalitic olivine compared to surrounding terrains (Mustard et al., 2005). Nicholis et al. (2006) showed that it is difficult to distinguish between fayalitic or coarse-grained olivines, Fe-rich glass of impact or volcanic origin, and Ferich glass with minor olivine crystals. Recently MEX OMEGA spectra acquired near Isidis basin on Mars have been interpreted by Mustard et al. (2007) as areas of preserved olivine-rich impact melt.

Reddish NIR spectral slopes indicative of fresh $\mathrm{Fe}^{3+}$-bearing glasses are not typical of Mars reflectance spectra. However, oxide/dust coatings (Morris and Neely, 1981; Singer and Roush 1983; Fisher and Pieters, 1993; Johnson and Grundy, 2001, Minitti et al. 2002, 2007b; Ehlmann 
et al. 2008) on the surface of dark glass and influence of atmospheric aerosols (Erard et al., 1994) may change positive NIR continuum slopes of Mars' glass spectra to neutral or negative slopes.

In the TIR spectral region the glasses from this study also do not seem to show distinctive characteristics. Glasses produced from Martian soil may have TIR spectra typical of basalt glasses and should show weaker TIR spectral features than more $\mathrm{SiO}_{2}$-rich glasses such as obsidian. Moreover, the glasses produced by laser shots (L-glasses), which we consider as a reasonably good simulation of small-scale meteorite impacts, exhibit subdued TIR spectral features because of their vesicular textures. Spectra of impact melt samples from Argentina also show low spectral contrasts in the TIR spectral range (Thomson, 2006). Thus, vesicular texture typical of impact glasses should further reduce their detectability in the TIR. In addition, it is difficult to distinguish between basaltic glasses of impact and volcanic origin, as well as between basaltic and plagioclase glasses, based on their TIR spectra. Furthermore, our results indicate that the absence of $12.1-\mu \mathrm{m}$ transparency feature in TIR spectra may help in the detection of glass accumulations at certain areas on Mars (Johnson et al., 2002), but only if these glass-rich deposits are free of fine dust. In addition, the presence of a well-pronounced 12.1- $\mu \mathrm{m}$ transparency feature in the spectra of Mars bright dust does not require high contents of feldspars or zeolites in the dust, suggested by Ruff and Christensen (2002), Bandfield and Smith (2003), and Ruff (2004).

Two principle spectral types of dark areas on Mars have been identified from the MGS TES data (Bandfield et al., 2000). The Surface Type 1 (ST1 or Syrtis Type) is consistent with a basaltic composition, while the deconvolution of the Surface Type 2 TES spectra (ST2 or Acidalia Type) requires a significant $\mathrm{SiO}_{2}$-rich glass component. The MGS TES team assumed that the latter glass component was a primary volcanic glass consistent with basaltic andesites (Bandfield et al., 2000). Many attempts have been made to derive alternative composition for the enigmatic ST2 spectral endmember (Wyatt and McSween, 2002; Minitti et al., 2002, 2007b; Kraft et al., 2003; Morris et al., 2003; Michalski et al., 2005, 2006). The composition of ST2 areas still remains a subject of considerable debate (Wyatt, 2007), but chemically altered basalts 
seem to be the most favored explanation. It has been shown by several researchers that $\mathrm{SiO}_{2}$-rich component is still required for the successful deconvolution of the ST2 spectra but may be just a secondary product (e.g., silica-rich amorphous coatings), rather than a primary volcanic glass (Kraft et al., 2003; Morris et al., 2003; Michalski et al., 2005, 2006; Minitti et al., 2007b; Ruff and Christensen, 2007). The recent orbital detection of opaline silica by CRISM (Milliken et al. 2008) and the recent discovery of opal in Gusev crater by the Spirit rover (Squires et al. 2008) show that amorphous silica indeed is not an uncommon weathering product on Mars. Our results do not contribute to the debate regarding the ST2 vs. ST1 compositions, since the TIR spectra of our glasses are consistent with $\mathrm{SiO}_{2}$-poor basalt glasses. Note, however, that our glasses are not "true" impact glasses. Schultz and Mustard (2004) suggested that ST2 areas may be enriched in impact glass, and the recent works of Wright et al. (2004), Thomson (2006), and Wrobel and Schultz (2007) support this alternative point of view. In particular, Wright et al. (2004) and Thomson (2006) showed that TIR spectra of natural impact glasses have V-shapes in the Reststrahlen range, typical of the $\mathrm{ST} 2$ spectra and $\mathrm{SiO}_{2}$-rich glasses. Due to the high fictive temperatures (Fujita et al. 2003) of natural impact glasses, their Reststrahlen bands (emission minima) may shift to shorter wavelengths, suggesting much higher "spectral" Si/O ratio than follows from real chemical compositions of the glasses (Thomson 2006). This way, relatively $\mathrm{SiO}_{2}$-poor impact glasses could be misinterpreted as $\mathrm{SiO}_{2}$-rich glass component in TES spectra of ST2 terrains. Indeed, Wright et al. (2004) have demonstrated that thermal emission spectra of impact glasses from the Lonar impact crater in India strongly resemble those of ST2 terrains, while the target rock (Deccan basalt) is a well-known spectral analogue for the ST1 dark materials (Bandfield et al. 2000; Hagerty and Newsome 2003). Despite recent efforts to collect spectral library of various glass endmembers for deconvolution of TES spectra of Mars (Noble and Pieters, 2001; Minitti et al., 2002, 2006, 2007a; Johnson et al., 2002; Wright et al. 2004, 2006; Byrnes et al., 2005), the list of potentially useful glassy materials is still incomplete.

Spectral variability of the Mars surface is known to increase with increasing spatial resolution of observations. Therefore, even though impact glasses are not easily detectable on the Martian 
surface at global scale by infrared observations, they might be detected in the future at certain locations where such glasses can be found in concentrated form. Schultz and Mustard (2004) discuss the distribution and most probable locations of impact glass on Mars in great detail. It should be noted that impact glasses on Mars may show significant spectral diversity, since dispersed impact products may range from vitreous impact glasses (high-silica distal glasses and low-silica proximal glasses) to crystallized melts (Schultz and Mustard 2004, Wrobel and Schultz 2007). Impact glasses may occur on Mars as: tektite-like strewnfields downrange from young oblique impacts, dark avalanches emerging from backwasting cliffs of easily eroded uncomformable deposits, global dispersal of glassy ejecta from large Hesperian and Amazonian craters, and dark mobile veneers emerging from Noachian craters (Schultz and Mustard 2004). Schultz and Mustard (2004) emphasize that many dark plains and mobile materials in certain regions (e.g., Acidalia Planitia) do not show expected absorption features of mafic minerals in their NIR spectra (Bell et al. 1997; Mustard et al., 2005) and could represent glass accumulations or lag deposits. Interpretation of MGS TES data is also consistent with high abundance of glasses in Acidalia (Bandfield et al. 2000), and the cratered highlands provide many traps (e.g., within craters) where dark impact glasses can accumulate (Schultz and Mustard 2004; Wrobel and Schultz 2007). Dark deposits trapped within craters are usually interpreted as basaltic sands (Bandfield et al. 2000; Wyatt et al. 2003; Jaumann et al. 2006; Tirsch et al. 2007; 2008), but may in fact represent accumulations of impact glass. Indeed, VNIR optical properties of mafic rocks containing olivine mixed with low-Ca pyroxene can easily be confused with those of Fe-bearing glasses. OMEGA spectra of many dark intra-crater dunes on Mars show weak broad NIR spectral features near $1 \mu \mathrm{m}$ and $1.9 \mu \mathrm{m}$, consistent with olivine-pyroxene sand mixtures (Tirsch, 2008; Tirsch and Jaumann, 2008). Alternatively, these dark dunes may be composed of mafic glasses (either impact or volcanic). In the TIR spectral range impact glasses also do not show distinct spectral signatures which could prove their impact origin.

Schultz and Mustard (2004) suggest that rocks at the Mars Pathfinder landing site may be pieces of impact melt. Some cobbles observed by Opportunity MER on Meridiani Planum may 
be locally derived impact melts (Jolliff et al. 2006; Herkenhoff et al. 2008). Basilevsky et al. (2000a) proposed that dark sand-sized particles of impact glass may be a source of aeolean deposits described in the south polar region of Mars (Herkenhoff and Murray, 1990). Wrobel and Schultz (2004) demonstrated that due to the effects of planetary rotation (Coriolis force) large impact craters $(220 \mathrm{~km}$ in diameter and larger) could supply a considerable amount of impact melt and glass to the opposite pole. This supports the hypothesis of Basilevsky et al. (2000a) regarding possible impact origin of circumpolar dark deposits. Spectral properties of glasses produced from JSC Mars-1 are consistent with hypotheses of Basilevsky et al. (2000a) and Schultz and Mustard (2004).

Despite challenges discussed above, it is possible that spectrometers with sufficient wavelength coverage and spatial resolution, such as OMEGA on MEX (0.35-5.1 $\mu \mathrm{m}$; spatial resolution up to $260 \mathrm{~m} \mathrm{pixel}^{-1}$; Bibring et al., 2005) and CRISM on MRO (0.362-3.92 $\mu \mathrm{m}$; spatial resolution up to 12-20 $\mathrm{m} \mathrm{pixel}^{-1}$; Murchie et al., 2007), will be able to detect impact glass deposits on Mars surface. For example, NIR spectral signatures consistent with hydrated volcanic or impact glass have recently been detected by the CRISM instrument (Swayze et al., 2007; Milliken et al. 2008). Mars Exploration Rovers (MER) Spirit and Opportunity (Squyres et al., 2003) are equipped with Mini-TES instruments (Christensen et al., 2003). Although impact glasses do not show unique spectral signatures in the TIR range, high contents of glass required for spectral deconvolution may be consistent with vitreous impact melts. This could be the case for the Watchtower and Clovis classes of rocks (35-50\% glass) at West Spur, Gusev crater (Ruff et al., 2006). Mini-TES spectra and some other characteristics of Voltaire complex (in particular, Descartes class outcrops) at Husband Hill, Gusev crater, are consistent with high content of oxidized, glassy impact breccias or melts (Arvidson et al. 2008; Ming et al., 2008; Yingst et al. 2008) . Van Cromphaut et al. (2007) suggest that MER Mössbauer spectra of Clovis class rocks are consistent with the presence of $\mathrm{Fe}^{3+}$-bearing glass, while Morris et al. (2008) and Arvidson et al. (2008) believe that highly-altered Clovis, Watchtower, and Descartes rocks contain only Fefree glasses, undetectable by Mössbauer spectroscopy. A Barnhill outcrop containing $\sim 45 \%$ 
basaltic glass likely of volcanic origin have been investigated by the Spirit MER at Home Plate. (Schmidt et al., 2008). Farrand et al. (2008) recently reported that Pancam VNIR spectra of Watchtower and Clovis rocks resemble laboratory spectra of red (oxidized) terrestrial impact melts from Manicouagan crater (Morris et al., 1995), whereas Descartes class rocks are spectrally similar to gray (fresher) impact melts from the same crater.

All these recent findings show that glassy materials deserve more attention from researchers involved in spectroscopic studies of Mars' surface, and that spectra of different glass endmembers, including natural and simulated impact glasses, should be included in spectral libraries.

Acknowledgments: We thank Janice Bishop, Carlton Allen, and Sho Sasaki for their constructive reviews. In particular, Janice Bishop provided us with many helpful comments and suggestions, which significantly improved quality of the paper. XRD and gasometric analyses of JSC Mars-1 samples have been performed at Fedorovsky All-Russian Research Institute for Mineral Resources (VIMS) Moscow, Russia (special thanks to N.I. Guseva). LVM and SSR are supported by the DLR MERTIS project funds.

\section{References:}

Aines, R.D., Rossman, G.R., 1984. Water in minerals? A peak in the infrared. J. Geophyis. Res. $89,4059-4071$.

Allen, C.C.,. Jager, K.M, Morris, R.V., Lindstrom, D.J., Lindstrom, M.M.,Lockwood, J.P., 1998. Martian soil simulant available for scientific, educational study. EOS Transactions, AGU, 79, 405-409.

Allen, C.C., Keil, K., Gooding, J.L., 1982. Hydrothermally altered impact melt rock and breccia Contributions to the soil of Mars. J. Geophys. Res. 87, 10083-10101.

Aronson, J.R., Emslie, A.G., McLinden, H.G., 1966. Infrared spectra from particulate surfaces. Science 152, 345-346. 
Arvidson, R.E., Ruff, S.W., Morris, R.V., Ming, D.W., Crumpler, L.S., Yen, A.S., Squyres, S.W., Sullivan, R.J., Bell, J.F., Cabrol, N.A., and 23 coauthors, 2008. Spirit Mars Rover Mission to the Columbia Hills, Gusev Crater: Mission overview and selected results from the Cumberland Ridge to Home Plate. J. Geophyis. Res. 113 (E12), CiteID E12S33.

Bancroft, G.M, Sham, T.K., Riddle, C., Smith, T.E., Turek, A., 1977. Ferric/ferrous-iron ratios in bulk rock samples by Mössbauer spectroscopy — the determination of standard rock samples G2, GA, WI and mica Fe. Chem. Geol. 19, 277-284.

Bandfield, J.L., Hamilton, V.E., Christensen, P.R., 2000. A global view of Martian surface compositions from MGS-TES, Science 287, 1626-1630.

Bandfield, J.L., Smith, M.D., 2003. Multiple emission angle surface-atmosphere separations of thermal emission spectrometer data. Icarus 161, 47-65.

Basilevsky, A.T., Yakovlev, O.I., Fisenko, A.V., Semjonova, L.F., Semenova, A.S., Barsukova, L.D., Roshchina, I.A., Galuzinskaya, A.Kh., Stroganov, I.A., Moroz, L.V., Pieters, C.M., Hiroi, T., Zinovieva, N.G., 2000a. Simulation of impact melting effect on spectral properties of Martian surface: Implications for polar deposits. Geochemistry International 38, Suppl. 3, S390-S403.

Basilevsky, A.T., Yakovlev, O.I., Fisenko, A.V., Semjonova, L.F., Semenova, A.S., Barsukova, L.D., Roshchina, I.A., Galuzinskaya, A.Kh., Stroganov, I.A., Moroz, L.V., Pieters, C.M., Hiroi, T., Zinovieva, N.G., 2000b. Simulation of impact melting effect on optical properties of Martian regolith. Lunar Planet. Sci. XXXI. Abstract 1214.

Beinroth, A., Arnold, G., 1996. Analysis of weak surface absorption bands in the near-infrared spectra of Mars obtained by Phobos 2. Vibr. Spectrosc. 11, 115-121.

Bell, J.F., III, McCord, T.B., Owensby, P.D., 1990. Observational evidence of crystalline iron oxides on Mars. J. Geophys. Res. 95, 14447-14461. Bell, J.F., III, 1996. Iron, sulfate, carbonate, and hydrated minerals on Mars. In: Dyar, M.D., McCammon, C., Schaefer, M.W. (Eds.), Mineral Spectroscopy: A Tribute to Roger G. Burns, Geochem. Soc. Spec. Pub. 5, pp. 359-380. 
Bell, J.F., III, Wolff, M.J., James, P.B., Clancy, R.T., Lee, S.W., Martin, L.J., 1997. Mars surface mineralogy from Hubble Space Telescope imaging during 1994-1995: Observations, calibration, and initial results. J. Geophys. Res. 102, 9109-9123.

Bell, J.F., McSween, H.Y., Crisp, J.A., Morris, R.V., Murchie, S.L., Bridges, N.T., Johnson, J.R., Britt, D.T., Golombek, M.P., Moore, H.J., and 14 coauthors, 2000. Mineralogic and compositional properties of Martian soil and dust: Results from Mars Pathfinder. J. Geophys. Res.105 (E1), 1721-1756.

Bell, P.M., Mao, H.K., Weeks, R.A., 1977. Optical spectra and electron paramagnetic resonance of lunar and synthetic glasses - A study of the effects of controlled atmosphere, composition, and temperature. Proc. Lunar Planet Sci. Conf. $7^{\text {th }}, 2543-2559$.

Bibring, J.-P., Langevin, Y., Soufflot, A., Combes, M., Cara, C., 1989. Results from the ISM experiment. Nature 341, 591-593.

Bibring, J.-P., Erard, S., 2001. The Martian surface composition. Space Sci. Rev. 96, 293-316.

Bibring, J.-P., Langevin, Y., Gendrin, A., Gondet, B., Poulet, F., Berthé, M., Soufflot, A., Arvidson, R., Mangold, N., Mustard, J., Drossart, P., and the OMEGA Team, 2005. Mars surface diversity as revealed by the OMEGA/Mars Express observations. Science 307, 1576-1581.

Bibring, J.-P., Squyres, S.W., Arvidson, R.E., 2006. Merging views on Mars. Science 313, 18991901.

Bishop J.L., Pieters, C.M., Edwards, J.O., 1994. Infrared spectroscopic analyses on the nature of water in montmorillonite. Clays and Clay Minerals 42, 706-716.

Bishop, J.L., Pieters, C.M., Hiroi, T., Mustard, J.F., 1998. Spectroscopic analysis of Martian meteorite ALH 84001 powder and applications for spectral identification of minerals and other soil components on Mars. Meteoritics. \& Planet. Sci. 33, 699-707.

Bishop, J.L., Lougear, A., Newton, J., Doran, P.T., Froeschl, H., Trautwein, A.X., Korner, W., Koeberl, C., 2001. Mineralogical and geochemical analyses of Antarctic lake sediments: a 
study of reflectance and Mössbauer spectroscopy and C, N, and S isotopes with applications for remote sensing on Mars. Geochim. Cosmochim. Acta. 65, 2875-2897.

Bishop, J.L., Schiffman, P., Southard, R., 2002a. Geochemical and mineralogical analyses of palagonitic tuffs and altered rinds of pillow basalts in Iceland and applications to Mars. In: Smellie, J.L., Chapman, M.G. (Eds.) Volcano-Ice Interactions on Earth and Mars. Special Publications of Geological Society of London, Special Publication 202., pp. 371-392.

Bishop, J.L., Pieters, C.M., Dyar, M.D., Hamilton, V.E., Harloff, J., 2002b. A spectral, chemical and mineralogical study of Mars analogue rocks. Lunar Planet. Sci. XXXIII. Abstract 1168.

Bishop, J.L., Schiffman, P., Southard, R., Drief, A., Verosub, K.L., 2003a. Constraints on Martian surface material from a study of volcanic alteration in Iceland and Hawaii. 6th Intern. Conf. on Mars, July 20-25, 2003, Pasadena, CA. Abstract 3009.

Bishop, J.L., Schiffman, P., Murad, E., Dyar, M.D., Drief, A., Lane, M.D., 2007. Characterization of alteration products in tephra from Haleakala, Maui: A visible-infrared spectroscopy, Mössbauer spectroscopy, XRD, EMPA and TEM study. Clays and Clay Minerals 55, 1-17.

Bishop, J.L., Dobrea, E.Z.N., McKeown, N.K.; Parente, M., Ehlmann, B.L., Michalski, J.R., Milliken, R.E., Poulet, F., Swayze, G.A., Mustard, J.F., and 2 coauthors, 2008. Diversity and Past Aqueous Activity Revealed at Mawrth Vallis, Mars. Science 321, 830-833.

Bouška, V., 1993. Natural Glasses. Ellis Horwood, New York. 354 p.

Bouška, V., Bell III, J.F., 1993. Assumptions about the presence of natural glasses on Mars. J. Geophys. Res. 98, 18,719-18,725.

Burns, R.G., 1970. Mineralogical applications to Crystal Field Theory. Cambridge Univ. Press, New York.

Byrnes, J.M.., King, P.L., Ramsey, M.S., Lee, R.J., 2005. Synthesis and analysis of silicate glasses: Applications to remote sensing of volcanic surface units on Earth and Mars Lunar Planet. Sci. XXXVI. Abstract 2089. 
Calas, G., Petiau, J., 1983. Structure of oxide glasses: Spectroscopic studies of local order and crystallochemistry. Geochemical implications. Bulletin de Minéralogie 106, 33-55.

Calvin, W.M., 1997. Variation of the 3- $\mu \mathrm{m}$ absorption feature on Mars: Observations over eastern Valles Marineris by the Mariner 6 infrared spectrometer. J. Geophys. Res. 102, 9097-9107.

Carpenter, P., Sebille, L., Boles, W., Chadwell, M., Schwarz, L., 2003. JSC Mars-1 Martian soil simulant: Melting experiments and electron microprobe studies. Microscopy and Microanalysis 9, 30-31 (Abstract).

Chevrier, V., Mathé, P.E., 2007. Mineralogy and evolution of the surface of Mars: A review. Planet. Space Sci. 55, 289-314.

Christensen, P.R., $\quad$ Mehall, G.L., $\quad$ Silverman, S.H., $\quad$ Anwar, S., Cannon, G., Gorelick, N., Kheen, R., Tourville, T., Bates, D., Ferry, S., and 10 coauthors, 2003. Miniature Thermal Emission Spectrometer for the Mars Exploration Rovers. J. Geophys. Res. 108, E12, pp. ROV 5-1, CiteID 8064, DOI 10.1029/2003JE002117.

Clark, B.C., Baird, A.K., Weldon, R.J., Tsusaki, D.M., Schnabel, L., Candelaria, M.P., 1982. Chemical composition of Martian fines. J. Geophys. Res. 87, 10059-10067.

Clark, R.N., King, T.V.V., Klejwa, M., Swayze, G.A., 1990. High spectral resolution reflectance spectroscopy of minerals. J. Geophys. Res. 95, 12,653-12,680.

Clifford, S.M., 1993. A model for the hydrologic and climatic behavior of water on Mars. J. Geophys. Res. 98, 10,973-11,016.

Combe, J.-Ph., Le Mouélic, S., Sotin, C., Gendrin, A., Mustard, J.F., Le Deit, L., Launeau, P., Bibring, J.-P., Gondet, B., langevin,Y., Pinet, P., and the OMEGA Science team, 2008. Analysis of OMEGA/Mars Express data hyperspectral data using a Multiple-Endmember Linear Spectral Unmixing Model (MELSUM): Methodology and first results. Planet. Space. Sci. 56, 951-975.

Cooper, B.L., Salisbury, J.W., Killen, R.M., Potter, A.E., 2002. Midinfrared spectral features of rocks and their powders. J. Geophys. Res. 107, 1-19. 
Conel, J.E., 1969. Infrared emissivities of silicates: Experimental results and a cloudy atmosphere model of spectral emission from condensed particulate mediums. J. Geophys. Res. 74, 1614-1634.

Coey, J.M.D., 1974. Amorphous solids: a review of the applications of the Mössbauer effect. J. Physique 35, C6-89-C6-105.

Cooper, C.D., Mustard, J.F., 2002. Spectroscopy of loose and cemented sulfate-bearing soils: Implications for duricrust on Mars. Icarus 158, 42-55.

Crisp, J., Kahle, A.B., Abbott, E.A., 1990. Thermal infrared spectral character of Hawaiian basaltic glasses. J. Geophys. Res. 95, 21657-21669.

Dyar, M.D., Birnie, D.P., 1984. The effects of quench media on iron partitioning and ordering in a lunar glass. J. Non-Cryst. Solids 67, 397-412.

Dyar, M.D., 1985. A review of Mössbauer data on inorganic glasses: the effects of composition on iron valency and coordination. Amer. Miner. 70, 304-316.

Dyar, M.D., 1987. A review of Mössbauer data on trioctahedral micas: Evidence for tetrahedral $\mathrm{Fe}^{3+}$ and cation ordering. Amer. Miner. 72, 102-112.

Dyar, M.D., Naney, M.T., Swanson, S.E., 1987. Effects of quench methods on $\mathrm{Fe}^{3+} / \mathrm{Fe}^{2+}$ ratios: A Mössbauer and wet-chemical study. Amer. Miner. 72, 792-800.

Dyar, M.D., Agresti, D.G., Schaefer, M.W., Grant, C.A., Sklute, E.C., 2006. Mössbauer spectroscopy of Earth and planetary materials. Ann. Rev. Earth. Planet. 34, 83-125.

Ehlmann, B.L., Mustard, J.F., Kumar, P.S., 2008. Infrared spectra of impact products from Lonar crater: the effects of weathering and implications for Mars. Lunar Planet. Sci. XXXIX, Abstract 2437.

Eisenberg, D., Kauzmann, W. 1969. The structure and properties of water. New York: Oxford Univ. Press, 296 p.

Erard, S., Mustard, J., Murchie, S., Bibring, J.-P., Cerroni, P., Coradini, A. 1994. Martian aerosols: Near-infrared spectral properties and effects on the observation of the surface. Icarus $111,317-337$. 
Esposito, F., Colangeli, L., Palomba, E., 2000. Infrared reflectance spectroscopy of Martian analogues. J. Geophys. Res. 105 (E7), 17643-17654.

Farmer ,V.C., ed. 1974. The infrared spectra of minerals. London: Mineralogical Society, 539 p. Farrand, W.H., Bell III, J.F., Johnson, J.F., Arvidson, R.E., Crumpler, L.S., Hurowitz, J.A, Schröder, C., 2008. Rock spectral classes observed by the Spirit rover's Pancam on the Gusev Crater Plains and in the Columbia Hills. J. Geophys. Res. (in press).

Fine, S., Stolper, E., 1985. The speciation of carbon dioxide in sodium aluminosilicate glasses. Contrib. Mineral. Petrol. 91, 105-121.

Fine, S., Stolper, E., 1986. Dissolved carbon dioxide in basaltic glasses: Concentrations and speciation. Earth Planet. Sci. Lett. 76, 263-278.

Fischer, E.M., Pieters, C.M., 1993. The continuum slope of Mars - bidirectional reflectance investigations and applications to Olympus Mons. Icarus 102, 185-202.

Fujita, S., Sakamoto, A., Tomozawa, M., 2003. Fictive temperature measurement of aluminosilicate glasses using IR spectroscopy. J. Non-Cryst. Solids 330, 252-258.

Gellert, R., Rieder, R., Anderson, R.C., Brückner, J., Clark, B.C., Dreibus, G., Economou, T., Klingelhöfer, G., Lugmair, G.W., Ming, D.W., and 5 coauthors, 2004. Chemistry of rocks and soils in Gusev crater from the Alpha Particle X-ray Spectrometer. Science 305, 829-833.

Gellert, R., Rieder, R., Brückner, J., Clark, B.C., Dreibus, G., Klingelhöfer, G., Lugmair, G., Ming, D.W., Wänke, H., Yen, A., and 2 coauthors. 2006. Alpha Particle X-Ray Spectrometer (APXS): Results from Gusev crater and calibration report. J. Geophys. Res. 111 (E2), CiteID E02S05.

Georgiev, G., Butler, J.E., 2005. Bidirectional reflectance distribution function and directionalhemispherical reflectance of a martian regolith simulant. Optical Engineering 44, 165-175.

Gibb, T.C., Greatrex, R., Greenwood, N.N., 1977. An assessment of results obtained from Mössbauer spectra of lunar samples. Phil. Transact.Royal Soc. London. Ser. A, Mathematical and Physical Sciences 285, 235-240. 
Goetz, W., Hecht, M.H., Marshall, J., Morookian, J.M., Parrat, D., Pike, W.T., Staufer, U.,

Vijendran, S., Sykulska, H.M. Madsen, M.B. and 3 coauthors, 2008. Microscopic views of the soils at the Phoenix landing site. Paneth Colloquium 2008, October 29-31, 2008,

Nördlingen, Germany, Abstract PC2008 \#019, p.6.

Goody, R.M. Yung, Y.L., 1989. Vibration-Rotation Spectra of Gaseous Molecules. In: Atmospheric Radiation, $2^{\text {nd }}$ ed., Oxford Univ. Press, New York, pp. 67-124.

Grant, J.A., Arvidson, R., Bell, J.F., Cabrol, N.A., Carr, M.H., Christensen, P., Crumpler, L., Des Marais, D.J., Ehlmann, B.L., Farmer, J., and 14 coauthors, 2004. Surficial deposits at Gusev crater along Spirit rover traverses. Science 305, 807-810.

Hafner, S.S., Janik, B., Virgo, D., 1970. Mössbauer Effect Methodology 6, Gruverman, I.J. (Ed.), Plenum, New York, 193 p.

Hagerty, J.J., Newsom, H.E., 2003. Hydrothermal alteration at the Lonar Lake impact structure, India: Implications for impact cratering on Mars. Meteoritics \& Planet. Sci. 38, 365-381.

Hamilton, V.E, Minitti, M., (2003) Are oxidized shergottite-like basalts an alternative to "andesite" on Mars? Geophys. Res. Lett. 30, PLA 1-1, CiteID 1915, DOI 10.1029/2003GL017839.

Hapke, B., 1996. A model of radiative and conductive energy transfer in planetary regoliths. J. Geophys. Res. 101, 16817-16832.

Hapke, B., 2001. Space weathering from Mercury to the asteroid belt J. Geophys. Res. 106 (E5), 10039-10074.

Helgason, Ö., Steinthorsson, S., Mørup, S., 1989. The ferric/ferrous ratio in basalt melt at different oxygen pressures. Hyperfine Interact. 45, 287-294.

Helgason, Ö., Steinthorsson, S., Mørup, S., 1992. Rates of redox reactions in basaltic melts determined by Mössbauer spectroscopy. Hyperfine Interact. 70, 985-988.

Heller-Kallai, L., Rozenson, I., 1981. The use of mössbauer spectroscopy of iron in clay mineralogy. Phys. Chem. Minerals 7, 223-238.

Herkenhoff, K.E., Murray, B.C., 1990. Color and albedo of the south polar deposits on Mars. J. 
Geophys. Res. 95, 1343-1358.

Herkenhoff, K.E., $\quad$ Grotzinger, J., ～Knoll, A.H., $\quad$ McLennan, S.M., $\quad$ Weitz, C., $\quad$ Yingst, A., Anderson, R., Archinal, B.A., Arvidson, R.E., Barrett, J.M., and 34 coauthors, 2008. Surface processes recorded by rocks and soils on Meridiani Planum, Mars: Microscopic Imager observations during Opportunity's first three extended missions. J. Geophys. Res. 113 (E12), CiteID E12S32.

Hiroi, T., Moroz, L.V., Shingareva, T.V., Basilevsky, A.T., Pieters C.M., 2003. Effects of microsecond pulse laser irradiation on Vis-NIR reflectance spectrum of carbonaceous chondrite simulant: Implications for Martian moons and primitive asteroids. Lunar Planet. Sci. XXXIV. Abstract 1324.

Housley, R.M., Grant, R.W., Muir, A.H., Jr., Blander, M., Abdel-Gawad, M., 1971. Mössbauer studies of Apollo 12 samples. Proc. Lunar Sci. Conf. 2, 2125-2136.

Jaumann, R., $\quad$ Stephan, K., $\quad$ Poulet, F., $\quad$ Tirsch, D., $\quad$ Wagner, R., Hoffmann, H., Reiss, D., Hauber, E., Bibring, J.-P., Neukum, G., HRSC Co-Investigator Team, 2006. Dark materials in Martian craters. Lunar Planet. Sci. XXXVII. Abstract 1735.

Johnson, J.R., Grundy, W.M, 2001. Visible/near-infrared spectra and two-layer modeling of palagonite-coated basalts. Geophys. Res. Lett. 28, 2101-2104.

Johnson, J.R., Hörz, F. Lucey, P.G., Christensen, P.R., 2002. Thermal infrared spectroscopy of experimentally shocked anorthosite and pyroxenite: Implications for remote sensing of Mars. J. Geophys. Res. 107 (E10), pp. 3-1, CiteID 5073, DOI 10.1029/2001JE001517.

Johnson, J.R., Hörz, F., Staid, M.I., 2003. Thermal infrared spectroscopy and modeling of experimentally shocked plagioclase feldspars. Amer. Mineral. 88, 1575-1582.

Johnson, J.R., Hörz, F., 2003. Visible/near-infrared spectra of experimentally shocked plagioclases. J. Geophys. Res. 108 (E11), pp. 6-1, CiteID 5120, DOI 10.1029/2003JE002127.

Johnson, J.R., Staid, M.I., 2005. Thermal infrared spectral deconvolution of experimentally shocked basaltic rocks using experimentally shocked plagioclase endmembers. Lunar 
Planet. Sci. XXXVI. Abstract 1848.

Johnson, J.R., Staid, M.I., Titus, T.N, Becker, K., 2006. Shocked plagioclase signatures in Thermal Emission Spectrometer data of Mars. Icarus 180, 60-74.

Jolliff, B.L., $\quad$ Farrand, W.H., $\quad$ Johnson, J.R., $\quad$ Schröder, C., $\quad$ Weitz, C.M., $\quad$ and Athena Science Team, 2006. Origin of rocks and cobbles on the Meridiani Plains as seen by Opportunity. Lunar Planet. Sci. XXXVII. Abstract 2401.

Jouglet, D., Poulet, F., Milliken, R.E., Mustard, J.F., Bibring, J.-P., Langevin, Y., Gondet, B.,

Gomez, C., 2007. Hydration state of the Martian surface as seen by Mars Express

OMEGA: 1. Analysis of the $3 \mu \mathrm{m}$ hydration feature. J. Geophys. Res. 112 (E8), CiteID E08S06.

Keppler, H., 1992. Crystal field spectra and geochemistry of transition metal ions in silicate melts and glasses. Amer. Mineral. 77, 62-75.

Kraft, M.D., Michalski, J.R., Sharp, T.G., 2003. Effects of pure silica coatings on thermal emission spectra of basaltic rocks: Considerations for Martian surface mineralogy. Geophys. Res. Lett. 30, PLA 5-1, CiteID 2288, DOI 10.1029/2003GL018848.

Kurkjian, C.R., 1970. Mössbauer spectroscopy in inorganic glasses. J. Non-Cryst. Solids 3, 157194.

Kuzmann, E., Nagy, S., Vertes, A., 2003. Critical review of analytical applications of Mössbauer spectroscopy illustrated by mineralogical and geological examples. Pure Appl. Chem. 75, $801-858$

Launer, P.J., 1952. Regularities in the infrared absorption spectra of silicate minerals. Am. Min.

Formatted: German Germany 37, 764-784.Loizeau, D., Mangold, N., Poulet, F., Bibring, J.-P., Gendrin, A., Ansan, V., Gomez, C., Gondet, B., Langevin, Y., Masson, P., Neukum, G., 2007. Phyllosilicates in the Mawrth Vallis region of Mars. J. Geoph. Res. 112, CiteID E08S08.

Lorenz, R.D., 2000. Microtectites on Mars: Volume and texture of distal impact ejecta deposits. Icarus $144,353-366$.

Lucey, P.G., Noble, S.K., 2008. Experimental test of a radiative transfer model of the optical 
effects of space weathering. Icarus 197, 348-353.

Lyon, R.J.P., 1964. Evaluation of Infrared Spectrophotometry for Compositional Analysis of Lunar and Planetary Soils. Part II: Rough and Powdered Surfaces. NASA-CR 100, Washington, DC.

Lyon, R.J.P., 1965. Analysis of rocks by spectral infrared emission (8 to 25 microns). Econ. Geol. 60, 715-736.

Lyon, R.J.P., Burns, E.A., 1963. Analysis of rocks and minerals by reflected infrared radiation. Econ. Geol. 58, 274-284.

Mangold, N., Poulet, F., Mustard, J.F., Bibring, J.-P., Gondet, B., Langevin, Y., Ansan, V., Masson, Ph., Fassett, C., Head, J. W., and 2 coauthors, 2007. Mineralogy of the Nili Fossae region with OMEGA/Mars Express data: 2. Aqueous alteration of the crust. J. Geophys. Res. 112, CiteID E08S04.

Mattey, D.P., 1991. Carbon dioxide solubility and carbon isotope fractionation in basaltic melt. Geochim. Cosmochim. Acta 55, 3467-3473.

Maturilli, A., Helbert, J., Witzke, A., Moroz, L.V., 2006. Emissivity measurements of analogue materials for the interpretation of data from PFS on Mars Express and MERTIS on BepiColombo. Planet. Space. Sci. 54, 1057-1064.

Maturilli, A., Helbert, J., Moroz, L.V., 2008. The Berlin Emissivity Database (BED). Planet. Space Sci. 56, 420-425.

McAdam, A.C., Leshin, L.A., Harvey, R.P., Hoffman, E.J., 2004. Antarctic soil derived from the Ferrar dolerite and implications for the formation of Martian surface materials. $2^{\text {nd }}$ Conf. on Early Mars, October 11-15, 2004, Jackson Hole, Wyoming. Abstract 8050.

McCord, T.B., Hansen, G.B., Clark, R.N., Martin, P.D., Hibbitts, C.A., Fanale, F.P., Granahan, J.C., Segura, M., Matson, D.L., Johnson, T.V., 3 coauthors, and The NIMS Team 1998. Non-water-ice constituents in the surface material of the icy Galilean satellites from the Galileo near-infrared mapping spectrometer investigation. J. Geophys. Res. 103, 86038626. 
McSween, H.Y., Murchie, S.L., Britt, D.T., Brückner, J., Dreibus, G., Economou, T., Ghosh, A., Golombek, M.P., Greenwood, J.P., Johnson, J.R., and 5 coauthors, 1999. Chemical, multispectral, and textural constraints on the composition and origin of rocks at the Mars Pathfinder landing site. J. Geophys. Res. 104 (E4), 8679-8716.

Michalski, J.R., Kraft, M.D., Sharp, T.G., Williams, L.B., Christensen, P.R., 2005. Mineralogical constraints on the high-silica martian surface component observed by TES. Icarus 174, 161-177.

Michalski, J.R., Kraft, M.D., Sharp, T.G., Williams, L.B., Christensen, P.R., 2006. Emission spectroscopy of clay minerals and evidence for poorly crystalline aluminosilicates on Mars from Thermal Emission Spectrometer data. J. Geophys. Res. 111 (E3), CiteID E03004.

Milliken, R.E., Mustard, J.F., 2005. Quantifying absolute water content of minerals using nearinfrared reflectance spectroscopy. J. Geophys. Res. 110 (E12), CiteID E12001.

Milliken, R.E., Mustard, J.F., Poulet, F., Jouglet, D., Bibring, J.-P., Gondet, B., Langevin, Y., 2007. Hydration state of the Martian surface as seen by Mars Express OMEGA: 2. $\mathrm{H}_{2} \mathrm{O}$ content of the surface J. Geophys. Res. 112 (E8), CiteID E08S07.Milliken, R.E., Swayze, G.A., Arvidson, R.E., Bishop, J.L., Clark, R.N., Ehlmann, B.N., Green, R.O., Grotzinger, J.P., Morris, R.V., Murchie S.L., and 2 coauthors, 2008. Opaline silica in young deposits on Mars. Geology 36, 847-850.

Ming, D.W., Gellert, R., Morris, R.W., Arvidson, R.E, Brückner, J., Clark, B.C., Cohen, B.A., d'Uston, Economou, T., Fleischer, I. and 9 coauthors, 2008. Geochemical properties of rocks and soils in Gusev crater, Mars: Results of the Alpha Particle X-Ray Spectrometer from Cumberland ridge to Home Plate. J. Geophys. Res. (in press).

Minitti, M.E., Rutherford, M.J., Mustard, J.F., 2002. Effects of glass content and oxidation on the spectra of SNC-like basalts: Applications to Mars remote sensing. J. Geophys. Res. 107, 61 - 6-14.Minitti, M.E., Hamilton, V.E., Wyatt, M.B., 2006. Investigation of the role of new glass compositions in remotely-sensed Martian lithologies. Lunar Planet. Sci. XXXVII. Abstract 2101. 
Minitti, M.E., Hamilton, V.E., Wyatt, M.B., 2007a. Deconvolution of Martian thermal infrared spectra using a simplified, glass-rich library. Lunar Planet. Sci. XXXVIII . Abstract 2099.

Minitti, M.E., Weitz, C.M., Lane, M.D., Bishop, J.L. 2007b Morphology, chemistry, and spectral properties of Hawaiian rock coatings and implications for Mars. J. Geophys. Res. 112, E05015, doi: 10.1029/2006JE002839.

Moore, H.J., Spitzer, C.R., Bradford, K.Z., Cates, P.M., Shorthill, R.W., Hutton, R.E., 1979. Sample fields of the Viking landers, physical properties, and aeolian processes. J. Geophys. Res. 84, 8365-8377.

Moroz, L.V., Fisenko, A.V., Semjonova, L.F., Pieters, C.M., Korotaeva, N.N., 1996. Optical effects of regolith processes on $\mathrm{S}$ asteroids as simulated by laser shots on ordinary chondrite and other mafic materials. Icarus 122, 366-382.

Moroz, L.V, Hiroi, T., Shingareva, T.V., Basilevsky, A.T., Fisenko, A.V., Semjonova, L.F., Pieters, C.M., 2004. Reflectance spectra of CM2 chondrite Mighei irradiated with pulsed laser and implications for low-albedo asteroids and Martian moons. Lunar. Planet. Sci. XXXV, Abstract 1279.

Morris, R.V., Neely, S.C., 1981. Diffuse reflectance spectra of pigmentary-sized iron oxides, iron oxyhydroxides, and their mixtures: Implications for the reflectance spectra of Mars. Lunar Planet Sci. XII, 720-722 (Abstract).

Morris, R.V., Lawson, C.A., Gibson, E.K., Jr., Lauer, H.V., Jr., Nace G.A., Stewart, C., 1985. Spectral and other physicochemical properties of submicron powders of hematite $(\alpha-$ Fe2O3), maghemite ( $\gamma$-Fe2O3), magnetite (Fe3O4), goethite $(\alpha-\mathrm{FeOOH})$, and lepidocrocite ( $\gamma$-FeOOH). J. Geophys. Res. 90, 3126-3144.

Morris, R.V., Golden, D.C., Bell III, J.F., Lauer, H.V., Jr., 1995. Hematite, pyroxene, and phyllosilicates on Mars: Implications from oxidized impact melt rocks from Manicouagan Crater, Quebec, Canada. J. Geophys. Res. 100, 5319-5328.

Morris, R.V., Klingelhöfer, G., Korotev, R.L., Shelfer, T.D., 1998. Mössbauer mineralogy on the Moon: The lunar regolith. Hyperfine Interact. 117, 405-432. 
Morris, R.V., Golden, D.C., Bell III, J.F., Shelfer, T.D., Scheinost, A.C., Hinman, N.W., Furniss, G., Mertzman, S.A., Bishop, J.L., Ming, D.W., Allen, C.C., Britt, D.T., 2000a. Mineralogy, composition, and alteration of Mars Pathfinder rocks and soils: Evidence from multispectral, elemental, and magnetic data on terrestrial analogue, SNC meteorite, and Pathfinder samples. J. Geophys. Res. 105, 1757-1818.Morris, R.V., Le, L., Lane, M.D., Golden, D.C., Shelfer, T.D., Lofgren, G.E., Christensen, P.R., $2000 \mathrm{~b}$. Multidisciplinary study of synthetic Mars Global Average Soil Glass. Lunar Planet. Sci. XXXI. Abstract 1611.

Morris, R.V., Lofgren, G.E., Le, L., Shelfer, T.D., 2001. Crystallization of oxide and silicate phases from impact melts with average Martian soil composition. Lunar Planet. Sci. XXXII. Abstract 2012.

Morris, R.V., Graff, T.G., Mertzman, S.A., Lane, M.D., Christensen, P.R., 2003. Palagonitic (not andesitic) Mars: Evidence from Thermal Emission and VNIR spectra of palgonitic alteration rinds on basaltic rock. 6th International Conf. on Mars, July 20-25, 2003, Pasadena, CA, Abstract 3211.

Morris, R.V., $\quad$ Klingelhöfer, G., $\quad$ Schröder, C., $\quad$ Rodionov, D.S., $\quad$ Yen, A., $\quad$ Ming, D.W., de Souza, P.A., Fleischer, I., Wdowiak, T., Gellert, R., and 10 coauthors, 2006a. Mössbauer mineralogy of rock, soil, and dust at Gusev crater, Mars: Spirit's journey through weakly altered olivine basalt on the plains and pervasively altered basalt in the Columbia Hills. J. Geophys. Res. 111 (E2), CiteID E02S13.

Morris, R.V., $\quad$ Klingelhöfer, G., $\quad$ Schröder, C., $\quad$ Rodionov, D.S., $\quad$ Yen, A., $\quad$ Ming, D.W., de Souza, P.A., Wdowiak, T., Fleischer, I., Gellert, R., and 14 coauthors, 2006b. Mössbauer mineralogy of rock, soil, and dust at Meridiani Planum, Mars: Opportunity's journey across sulfate-rich outcrop, basaltic sand and dust, and hematite lag deposits J. Geophys. Res. 111 (E2), CiteID E12S15.

Morris, R.V., Klingelhöfer, G., Schröder, C., Fleischer, I., Ming, D.W., Yen, A., Gellert, R., Arvidson, R.E., Rodionov, D.S., Crumpler, L.S., and 7 coauthors, 2008. Iron mineralogy 
and aqueous alteration from Husband Hill through Home Plate at Gusev crater, Mars: Results from Mössbauer instrument on the Spirit Mars Exploration Rover J. Geophys. Res. (in press).

Le Mouélic, S., Sotin, C., Combe, J.-Ph., Ledeit, L., Gendrin, A., Mustard, J., Bibring, J.-P., Langevin, Y., Gondet, B., Pinet, P., 2006. Composition of the dust on Mars derived from OMEGA hyperspectral images. Lunar Planet. Sci. XXXVII. Abstract 1409.

Murchie, S., Mustard, J., Bishop, J., Head, J., Pieters, C., Erard, S., 1993. Spatial variations in the spectral properties of bright regions on Mars. Icarus 105, 454-468.

Murchie, S., Kirkland, L., Erard, S., Mustard, J., Robinson, M. 2000. Near-infrared spectral variations of Martian surface materials from ISM Imaging Spectrometer data. Icarus 147, 444-471.Murchie, S., Arvidson, R., Bedini, P., Beisser, K., Bibring, J.-P., Bishop, J.,

Boldt, J., Cavender, P., Choo, T., Clancy, R. T., and 40 coauthors, 2007. Compact Reconnaissance Imaging Spectrometer for Mars (CRISM) on Mars Reconnaissance Orbiter (MRO). J. Geophys. Res. 112, E5, CiteID E05S03.

Mustard, J.F., Hays, J.E., 1997. Effects of hyperfine particles on reflectance spectra from 0.3 to $25 \mu \mathrm{m}$. Icarus 145, 145-163.Mustard, J.F., Bell, J.F., III, 1994. New composite reflectance spectra of Mars from 0.4 to $3.13 \mu \mathrm{m}$. Geophys. Res. Lett. 21, 353-356.

Mustard, J.F., Sunshine, J.M., 1995. Seeing through the dust - Martian crustal heterogeneity and links to the SNC meteorites. Science 267, 1623-1626.

Mustard, J.F., Poulet, F., Gendrin, A., Bibring, J.-P., Langevin, Y., Gondet, B., Mangold, N., Bellucci, G., Altieri, F., 2005. Olivine and pyroxene diversity in the crust of Mars. Science 307, 1594-1597.

Mustard, J.F., Poulet, F., Head, J.W., Mangold, N., Bibring, J.-P., Pelkey, S.M., Fassett, C., Langevin, Y., Neukum, G., 2007. Mineralogy of the Nili Fossae region with OMEGA/Mars Express data: 1. Ancient impact melt in the Isidis Basin and implications for the transition from the Noachian to Hesperian. J. Geophys. Res. 112, CiteID E08S03. 
Mustard, J.F., $\quad$ Murchie, S.L., $\quad$ Pelkey, S.M., ～Ehlmann, B.L., $\quad$ Milliken, R.E., Grant, J.A., Bibring, J.-P., Poulet, F., Bishop, J., Dobrea, E.N., and 26 coauthors, 2008. Hydrated silicate minerals on Mars observed by the Mars Reconnaissance Orbiter CRISM instrument. Nature 454, 305-309.

Mutch, T.A., Arvidson, R.E., Guinness, E.A., Binder, A.B., Morris, E.C., 1977. The geology of the Viking Lander 2 site. J. Geophys. Res. 82, 4452-4467.

Mysen, B.O., Eggler, D.H., Seitz, M.G., Holloway, J.R., 1976. Carbon dioxide in silicate melts and crystals; Part I, Solubility measurements. Amer. J. Sci. 276, 455-479.

Mysen, B.O., Seifert, F., Virgo, D., 1980. Structure and redox equilibria of iron-bearing silicate melts. Amer. Miner. 65, 867-884.

Mysen, B.O., Carmichael, I.S.E., Virgo, D., 1985. A comparison of iron redox ratios in silicate glasses determined by wet-chemical and ${ }^{57} \mathrm{Fe}$ Mössbauer resonant absorption methods. Contrib. Mineral. Petrol. 90, 101-106.

Nash, D.B., Salisbury, J.W., 1991. Infrared reflectance spectra (2.2-15 microns) of plagioclase feldspars. Geophys. Res. Lett. 18, 1151-1154.

Newsom, H.E., 1980. Hydrothermal alteration of impact melt sheets with implications for Mars. Icarus 44, 207-216.

Nicholis, M., Milliken, R.E., Mustard, J.F., Rutherford, M., 2006. VIS-NIR spectral properties of olivine in a basaltic glass: Implications for olivine-rich terrains on Mars. Lunar. Planet. Sci. XXXVII. Abstract 2378.

Noble, S.K., Pieters, C.M., 2001. Type 2 Terrain: Compositional constraints on the Martian lowlands. Lunar. Planet. Sci. XXXII. Abstract 1230.

Noble, S.K., Pieters, C.M., Keller, L.P., 2007. An experimental approach to understanding the optical effects of space weathering. Icarus 192, 629-642.

Parke, S., 1974. Glasses. In: Farmer, V.C. (Ed.) The Infrared Spectra of Minerals. Mineralogical Society, London, pp. 483-514.

Pieters, C.M., 1983. Strength of mineral absorption features in the transmitted component of 
near-infrared reflected light - First results from RELAB. J. Geophys. Res. 88, 9534-9544.

Pieters, C.M., Klima, R.L., Hiroi, T., Dyar, M.D., Lane, M.D., Treiman, A.H., Noble, S.K., Sunshine, J.M., Bishop, J.L., 2008. Martian dunite NWA 2737: Integrated spectroscopic analyses of brown olivine J. Geophys. Res. 113, Issue E6, CiteID E06004.

Pinet, P., Chevrel, S., 1990. Spectral identification of geological units on the surface of Mars related to the presence of silicates from earth-based near-infrared telescopic charge-coupled device imaging J. Geophys. Res. 95, 14,435-14,446.

Pollack, J.B., Toon, O.B., Khare, B.N., 1973. Optical properties of some terrestrial rocks and glasses. Icarus 19, 372-389.Poulet, F., Bibring, J.-P., $\quad$ Mustard, J.F., Gendrin, A., Mangold, N., Langevin, Y., Arvidson, R. E., Gondet, B., Gomez, C., and the OMEGA Team, 2005. Phyllosilicates on Mars and implications for early martian climate, Nature 438, 623-627.

Poulet, F., Gomez, C., Bibring, J.-P., Langevin, Y., Gondet, B., Pinet, P., Belluci, G., Mustard, J., 2008. Martian surface mineralogy from Observatoire pour la Minéralogie, l'Eau, les Glaces et l'Activité on board the Mars Express spacecraft (OMEGA/MEX): Global mineral maps. J. Geophys. Res. 112, CiteID E08S02.

Rehman, I., Bonfield, W., 1997. Characterization of hydroxyapatite and carbonated apatite by photo acoustic FTIR spectroscopy. J. Materials Science: Materials in Medicine 8, 1-4.

Rieder, R., Economou, T., Wänke, H., Turkevich, A., Crisp, J., Breckner, J., Dreibus, G., McSween, H.Y., Jr., 1997. The chemical composition of Martian soil and rocks returned by the mobile Alpha Proton X-ray Spectrometer: Preliminary results from the X-ray mode. Science 278, 1771-1774.

Rieder, R., Gellert, R., Anderson, R.C., Brückner, J., Clark, B.C., Dreibus, G., Economou, T., Klingelhöfer, G., Lugmair, G.W., Ming, D.W., and 5 coauthors, 2004. Chemistry of rocks and soils at Meridiani Planum from the Alpha Particlo X-ray Spectrometer. Science 306, 1746-1749. 
Ruff, S.W., Christensen, P.R., 2002. Bright and dark regions on Mars: Particle size and mineralogical characteristics based on Thermal Emission Spectrometer data. J. Geophys. Res. 107 (E12), CiteID 5127, DOI 10.1029/2001JE001580.

Ruff, S.W., 2004. Spectral evidence for zeolite in the dust on Mars. Icarus 168, 131-143.

Ruff, S.W., Christensen, P.R., Blaney, D.L., Farrand, W.H., Johnson, J.R., Michalski, J.R., Moersch, J.E., Wright, S.P., Squyres, S.W., 2006. The rocks of Gusev Crater as viewed by the Mini-TES instrument. J. Geophys. Res. 111 (E12), CiteID E12S18.

Ruff, S.W., Christensen, P.R., 2007. Basaltic andesite, altered basalt, and a TES-based search for smectite clay minerals on Mars. Geophys. Res. Lett. 34, CiteID L10204.

Rusakov, V.S., 2000. Mössbauer Spectroscopy of Locally Inhomogeneous Systems. INP NNC of Kazakhstan, Almaty, 431 p.

Rusakov, V.S., Kadyrzhanov, K.K., 2005. Mössbauer Spectroscopy of Locally Inhomogeneous Systems. Interact. 164, 87-97.

Sack, R.O., Carmichael, I.S.E., Rivers, M., Chiorso, M.S., 1980. Ferric-ferrous equilibria in natural silicate liquids at 1 bar. Contrib. Mineral. Petrol. 75, 369-376.

Salisbury, J.W., Eastes, J.W., 1985. The effect of particle size and porosity on spectral contrast in the mid-infrared. Icarus $64,568-588$.

Salisbury, J.W., Walter, L.S., Vergo, N., D’Aria, D.M., 1991. Infrared (2.1-25 $\mu \mathrm{m})$ spectra of minerals. Johns Hopkins Univ. Press, Baltimore, 267 p.

Salisbury, J.W., Wald, A., 1992. The role of volume scattering in reducing spetctral contrast of Reststrahlen bands in the spectra of powdered minerals. Icarus 96, 121-128.

Salisbury, J.W., 1993. Mid-infrared spectroscopy: Laboratory data. In: Pieters, C.M., Englert, P.A. (Eds.), Remote Geochemical Analysis: Elemental and Mineralogical Composition, Cambridge Univ. Press, Cambridge, pp. 79-98.

Schiffman, P., Southard, R. J., Eberl, D. D., and Bishop, J.L. 2002. Distinguishing palagonitized from pedogenically-altered basaltic Hawaiian tephra: mineralogical and geochemical criteria. In: J. L. Smellie and M. G. Chapman (eds.) Volcano-Ice Interactions on Earth and 
Mars. Special Publications of Geological Society of London, Special Publication 202., pp. 393-405.

Schmidt, M.E., Ruff, S.W., McCoy, T.J., Farrand, W.H., Johnson, J.R., Gellert, R., Ming, D.W., Morris, R.V., Cabrol, N., Lewis, K.W., Schroeder, C., 2008. Hydrothermal origin of halogens at Home Plate, Gusev Crater. J. Geophys. Res. 113, (E6), CiteID E06S12.

Schultz, P.H., Zárate, M., Hames, B., Koeberl, C., Bunch, Th., Storzer, D., Renne, P., Wittke, J., 2004. The Quaternary impact record from the Pampas, Argentina. Earth Planet. Sci. Lett. 219, 221-238.

Schultz, P.H., Mustard, J.F., 2004. Impact melts and glasses on Mars. J. Geophys. Res. 109 (E1), CiteID E01001.

Singer, R.B., McCord, T.B., 1979. Mars - Large scale mixing of bright and dark surface materials and implications for analysis of spectral reflectance. Proc. Lunar Planet. Sci. Conf. 10th, 1835-1848.

Singer, R.B., Roush, T.L., 1983. Spectral Reflectance Properties of Particulate Weathered Coatings on Rocks: Laboratory Modeling and Applicability to Mars. Lunar Planet. Sci. XIV, 708-709 (Abstract).

Sherman, D.M., Burns, R.G., Burns, V.M. 1982. Spectral characteristics of the iron oxides with application to the Martian bright region mineralogy. J. Geophys. Res. 87, 10,169-10,180.

Sherman, D.M. 1985. The electronic structures of $\mathrm{Fe}^{3+}$ coordination sites in iron oxides; applications to spectra, bonding, and magnetism. Phys. Chem. Minerals 12, 161-175.

Simon, I., McMahon, H.O., 1953. Study of some binary silicate glasses by means of reflection in the infrared. J. Am. Ceram. Soc. 36, 160-164.

Smith, P.H., Tamppari, L., Arvidson, R.E., Bass, D., Blaney, D., Boynton, W., Carswell, A., Catling, D., Clark, B., Duck, T., and 29 coauthors, 2008. Introduction to special section on the Phoenix Mission: Landing site characterization, experiments, mission overviews, and expected science. J. Geophys. Res. 113 (E12), CiteID E00A18. 
Squyres, S.W., Arvidson, R.E., Baumgartner, E.T., Bell, J.F., Christensen, P.R., Gorevan, S., Herkenhoff, K.E., Klingelhöfer, G., Madsen, M.B., Morris, R.V., and 2 coauthors, 2003 Athena Mars rover science investigation. J. Geophys. Res. 108 (E12), pp. ROV 3-1, CiteID 8062, DOI 10.1029/2003JE002121.

Squyres, S.W., Arvidson, R.E., Ruff, S., Gellert, R., Morris, R.V., Ming, D.W., Crumpler, L., Farmer, J.D., Des Marais, D.J., Yen, A., and 8 coauthors, 2008. Detection of silica-rich deposits on Mars. Science 320, 1063-1067.

Stubičan, V., Roy, R., 1961. Infrared spectra of layer-lattice silicates. J. Am. Ceram. Soc., 44, 625-627.

Swayze, G.A., $\quad$ Milliken, R.E., $\quad$ Clark, R.N., $\quad$ Bishop, J.L., $\quad$ Ehlmann, B.L., $\quad$ Pelkey, S.M., Mustard, J.F., Murchie, S.L., Brown, A.J., MRO Crism Team, 2007. Spectral evidence for hydrated volcanic and/or impact glass on Mars with MRO CRISM. 7th International Conf. on Mars, July 9-13, 2007, Pasadena, CA, LPI Contribution No. 1353, p. 3384.

Thomson, B.J., Schultz, P.H., 2002. Mid-infrared spectra of Argentine impact melts: Implications for Mars. Lunar Planet. Sci. XXXIII. Abstract 1595.

Thomson, B.J., 2006. Recognizing impact glass on Mars using surface texture, mechanical properties, and mid-infrared spectroscopic methods. Proquest Dissertations And Theses 2006. Section 0024, Part 0372, 180 pages; [Ph.D. dissertation]. Brown University; 2006. Publication Number: AAT 3227949.

Tirsch, D., Jaumann, R., Reiss, D., Helbert, J., Forget, F., Millour, E., Poulet, F., Neukum, G., 2007. Dark dunes in Martian craters. Lunar Planet. Sc. XXXVIII. Abstract 1569.

Tirsch, D., Jaumann, R., Poulet, F., Matz, K.-D., Bibring, J.-P., Neukum, G., 2008. Global view on the mineralogical composition of dark dunes on Mars. XXXIX, Abstract 1693.

Tirsch, D., Jaumann, R., 2008. Mars: Dark intra-crater dunes on a regional scale. Planetary Dunes Workshop: A Record of Climate Change, April 29 - May 2, 2008, Alamogordo, New Mexico. LPI Contrib. No. 1403, p.71-72. 
Toulmin, P., III, Rose, H.J., Jr., Christian, R.P., Baird, A.K., Evans, P.H., Clark, B.C., Keil, K., Kelliher, W.C., 1977. Geochemical and mineralogical interpretation of the Viking inorganic chemical results. J. Geophys. Res. 82, 4625-4634.

Van Cromphaut, C., de Resendle, V.G., de Grave, E., Van Alboom, A., Vandenberghe, R.E., and Klingelhöfer, G., 2007. Characterization of the magnetic iron phases in Clovis Class rocks in Gusev crater from the MER Spirit Mössbauer spectrometer. Geochim. Cosmochim. Acta 71, 4814-4822.

Van de Moortèle, B., Reynard, B., Rochette, P., Jackson, M., Beck, P., Gillet, P., McMillan, P.F., McCammon, C.A., 2007. Shock-induced metallic iron nanoparticles in olivine-rich Martian meteorites. Earth. Planet. Sci. Lett. 262, 37-49.

Vincent, R.K., Hunt, G.R., 1968. Infrared reflectance from mat surfaces. Appl. Opt. 7, 53-59.

Virgo, D., Mysen, B.O., 1985. The structural state of iron in oxidized vs. reduced glasses at 1 atm: a ${ }^{57}$ Fe Mössbauer study. Phys. Chem. Minerals 12, 65-76.

Walter, L.S., Salisbury, J.W., 1989. Spectral characterization of igneous rocks in the 8- to $12-\mu \mathrm{m}$ region. J. Geophys. Res., 94, 9203-9213.

Wang, A., Bell III, J.F., Li, R., Johnson, J.R., Farrand, W.H., Cloutis, E.A., Arvidson, R.E., Crumpler, L., Squyres, S.W., McLennan, S.M., 5 coauthors and the Athena Science Team, 2008. Light-toned salty soils and co-existing Si-rich species discovered by the Mars Exploration Rover Spirit in Columbia Hills. J. Geophys. Res. (in press).

Wells, E., Hapke, B., 1977. Lunar soil - iron and titanium bands in the glass fraction. Science 195, 977-979.

Wiseman, S.M., Arvidson, R.E., Andrews-Hanna, J.C., Clark, R.N., Lanza, N.L. Des Marais, D., Marzo, G.A., Morris, R.V., Murchie, S.L., Newsom, H.E., and 6 coauthors, 2008. Phyllosilicate and sulfate-hematite deposits within Miyamoto crater in southern Sinus Meridiani, Mars. Geophys. Res. Lett. 35, CiteID L19204.

Wright, S.P., Farrand, W.H., Newsom, H.E., Misra, S., Narasimham, V.L., 2004. Visible, near-, and thermal infrared spectroscopy of shocked and hydrothermally altered basalt from 
Lonar crater, India: Implications for current and future Mars data sets. 2nd Conf. on Early Mars: Geologic, Hydrologic, and Climatic Evolution and the Implications for Life, October 11-15, 2004, Jackson Hole, Wyoming, Abstract 8067.

Wright, S.P., Christensen, P.R., Sharp, T.G., 2006. Thermal emission spectroscopy of shocked basalt from the Earth and Mars: A review plus new insights. Lunar Planet. Sci. XXXVII. Abstract 1786.

Wrobel, K.E., Schultz, P.H., 2004. Effect of planetary rotation on distal tektite deposition on Mars. J. Geophys. Res., 109 (E5), CiteID E05005.

Wrobel, K.E., Schultz, P.H., 2007. The significant contribution of impact glass to the Martian surface record. International Conf. on Mars, July 9-13, 2007, Pasadena, CA, LPI Contribution No. 1353, p. 3093.

Wyatt, M.B., Hamilton, V.E., McSween, H.Y., Christensen, P.R., Taylor, L.A., 2001. Analysis of terrestrial and Martian volcanic compoitions using thermal emission spectroscopy: 1. Determination of mineralogy, chemistry, and classification strategies. J. Geophys. Res. 106 (E7), 14711-14732.

Wyatt, M.B., McSween, H.Y., 2002. Spectral evidence for weathered basalt as an alternative to andesite in the northern lowlands of Mars. Nature 417, 263-266.

Wyatt, M.B., McSween, H.Y., Moersch, J.E., Christensen, P.R., 2003. Analysis of surface compositions in the Oxia Palus region on Mars from Mars Global Surveyor Thermal Emission Spectrometer Observations. J. Geophys. Res. 108 (E9), pp. 11-1, CiteID 5107, DOI 10.1029/2002JE001986.

Wyatt, M.B., 2007. The chemically altered basaltic Northern plains of Mars: TES, OMEGA, and GRS integrated data sets and conclusions. 7th International Conf. on Mars, July 9-13, Pasadena, CA, LPI Contribution No. 1353, p.3402.

Yen, A.S., Gellert, R., Schröder, C., Morris, R.V., Bell, J.F., Knudson, A.T., Clark, B.C., Ming, D.W., Crisp, J.A., Arvidson, R.E., and 26 coauthors, 2005. An integrated view of the chemistry and mineralogy of martian soils. Nature 436, 49-54. 
Yen, A.S., Morris, R.V., Clark, B.C., Gellert, R., Knudson, A.T., Squyres, S., Mittlefehldt, D.W.; Ming, D.W., Arvidson, R., McCoy, T., and 4 coauthors, 2008. Hydrothermal processes at Gusev Crater: An evaluation of Paso Robles class soils. J. Geophys. Res. 113 (E6), CiteID E06S10.

Yingst, R.A., Crumpler, L., Farrand, W.H., Li, R. Cabrol., N.A., Neakrase, L.D., 2008. Morphology and texture of particles along the Spirit rover traverse from sol 450 to sol 475 . J. Geophys. Res. (in press).

Zotov, N., 2003. Structure of natural volcanic glasses: Diffraction versus spectroscopic perspective. J. Non-Cryst. Sol. 323, 1-6. 


\section{Table I}

Contents of iron species in the samples

\begin{tabular}{ccccc}
\hline Sample & $\mathrm{Fe}^{2+}$, at.\% & $\mathrm{Fe}^{3+}$, at.\% & $\mathrm{Fe}_{3} \mathrm{O}_{4}$, at. $\%$ & $\alpha-\mathrm{Fe}$, at.\% \\
& & & & \\
\hline JSC Mars-1 & $24.1 \pm 1.0$ & $65.2 \pm 0.9$ & $10.7 \pm 4.6$ & - \\
F glass & $51.9 \pm 2.8$ & $31.3 \pm 1.9$ & $16.8 \pm 2.6$ & - \\
S glass & $72.7 \pm 2.0$ & $23.9 \pm 1.6$ & $3.4 \pm 0.9$ & \\
L2 glass & $89.6 \pm 3.0$ & $4.0 \pm 1.5$ & - & $6.4 \pm 2.4$ \\
L4 glass & $93.0 \pm 2.4$ & $4.1 \pm 0.8$ & - & $2.9 \pm 1.6$ \\
& & & & \\
\hline
\end{tabular}




\section{FIGURE CAPTIONS}

Figure 1. BSE image of a typical JSC Mars-1 volcanic soil particle, which was the starting material for the simulated Martian impact glasses analyzed in this study. The margins of the particles are significantly weathered, while the central parts are only slightly weathered. The dark rod-like crystals embedded in the basaltic glass is plagioclase (from Basilevsky et al., 2000a).

Figure 2. SE images of the three glasses: (a) an L-glass spherule, with the FIB lamella produced for TEM analysis shown by an arrow, (b) F-glass particles, (c) S-glass particles.

Figure 3. BSE images of simulated Martian impact glass particles. (a) A $280 \times 90 \mu \mathrm{m}$ particle of heterogeneous F-glass with dark lath-like inclusions of plagioclase and smaller bright particles of Fe-Ti oxides. (b) A $200 \times 200 \mu \mathrm{m}$ particle of F-glass with a relatively large $(\sim 100 \mu \mathrm{m})$ gas bubble. The varying brightness of the glass is due to compositional heterogeneity. (c) A $300 \times 400 \mu \mathrm{m}$ ovoid L2-glass droplet with central large gas bubbles. (d) A $150 \times 240 \mu \mathrm{m}$ fragment of massive compositionally homogenous S-glass with arcuate edges due to large gas bubbles.

Figure 4. Mössbauer spectra of JSC Mars-1 (P-4), F-glass (F-4), and L-glass (L-2). Note the enrichment in the F-glass of $\mathrm{Fe}^{2+}$ relative to the JSC Mars-1 soil and the high abundance of $\mathrm{Fe}^{2+}$ in the L-glass.

Figure 5. Bright-field TEM image of a crystalline area within the S-glass.

Figure 6. (a) Bright field TEM image of the L-glass showing sparsely distributed nanophase inclusions. (b) HRTEM image of a nanophase inclusion. (c) HRTEM image of crystal 
lattice fringes within the inclusion shown in Fig. $6 b$, including the $\{110\}$ spacing of 0.20 $\mathrm{nm}$ of $\alpha-\mathrm{Fe}(\mathrm{bcc})$.

Figure 7. Reflectance spectra of JSC Mars-1 soil particle separates in (a) the visible and nearinfrared, acquired at the Brown University Keck ReLab, and in (b) the thermal infrared.

Figure 8 . Reflectance spectra of 40-80 $\mu \mathrm{m}$ particle separates of JSC Mars-1 and experimentally produced glasses in (a) the visible and near-infrared and in (b) the thermal infrared.

Figure 9. Reflectance spectra of F-glass separates (resistance furnace, fast cooling) in (a) the visible and near-infrared and in (b) the thermal infrared.

Figure 10. Reflectance spectra of S-glass separates (resistance furnace, slow cooling) in (a) the visible and near-infrared and in (b) the thermal infrared.

Figure 11. Reflectance spectra of L2-glass separates (laser shots at $10^{-2} \mathrm{~mm} \mathrm{Hg}$ ) in (a) the visible and near-infrared and in (b) the thermal infrared.

Figure 12. $\mathrm{CO}_{2}$ absorption features in the infrared spectra of L-glasses. (a) $\mathrm{CO}_{2}$ feature in the spectra of the size separates of L2-glass (b) $\mathrm{CO}_{2}$ features in the spectra of $\mathrm{L} 2$ and L4 separates after the removal of straight line continua. The spectra are offset for clarity. Note the variations in shape, width and complexity of the $\mathrm{CO}_{2}$ absorption features as a function of particle size. 


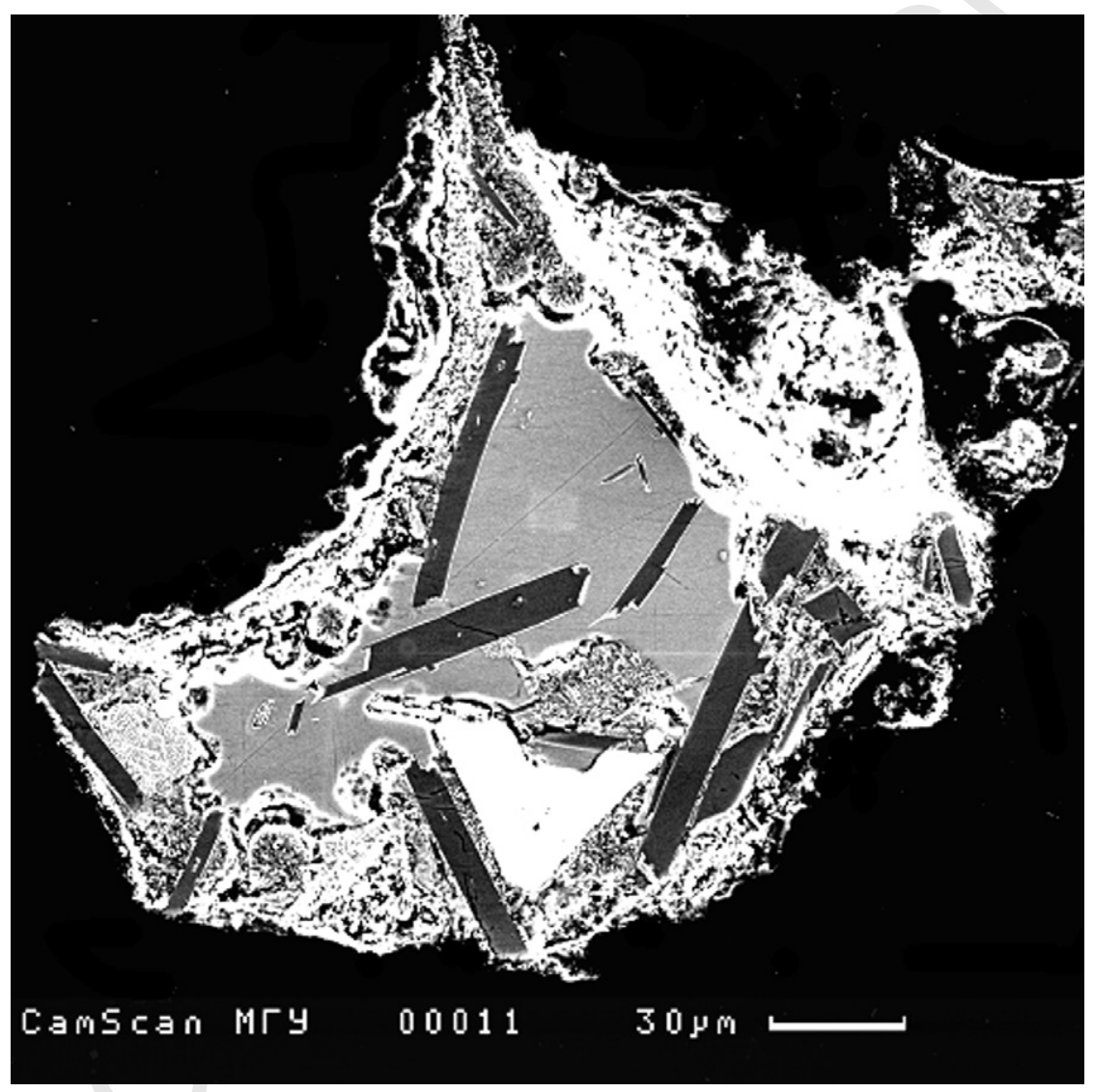




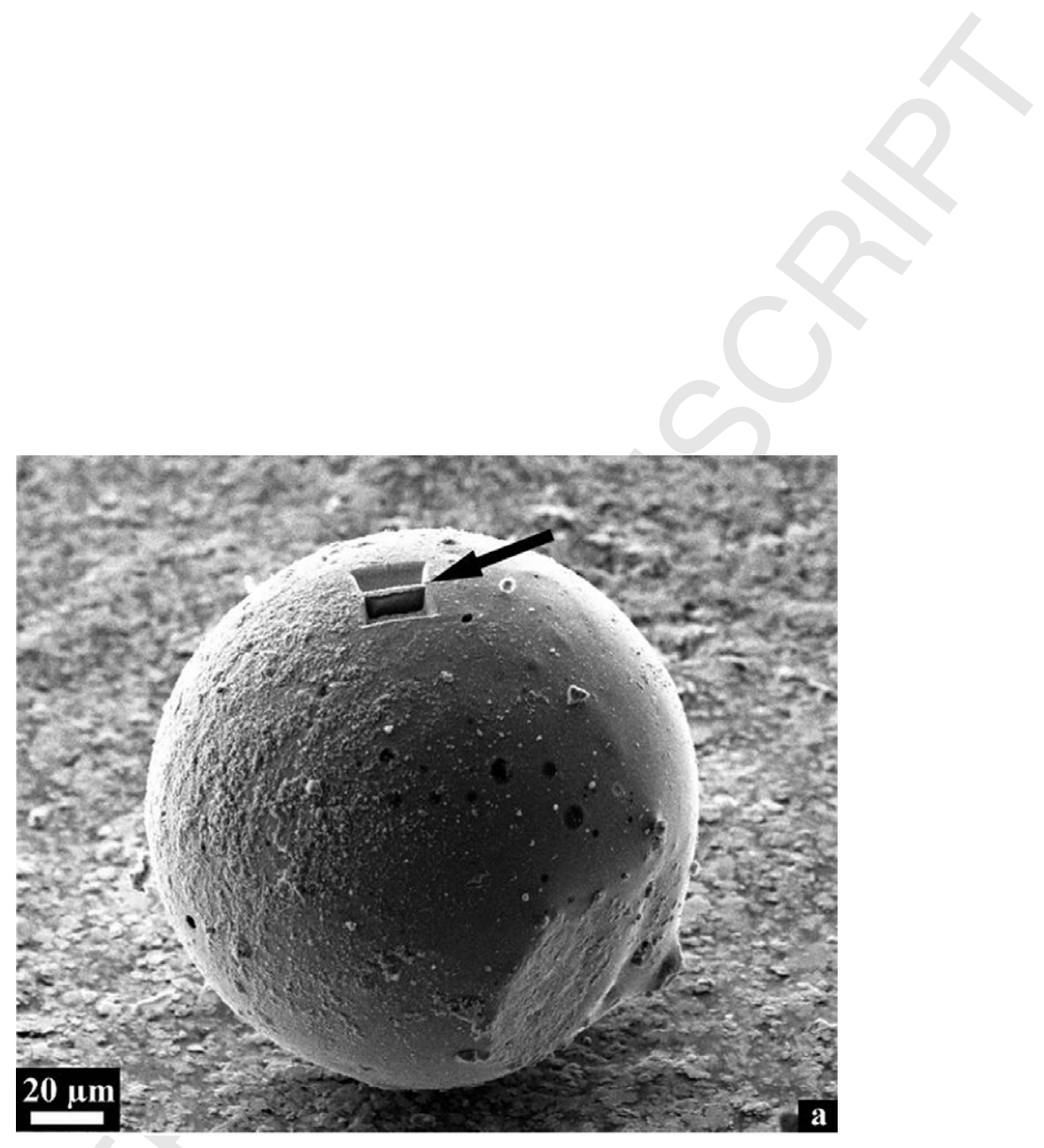




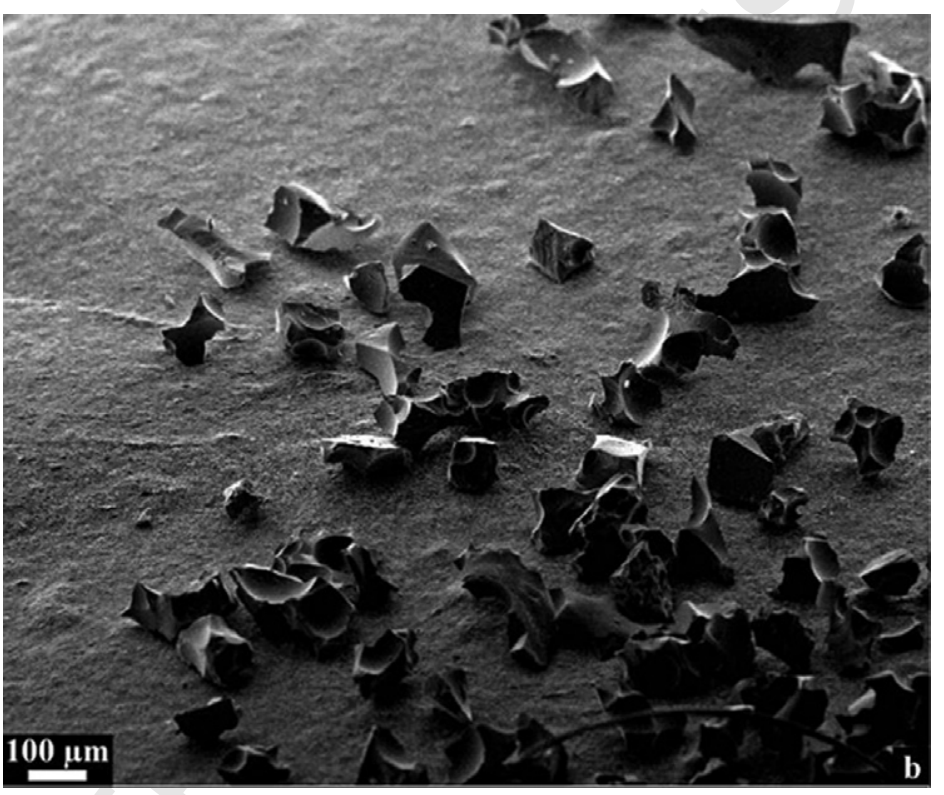




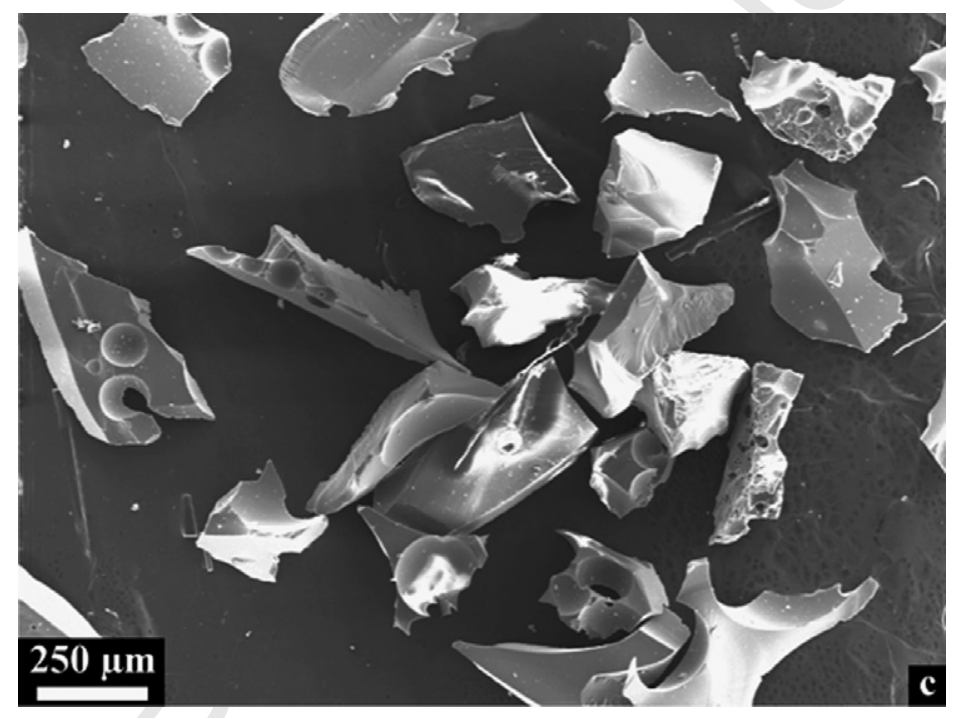



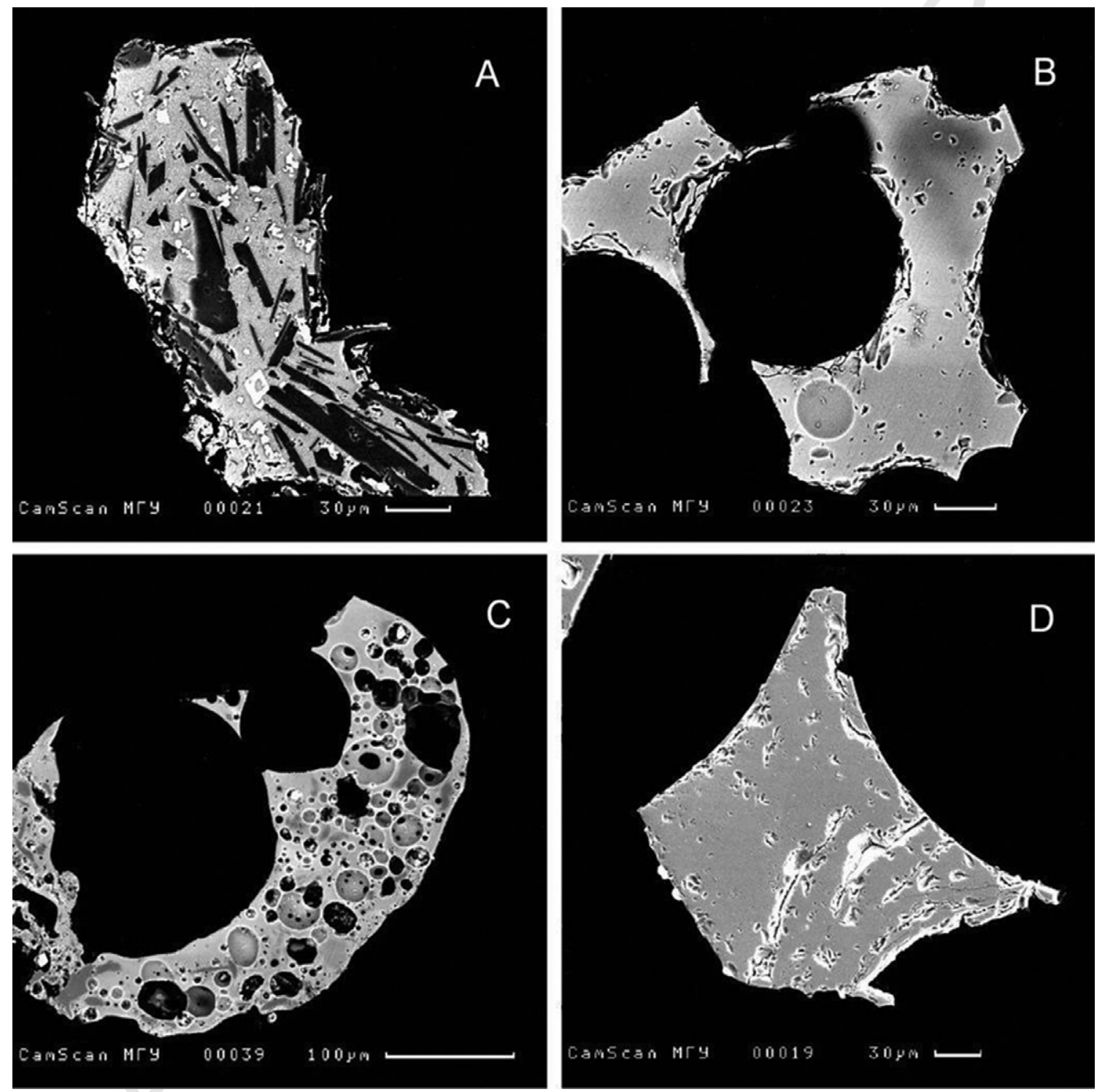


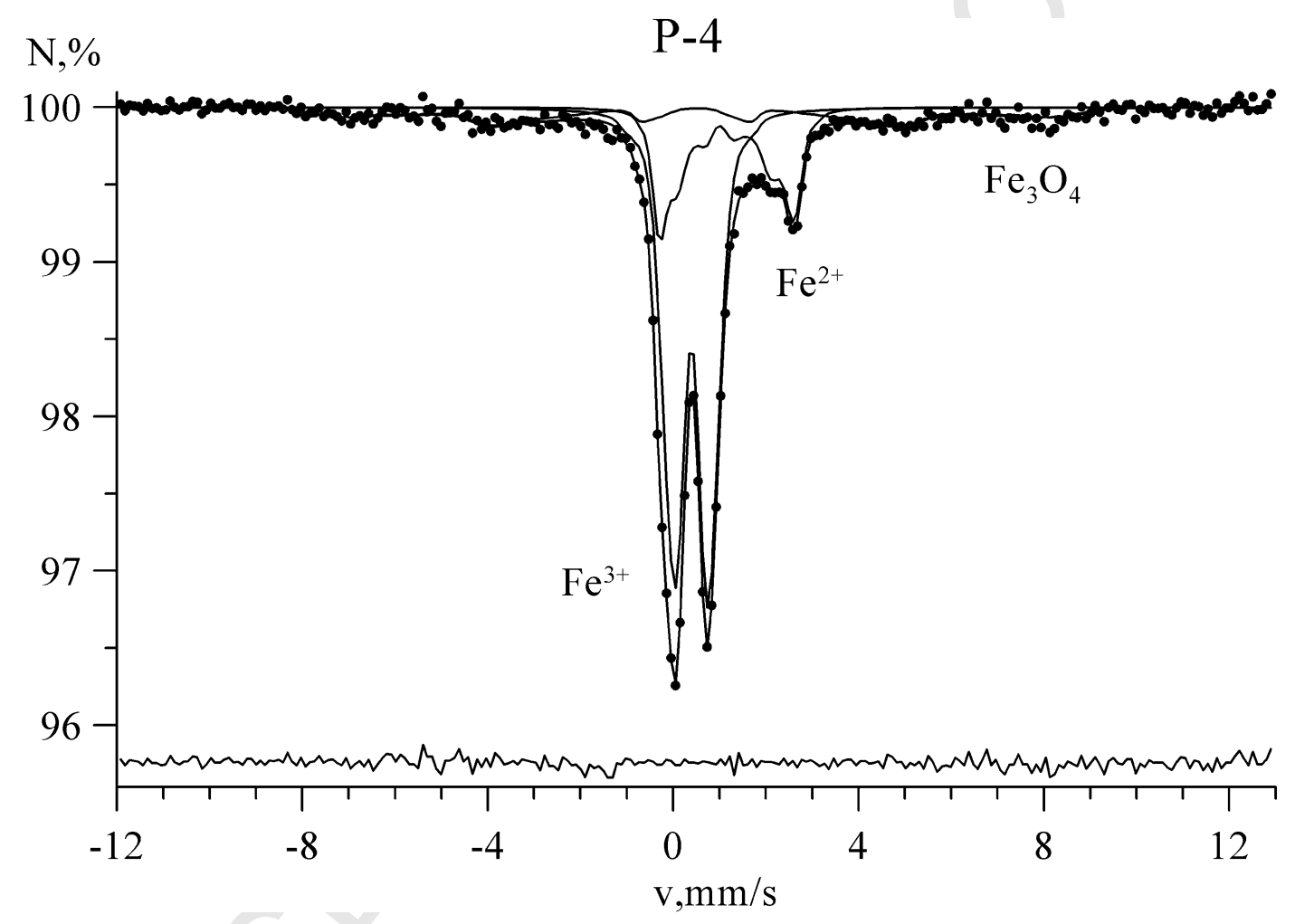




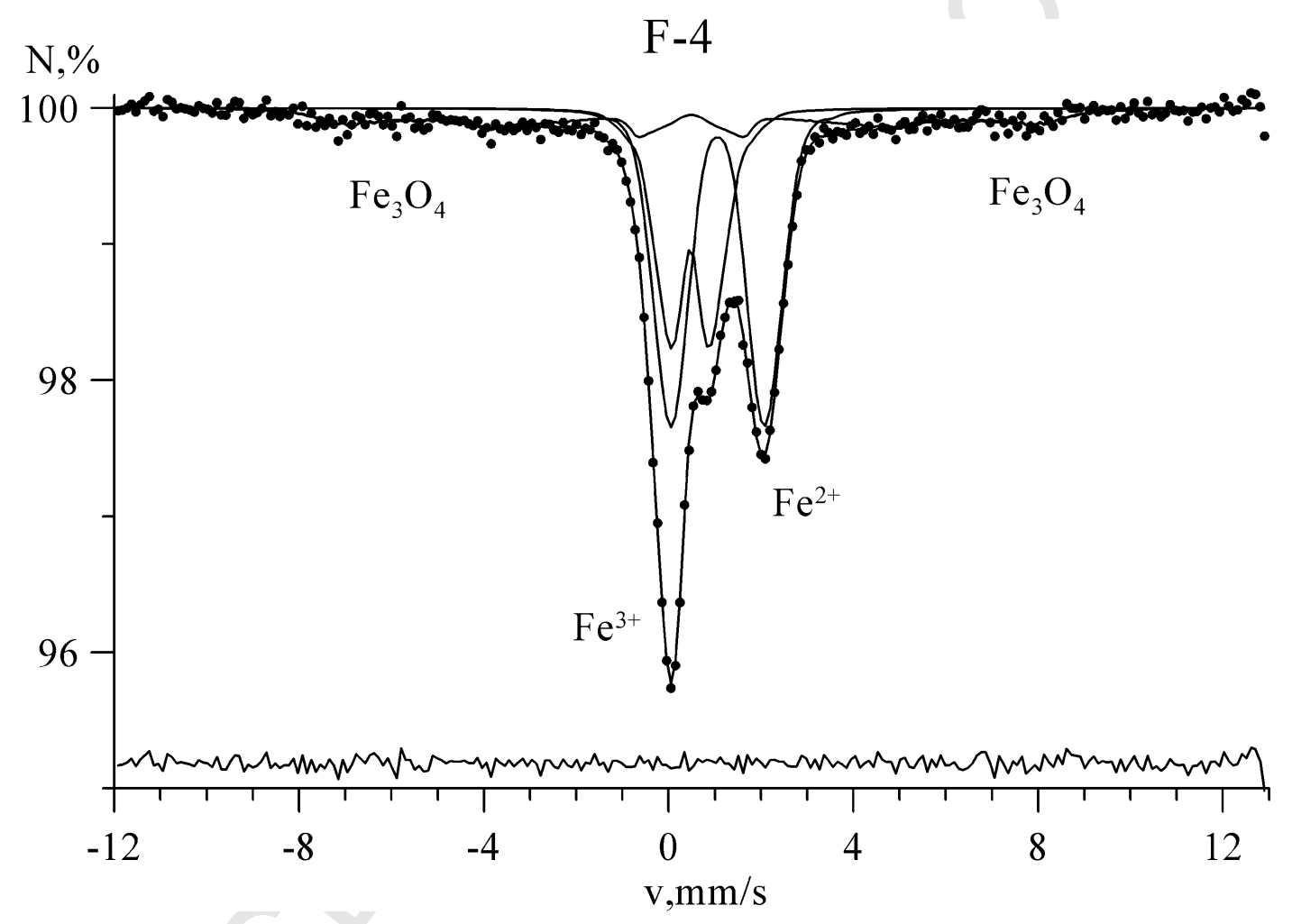




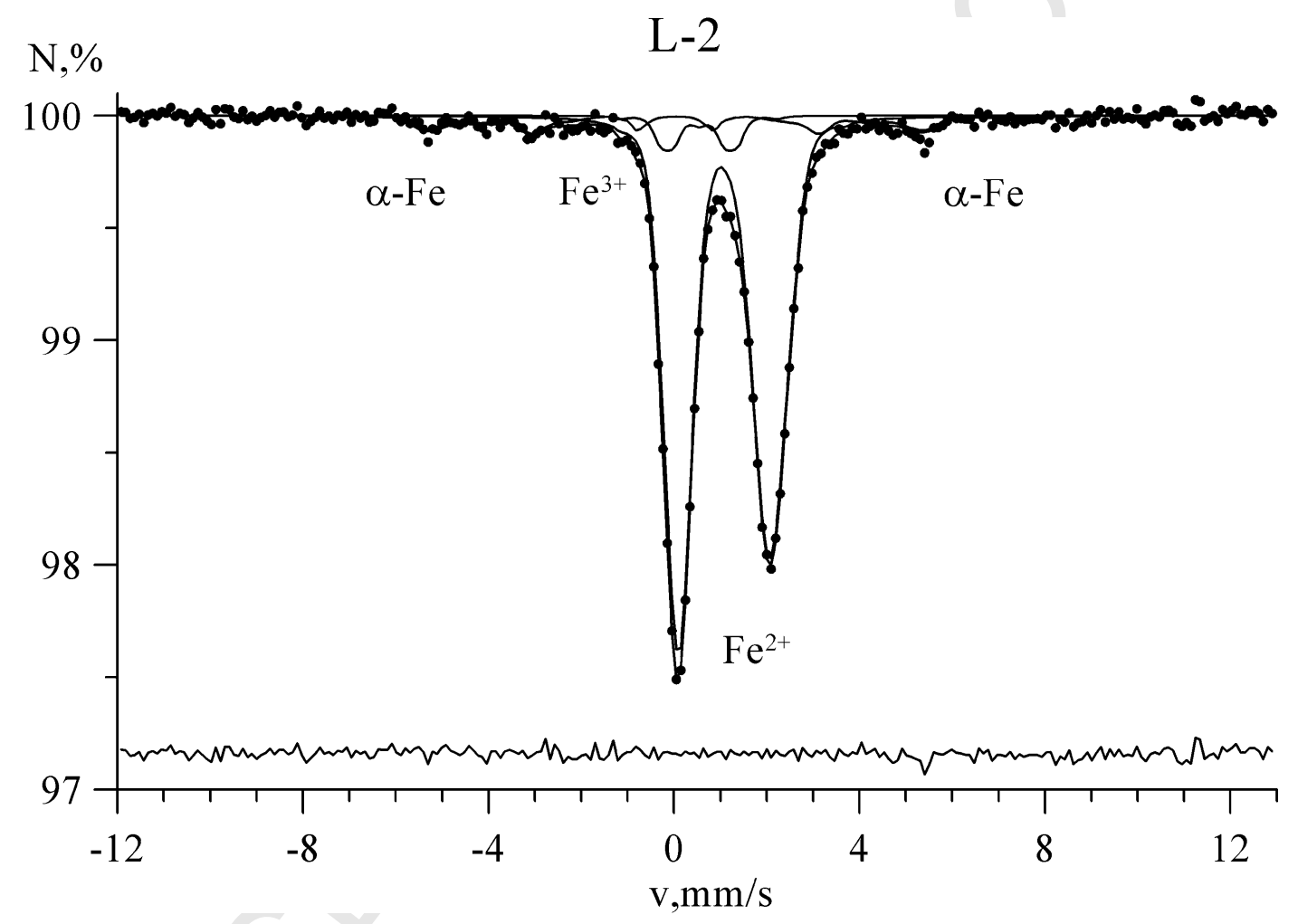




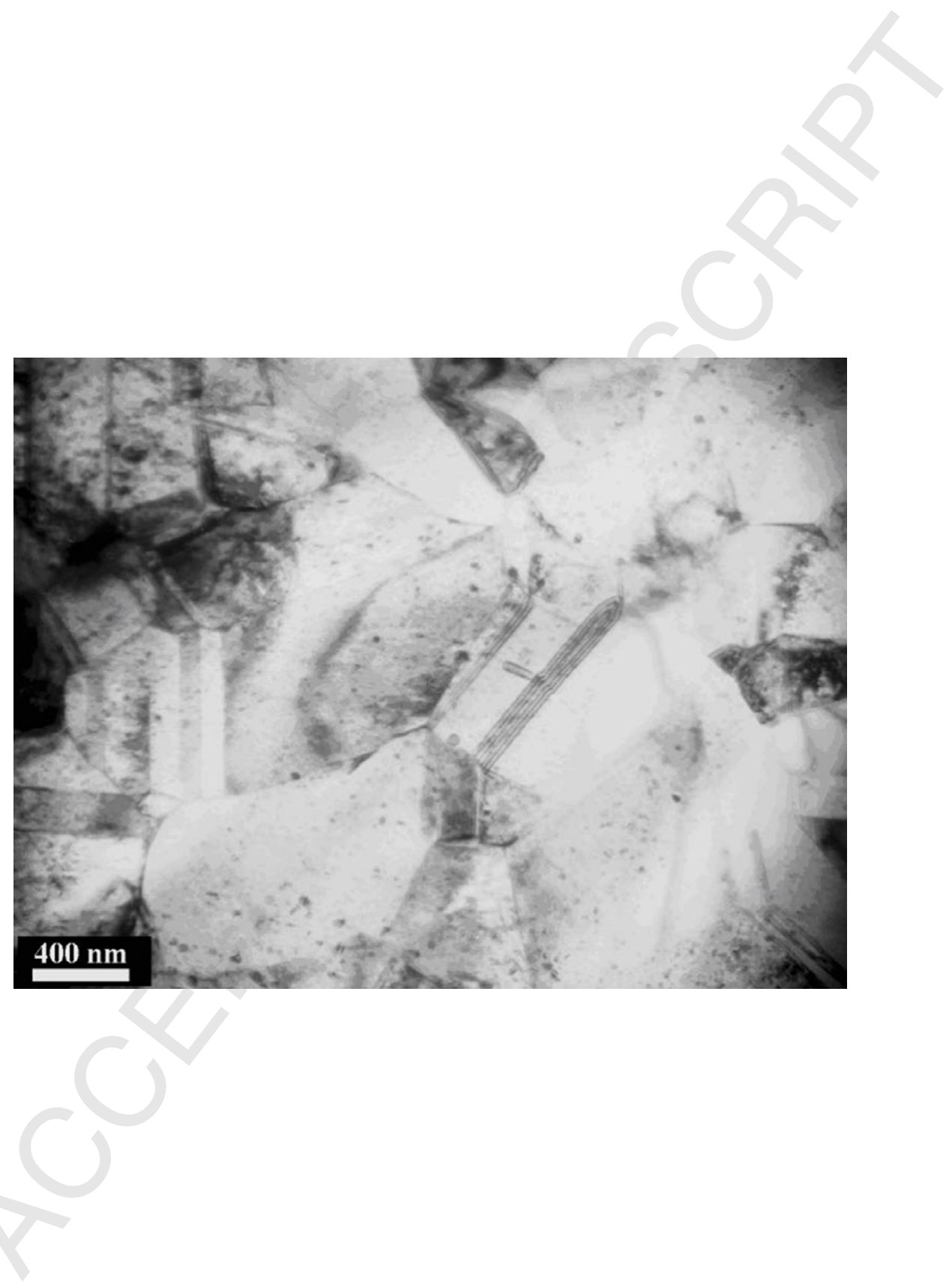




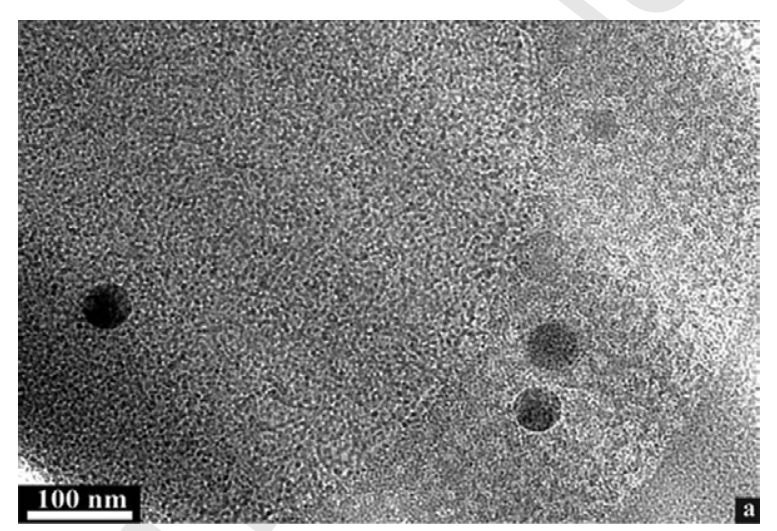




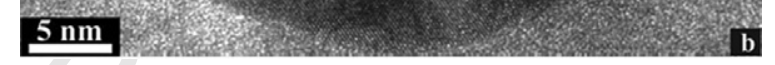




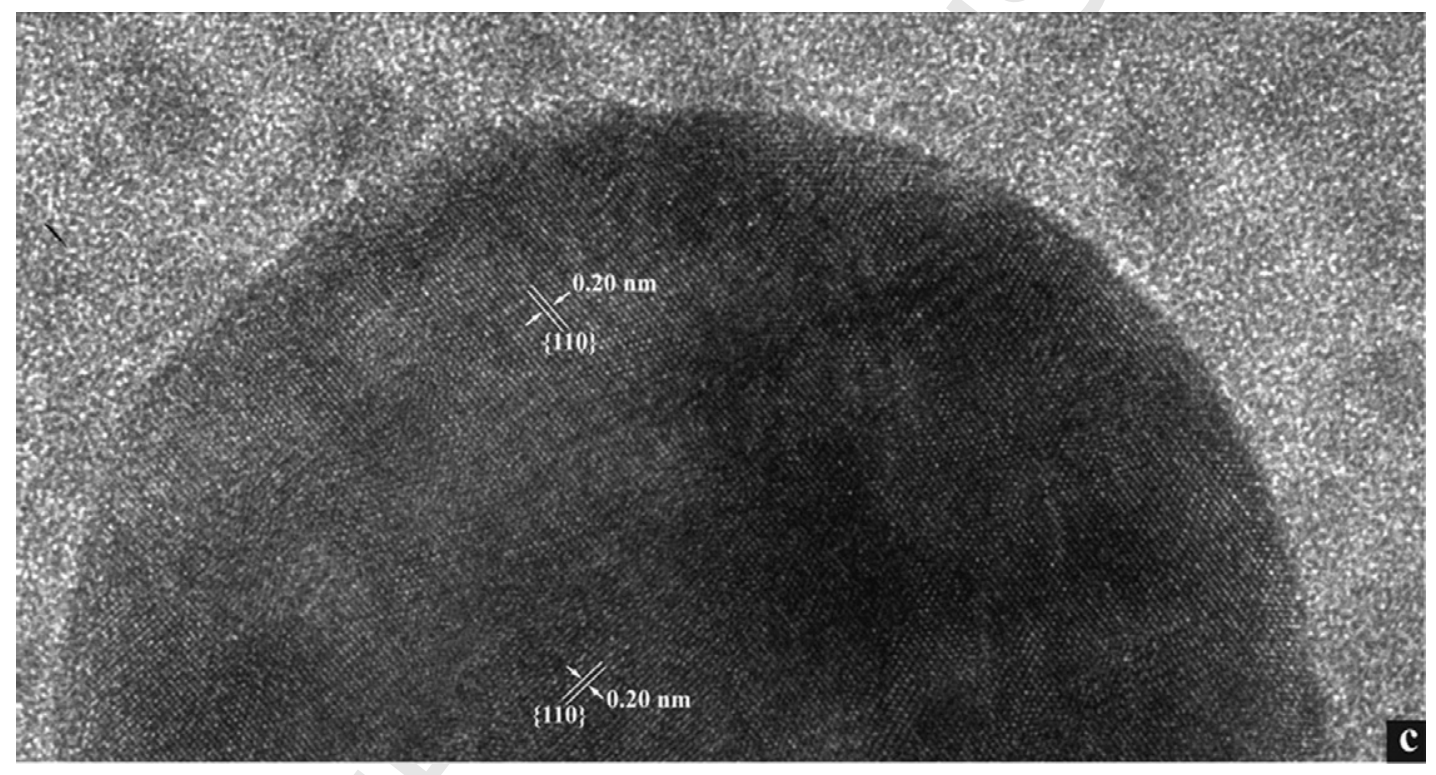




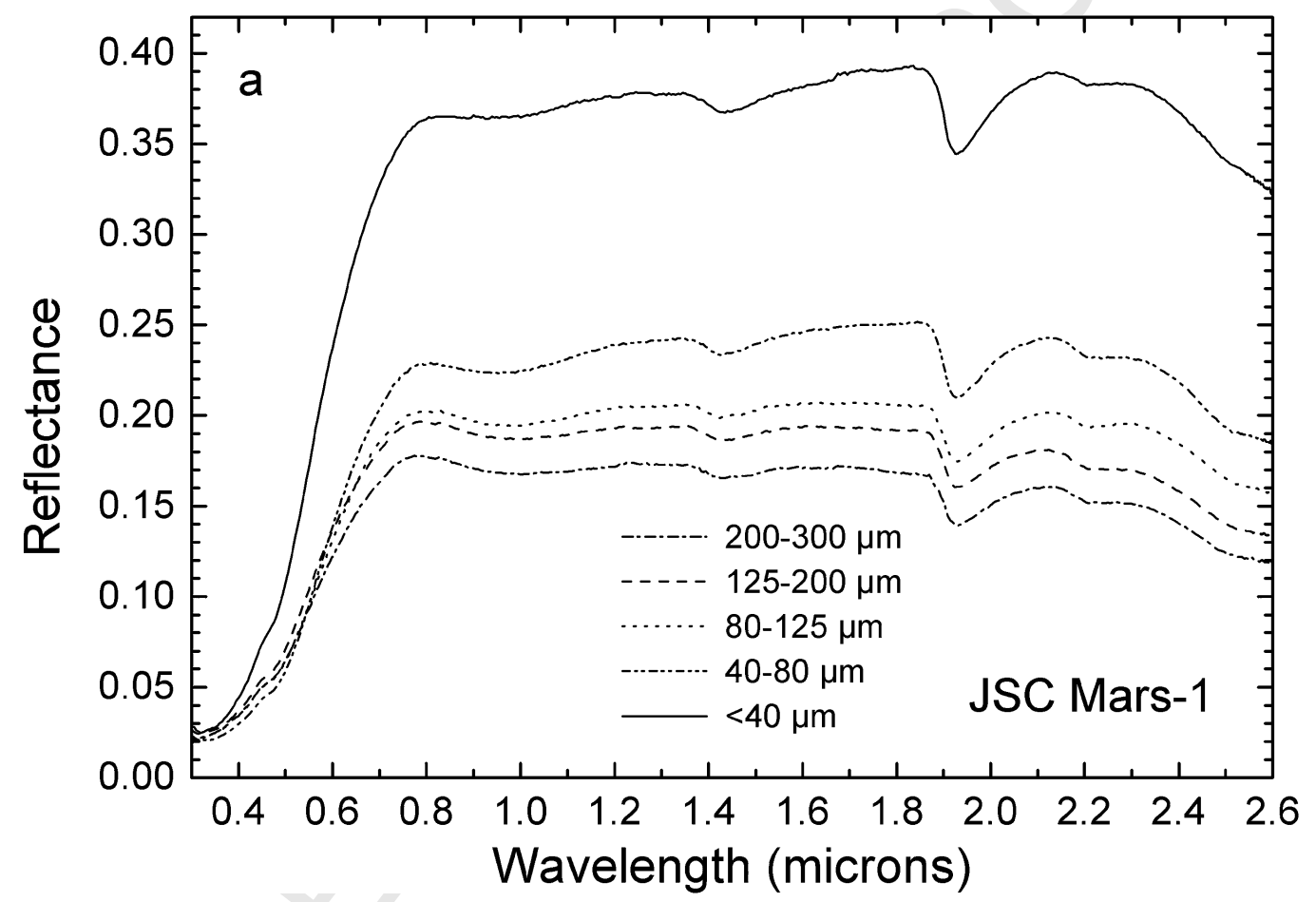




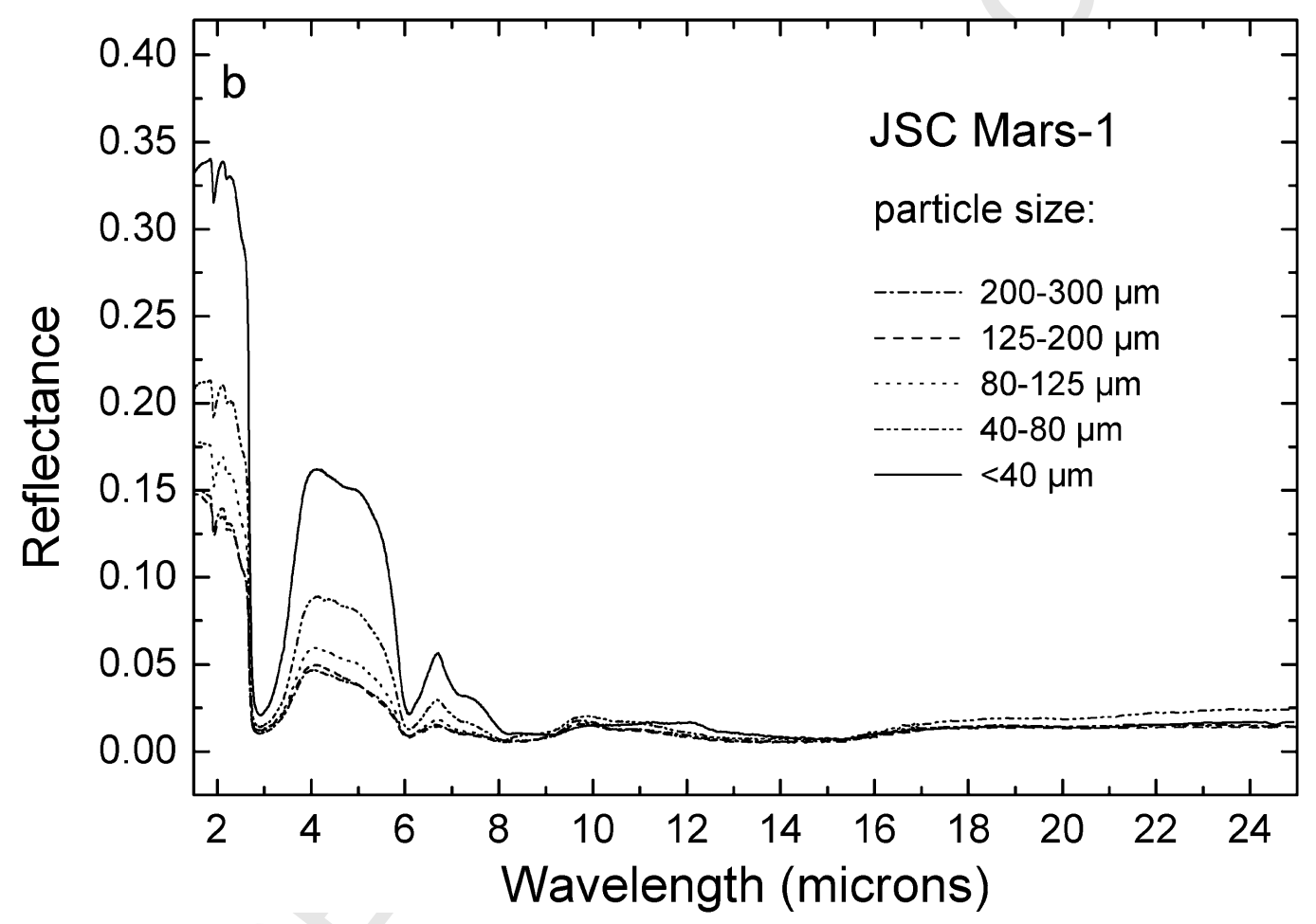




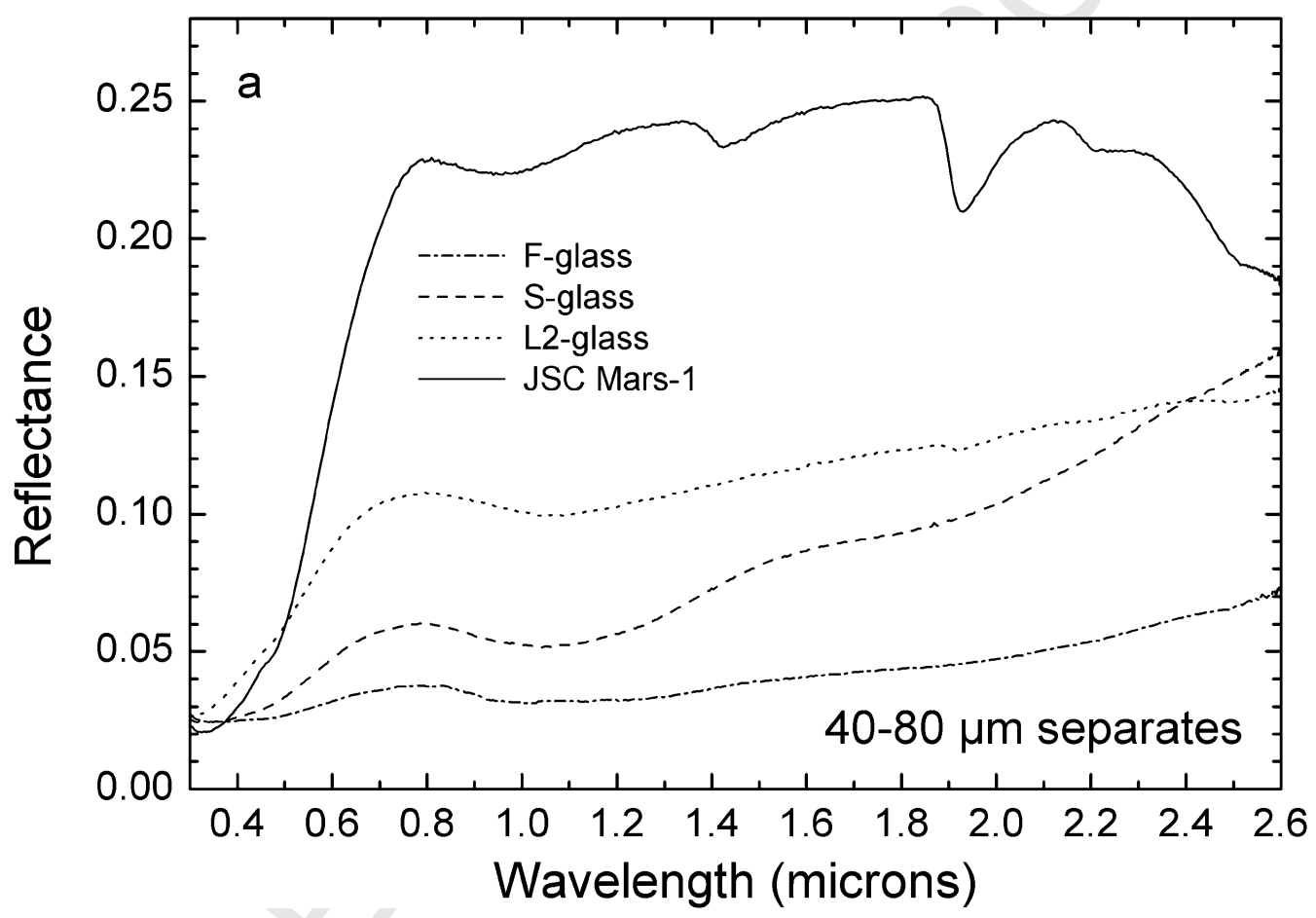




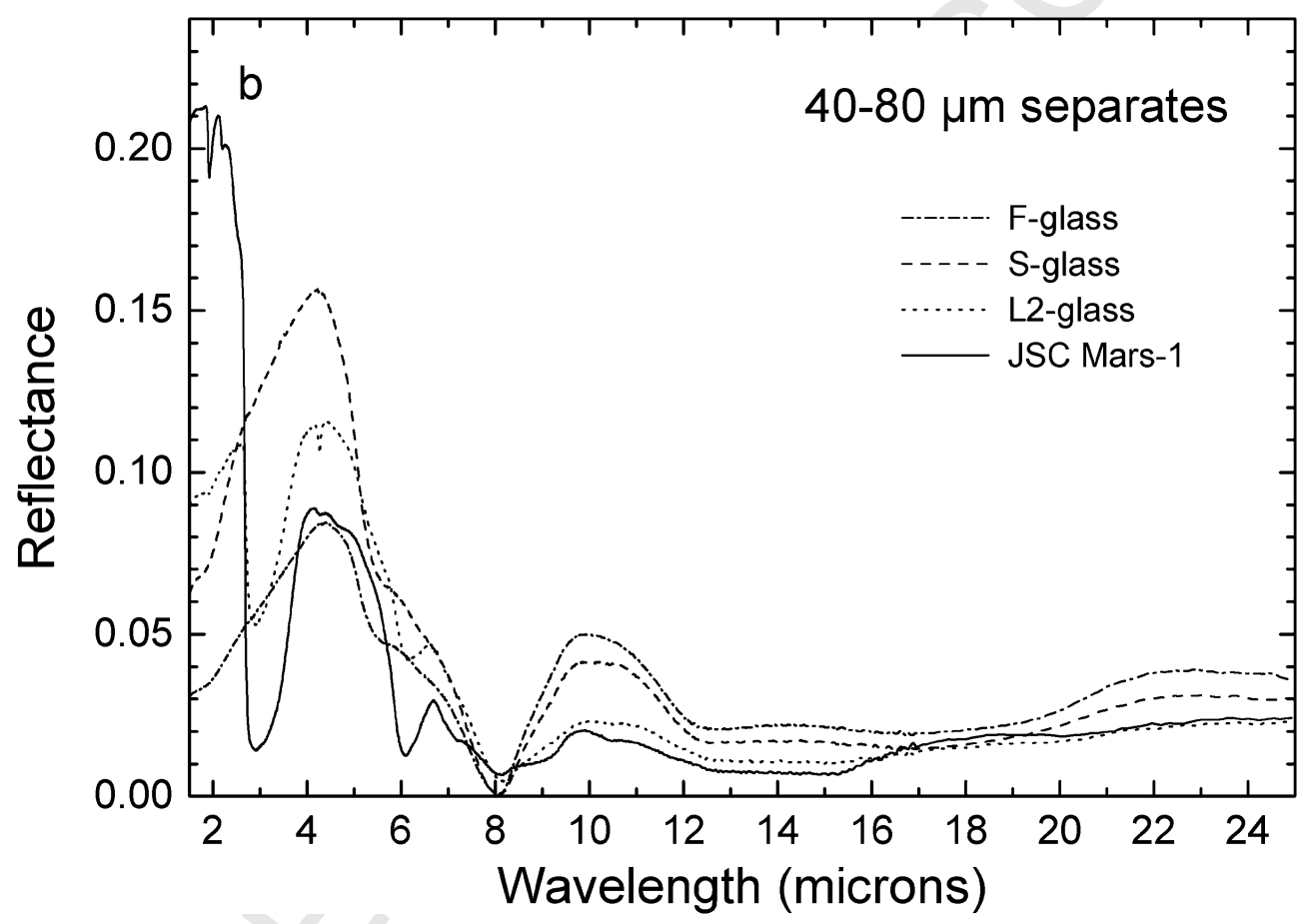




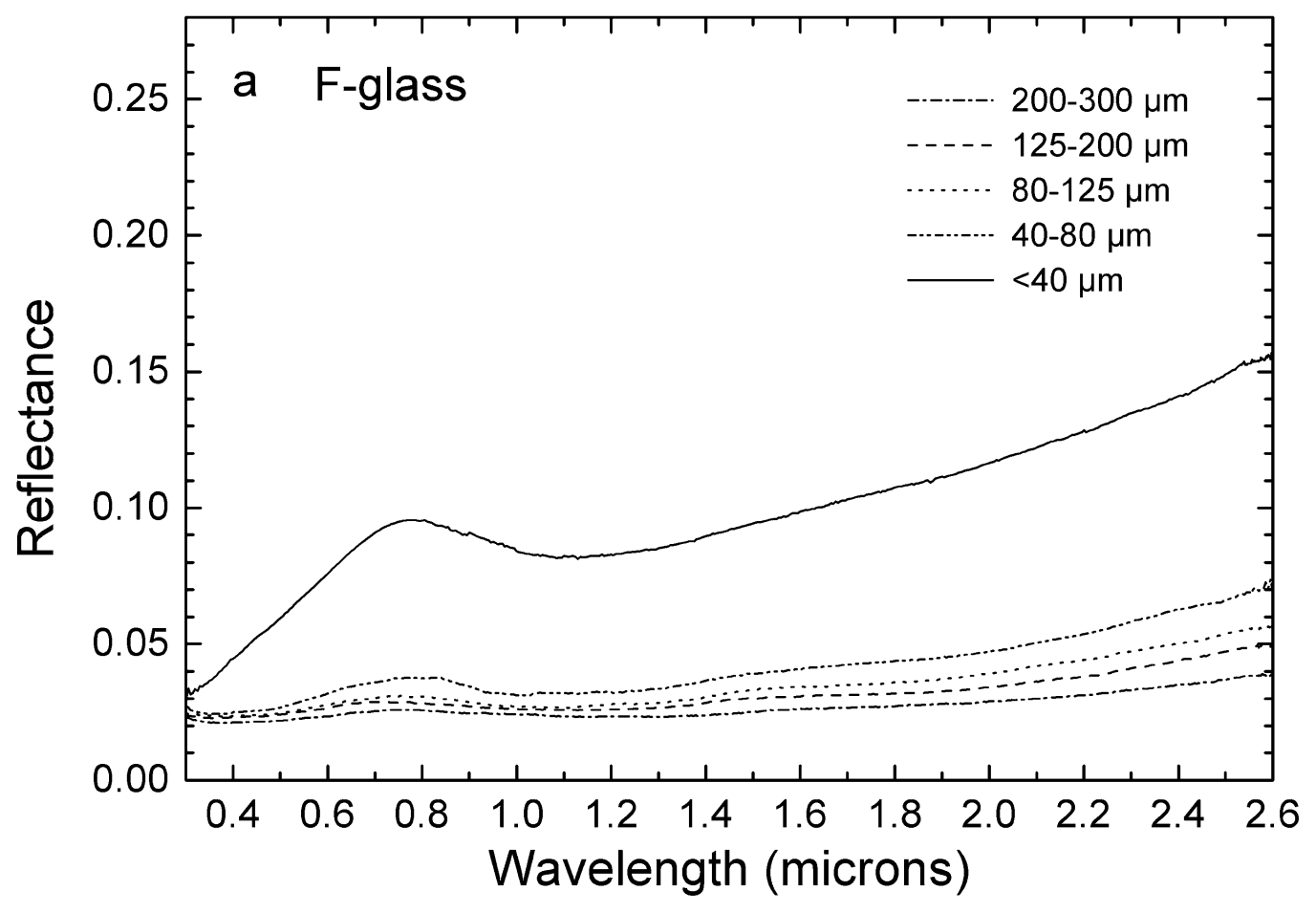




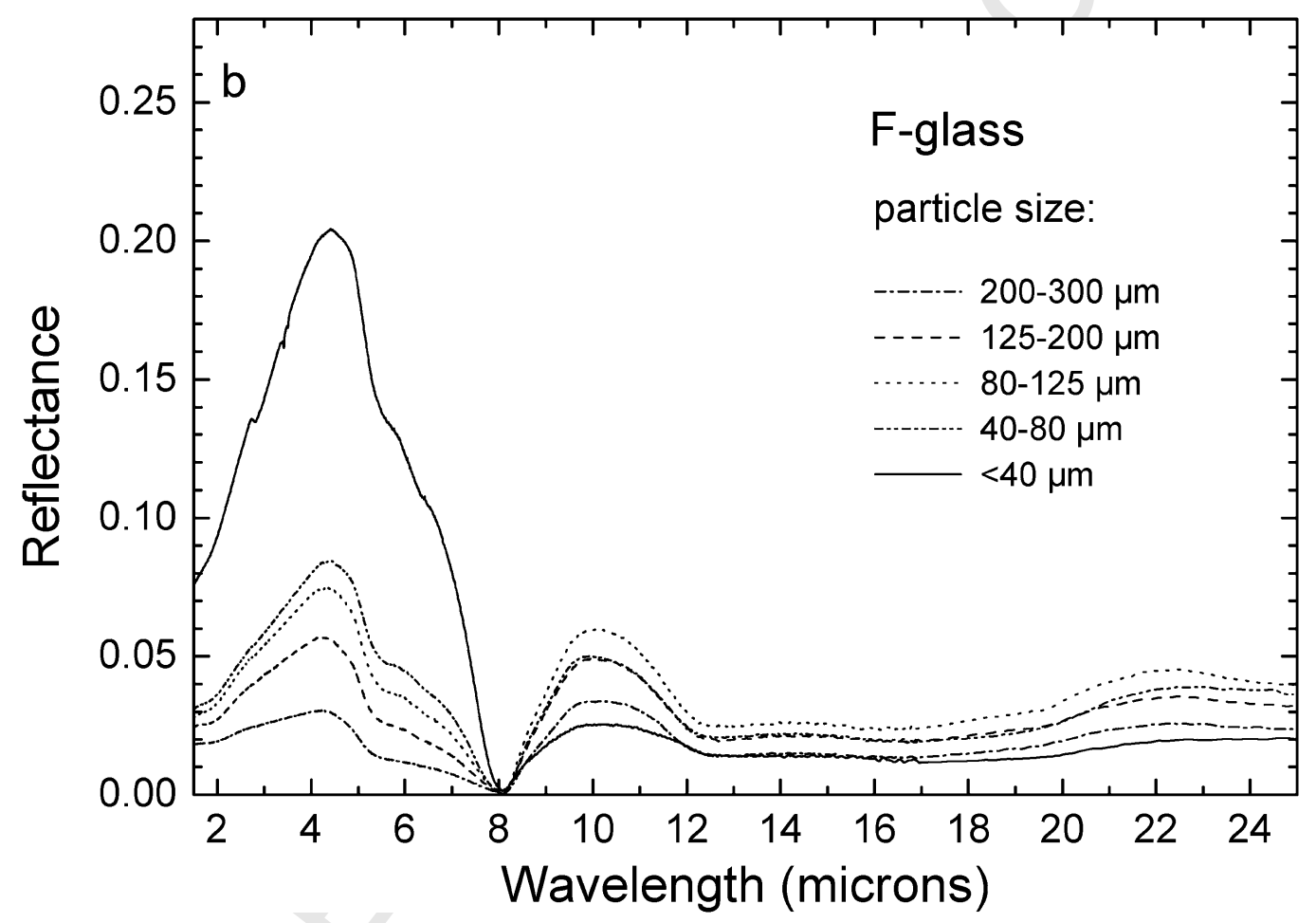




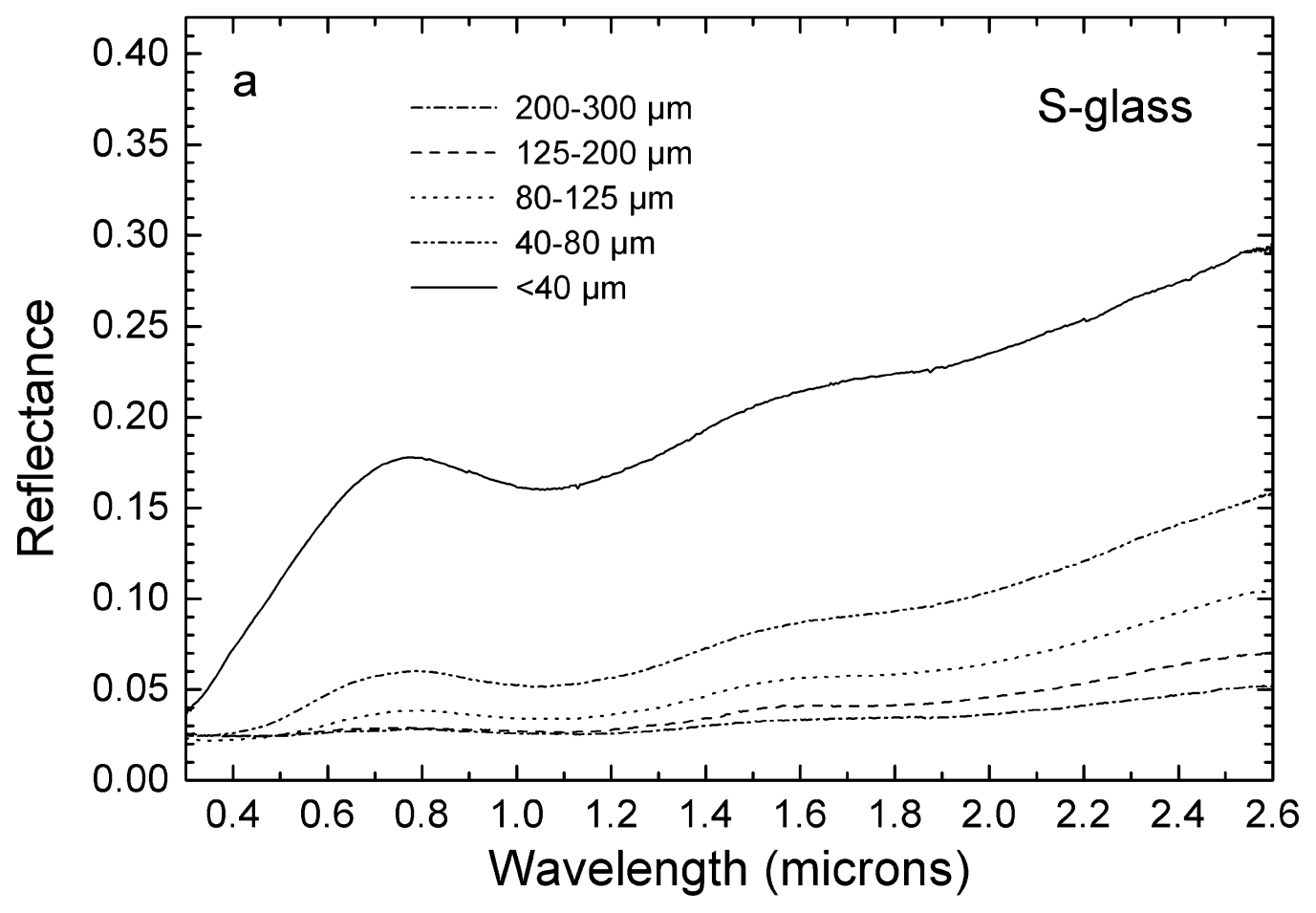




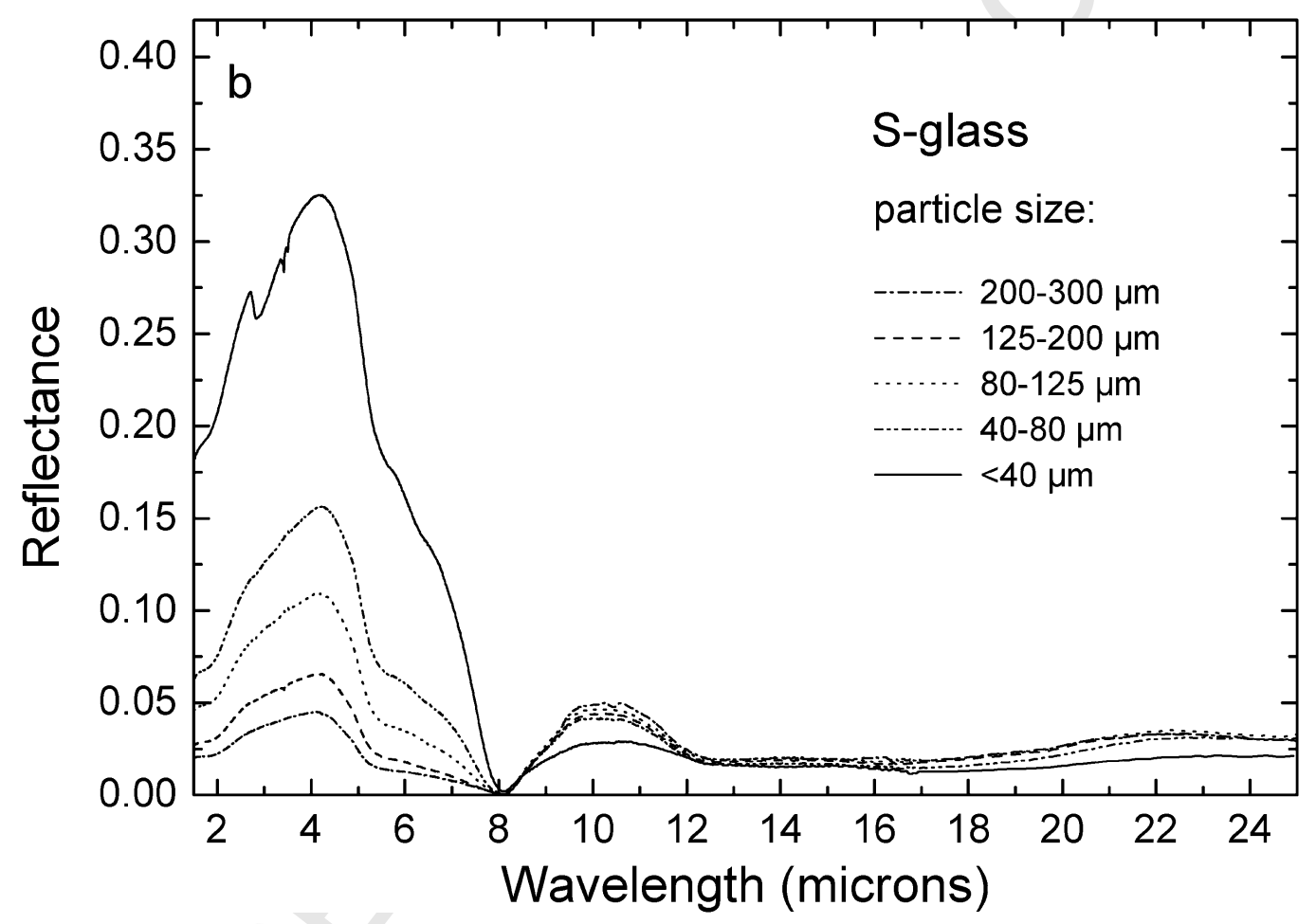




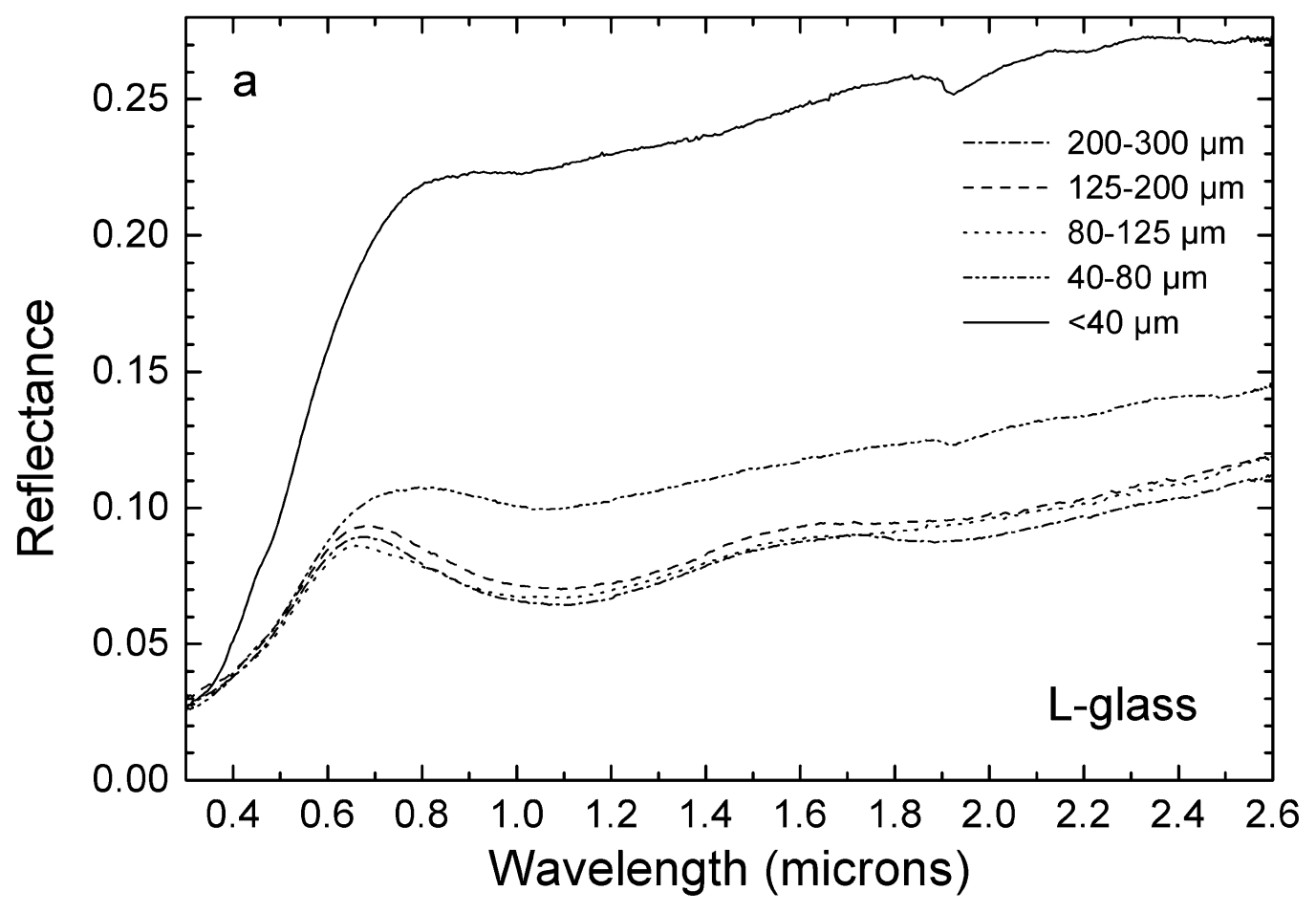




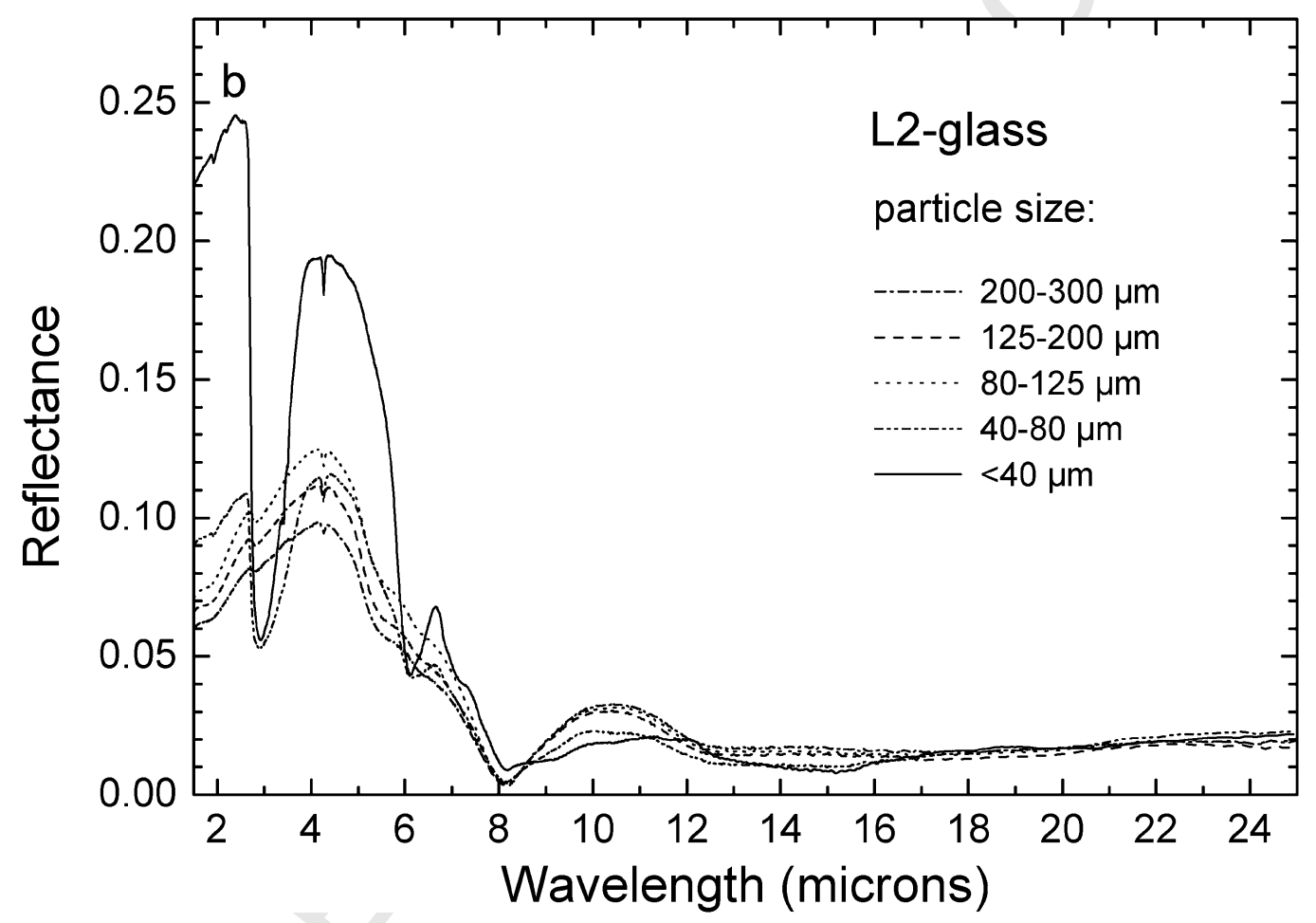




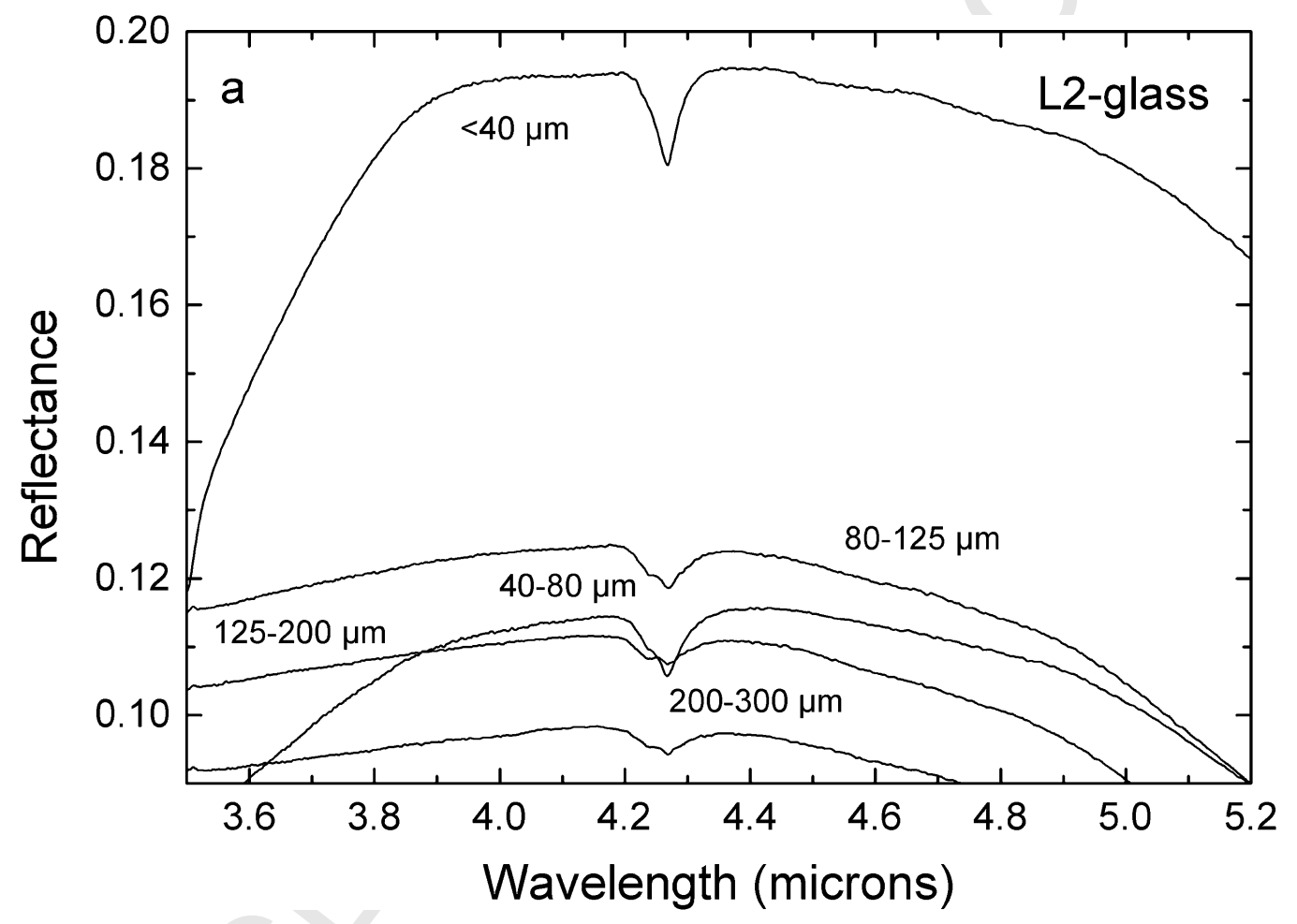




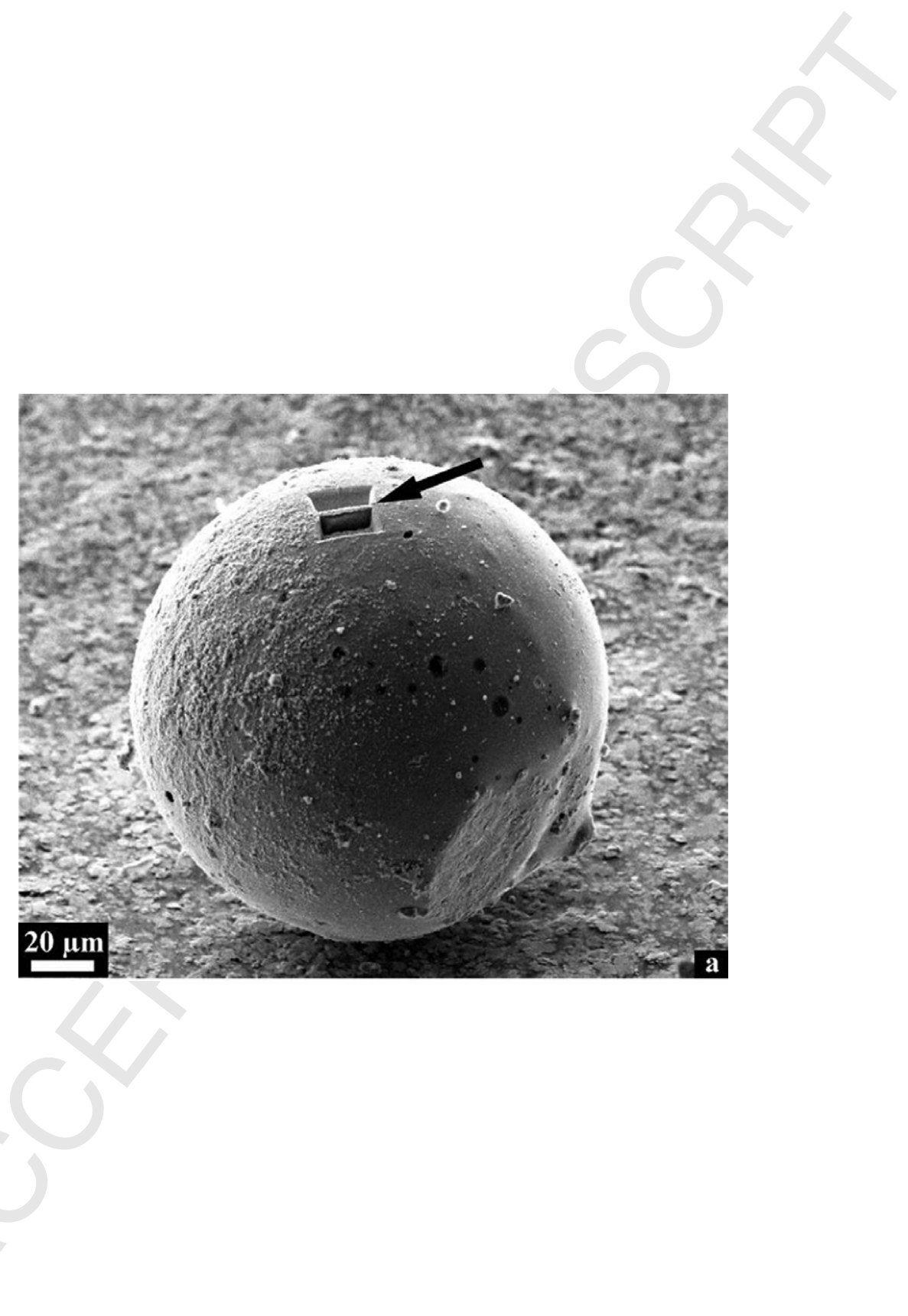

